\title{
ATIVIDADES CIENTÍFICAS E TECNOLÓGICAS NO CAMPO DA ENGENHARIA MECÂNICA
}

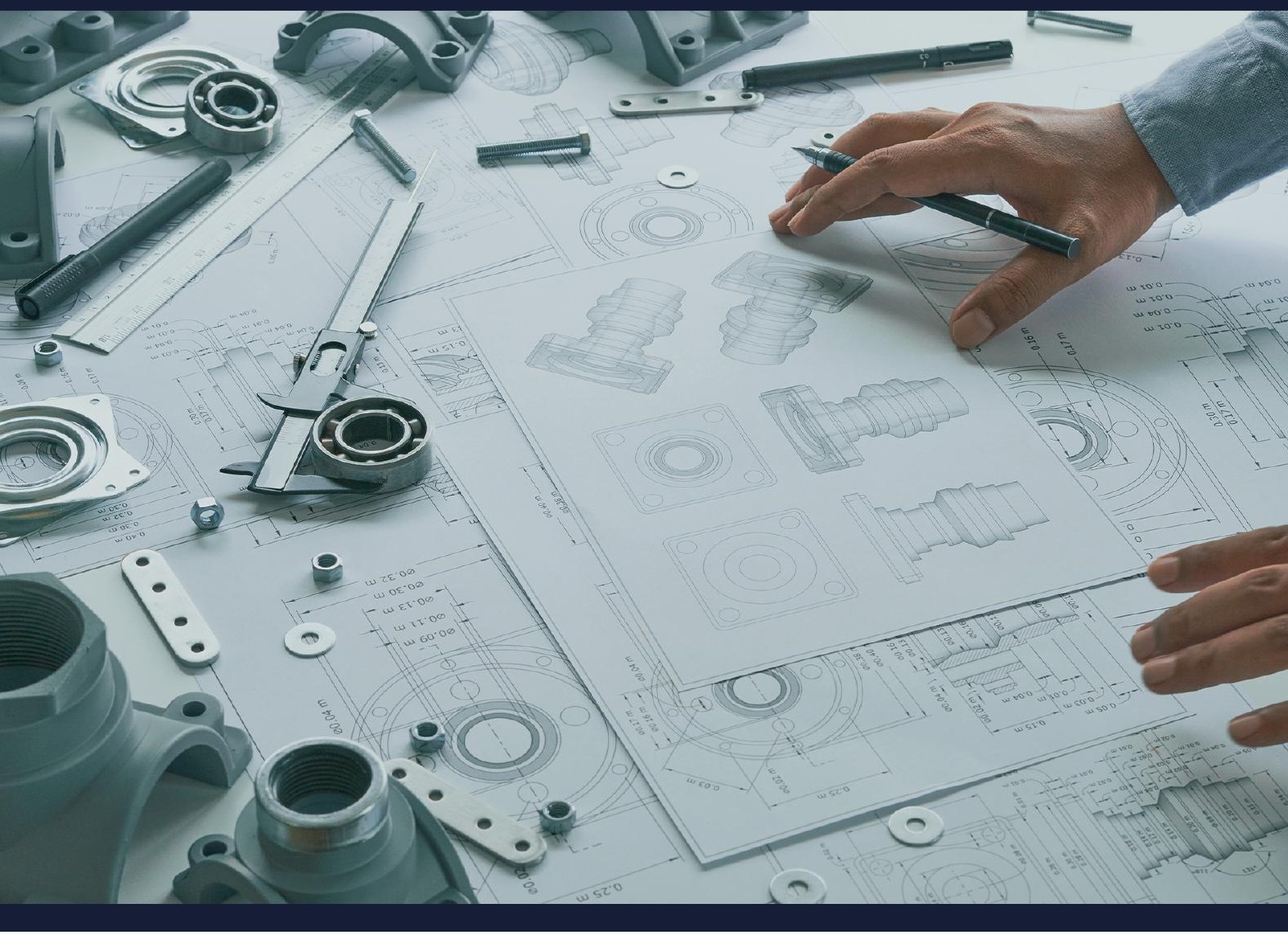

HENRIQUE AJUZ HOLZMANN

JOÃO DALLAMUTA

(ORGANIZADORES)

Q

Ano 2020 


\section{ATIVIDADES CIENTÍFICAS E TECNOLÓGICAS NO CAMPO DA ENGENHARIA MECÂNICA}

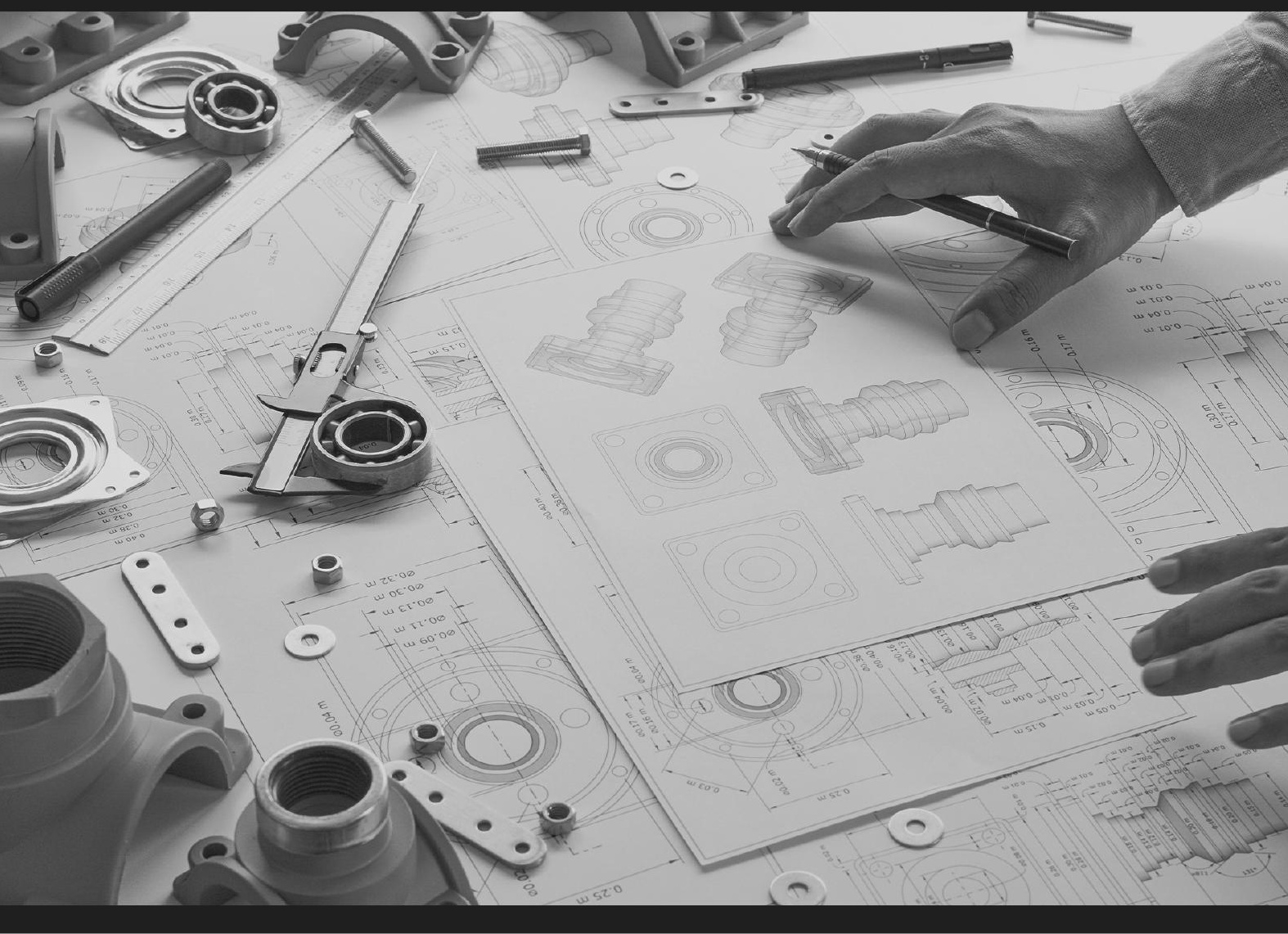

HENRIQUE AJUZ HOLZMANN

JOÃO DALLAMUTA

(ORGANIZADORES)

Q

Ano 2020 


\section{Editora Chefe}

Prof $^{a}$ Dr $^{a}$ Antonella Carvalho de Oliveira

Assistentes Editoriais

Natalia Oliveira

Bruno Oliveira

Flávia Roberta Barão

Bibliotecária

Janaina Ramos

Projeto Gráfico e Diagramação

Natália Sandrini de Azevedo

Camila Alves de Cremo

Luiza Alves Batista

Maria Alice Pinheiro

Imagens da Capa

Shutterstock

Edição de Arte

Luiza Alves Batista

Revisão

Os Autores

\section{0 by Atena Editora}

Copyright (C) Atena Editora

Copyright do Texto (c) 2020 Os autores

Copyright da Edição (c) 2020 Atena Editora

Direitos para esta edição cedidos à Atena

Editora pelos autores.

\section{(c) (1) @ $\Theta$}

Todo o conteúdo deste livro está licenciado sob uma Licença de Atribuição Creative Commons. Atribuição-Não-ComercialNãoDerivativos 4.0 Internacional (CC BY-NC-ND 4.0).

O conteúdo dos artigos e seus dados em sua forma, correção e confiabilidade são de responsabilidade exclusiva dos autores, inclusive não representam necessariamente a posição oficial da Atena Editora. Permitido o download da obra e o compartilhamento desde que sejam atribuídos créditos aos autores, mas sem a possibilidade de alterá-la de nenhuma forma ou utilizá-la para fins comerciais.

A Atena Editora não se responsabiliza por eventuais mudanças ocorridas nos endereços convencionais ou eletrônicos citados nesta obra.

Todos os manuscritos foram previamente submetidos à avaliação cega pelos pares, membros do Conselho Editorial desta Editora, tendo sido aprovados para a publicação.

\section{Conselho Editorial}

\section{Ciências Humanas e Sociais Aplicadas}

Prof. Dr. Alexandre Jose Schumacher - Instituto Federal de Educação, Ciência e Tecnologia do Paraná

Prof. Dr. Américo Junior Nunes da Silva - Universidade do Estado da Bahia

Prof. Dr. Antonio Carlos Frasson - Universidade Tecnológica Federal do Paraná

Prof. Dr. Antonio Gasparetto Júnior - Instituto Federal do Sudeste de Minas Gerais

Prof. Dr. Antonio Isidro-Filho - Universidade de Brasília

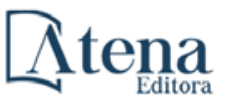

Ano 2020 
Prof. Dr. Carlos Antonio de Souza Moraes - Universidade Federal Fluminense

Prof $^{a}$ Dr $^{\text {a }}$ Cristina Gaio - Universidade de Lisboa

Prof. Dr. Daniel Richard Sant'Ana - Universidade de Brasília

Prof. Dr. Deyvison de Lima Oliveira - Universidade Federal de Rondônia

Prof $^{a}$ Dr $^{a}$ Dilma Antunes Silva - Universidade Federal de São Paulo

Prof. Dr. Edvaldo Antunes de Farias - Universidade Estácio de Sá

Prof. Dr. Elson Ferreira Costa - Universidade do Estado do Pará

Prof. Dr. Eloi Martins Senhora - Universidade Federal de Roraima

Prof. Dr. Gustavo Henrique Cepolini Ferreira - Universidade Estadual de Montes Claros

Prof $^{a} \mathrm{Dr}^{\mathrm{a}}$ Ivone Goulart Lopes - Istituto Internazionele delle Figlie de Maria Ausiliatrice

Prof. Dr. Jadson Correia de Oliveira - Universidade Católica do Salvador

Prof. Dr. Julio Candido de Meirelles Junior - Universidade Federal Fluminense

Prof $^{a} \mathrm{Dr}^{\mathrm{a}}$ Lina Maria Gonçalves - Universidade Federal do Tocantins

Prof. Dr. Luis Ricardo Fernandes da Costa - Universidade Estadual de Montes Claros

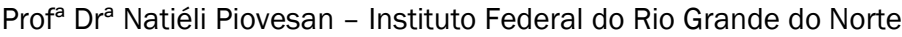

Prof. Dr. Marcelo Pereira da Silva - Pontifícia Universidade Católica de Campinas

Prof $^{a}$ Dr $^{a}$ Maria Luzia da Silva Santana - Universidade Federal de Mato Grosso do Sul

Prof $^{a}$ Dr $^{a}$ Paola Andressa Scortegagna - Universidade Estadual de Ponta Grossa

Prof $^{a}$ Dr $^{a}$ Rita de Cássia da Silva Oliveira - Universidade Estadual de Ponta Grossa

Prof. Dr. Rui Maia Diamantino - Universidade Salvador

Prof. Dr. Urandi João Rodrigues Junior - Universidade Federal do Oeste do Pará

Prof $^{a}$ Dr $^{a}$ Vanessa Bordin Viera - Universidade Federal de Campina Grande

Prof. Dr. William Cleber Domingues Silva - Universidade Federal Rural do Rio de Janeiro

Prof. Dr. Willian Douglas Guilherme - Universidade Federal do Tocantins

\section{Ciências Agrárias e Multidisciplinar}

Prof. Dr. Alexandre Igor Azevedo Pereira - Instituto Federal Goiano

Prof $^{\mathrm{a}} \mathrm{Dr}^{\mathrm{a}}$ Carla Cristina Bauermann Brasil - Universidade Federal de Santa Maria

Prof. Dr. Antonio Pasqualetto - Pontifícia Universidade Católica de Goiás

Prof. Dr. Cleberton Correia Santos - Universidade Federal da Grande Dourados

Prof $^{a}$ Dr $^{a}$ Daiane Garabeli Trojan - Universidade Norte do Paraná

Prof ${ }^{a}$ Dr $^{a}$ Diocléa Almeida Seabra Silva - Universidade Federal Rural da Amazônia

Prof. Dr. Écio Souza Diniz - Universidade Federal de Viçosa

Prof. Dr. Fábio Steiner - Universidade Estadual de Mato Grosso do Sul

Prof. Dr. Fágner Cavalcante Patrocínio dos Santos - Universidade Federal do Ceará

Prof ${ }^{a}$ Dr $^{a}$ Girlene Santos de Souza - Universidade Federal do Recôncavo da Bahia

Prof. Dr. Jael Soares Batista - Universidade Federal Rural do Semi-Árido

Prof. Dr. Júlio César Ribeiro - Universidade Federal Rural do Rio de Janeiro

Prof $^{a}$ Dr $^{a}$ Lina Raquel Santos Araújo - Universidade Estadual do Ceará

Prof. Dr. Pedro Manuel Villa - Universidade Federal de Viçosa

Prof $^{a}$ Dr $^{a}$ Raissa Rachel Salustriano da Silva Matos - Universidade Federal do Maranhão

Prof. Dr. Ronilson Freitas de Souza - Universidade do Estado do Pará

Prof $^{a}$ Dr $^{a}$ Talita de Santos Matos - Universidade Federal Rural do Rio de Janeiro

Prof. Dr. Tiago da Silva Teófilo - Universidade Federal Rural do Semi-Árido

Prof. Dr. Valdemar Antonio Paffaro Junior - Universidade Federal de Alfenas

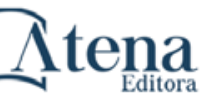

Ano 2020 


\section{Ciências Biológicas e da Saúde}

Prof. Dr. André Ribeiro da Silva - Universidade de Brasília

Prof $^{a}$ Dr $^{a}$ Anelise Levay Murari - Universidade Federal de Pelotas

Prof. Dr. Benedito Rodrigues da Silva Neto - Universidade Federal de Goiás

Prof $^{a}$ Dr $^{a}$ Débora Luana Ribeiro Pessoa - Universidade Federal do Maranhão

Prof. Dr. Douglas Siqueira de Almeida Chaves -Universidade Federal Rural do Rio de Janeiro

Prof. Dr. Edson da Silva - Universidade Federal dos Vales do Jequitinhonha e Mucuri

Prof $^{a}$ Dr $^{a}$ Eleuza Rodrigues Machado - Faculdade Anhanguera de Brasília

Prof $^{\mathrm{a}} \mathrm{Dr}^{\mathrm{a}}$ Elane Schwinden Prudêncio - Universidade Federal de Santa Catarina

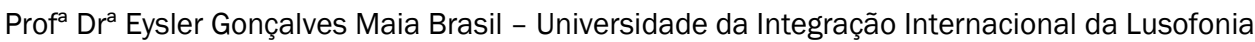
Afro-Brasileira

Prof. Dr. Ferlando Lima Santos - Universidade Federal do Recôncavo da Bahia

Prof $^{a}$ Dr $^{\text {a }}$ Gabriela Vieira do Amaral - Universidade de Vassouras

Prof. Dr. Gianfábio Pimentel Franco - Universidade Federal de Santa Maria

Prof. Dr. Helio Franklin Rodrigues de Almeida - Universidade Federal de Rondônia

Prof $^{a}$ Dr $^{a}$ lara Lúcia Tescarollo - Universidade São Francisco

Prof. Dr. Igor Luiz Vieira de Lima Santos - Universidade Federal de Campina Grande

Prof. Dr. Jefferson Thiago Souza - Universidade Estadual do Ceará

Prof. Dr. Jesus Rodrigues Lemos - Universidade Federal do Piauí

Prof. Dr. Jônatas de França Barros - Universidade Federal do Rio Grande do Norte

Prof. Dr. José Max Barbosa de Oliveira Junior - Universidade Federal do Oeste do Pará

Prof. Dr. Luís Paulo Souza e Souza - Universidade Federal do Amazonas

Prof ${ }^{a}$ Dr $^{a}$ Magnólia de Araújo Campos - Universidade Federal de Campina Grande

Prof. Dr. Marcus Fernando da Silva Praxedes - Universidade Federal do Recôncavo da Bahia

Prof $^{\mathrm{a}} \mathrm{Dr}^{\mathrm{a}}$ Maria Tatiane Gonçalves Sá - Universidade do Estado do Pará

Prof $^{\mathrm{a}} \mathrm{Dr}^{\mathrm{a}}$ Mylena Andréa Oliveira Torres - Universidade Ceuma

Prof $^{a}$ Dr $^{a}$ Natiéli Piovesan - Instituto Federacl do Rio Grande do Norte

Prof. Dr. Paulo Inada - Universidade Estadual de Maringá

Prof. Dr. Rafael Henrique Silva - Hospital Universitário da Universidade Federal da Grande Dourados

Prof $^{a}$ Dr $^{a}$ Regiane Luz Carvalho - Centro Universitário das Faculdades Associadas de Ensino

Prof $^{\mathrm{a}} \mathrm{Dr}^{\mathrm{a}}$ Renata Mendes de Freitas - Universidade Federal de Juiz de Fora

Prof $^{a}$ Dr $^{a}$ Vanessa Lima Gonçalves - Universidade Estadual de Ponta Grossa

Prof $^{a}$ Dr $^{a}$ Vanessa Bordin Viera - Universidade Federal de Campina Grande

\section{Ciências Exatas e da Terra e Engenharias}

Prof. Dr. Adélio Alcino Sampaio Castro Machado - Universidade do Porto

Prof. Dr. Carlos Eduardo Sanches de Andrade - Universidade Federal de Goiás

Prof ${ }^{a}$ Dr $^{a}$ Carmen Lúcia Voigt - Universidade Norte do Paraná

Prof. Dr. Douglas Gonçalves da Silva - Universidade Estadual do Sudoeste da Bahia

Prof. Dr. Eloi Rufato Junior - Universidade Tecnológica Federal do Paraná

Prof $^{a}$ Dr $^{a}$ Érica de Melo Azevedo - Instituto Federal do Rio de Janeiro

Prof. Dr. Fabrício Menezes Ramos - Instituto Federal do Pará

Prof $^{a}$ Dra. Jéssica Verger Nardeli - Universidade Estadual Paulista Júlio de Mesquita Filho

Prof. Dr. Juliano Carlo Rufino de Freitas - Universidade Federal de Campina Grande

Prof $^{a}$ Dr $^{a}$ Luciana do Nascimento Mendes - Instituto Federal de Educação, Ciência e Tecnologia

do Rio Grande do Norte

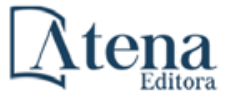


Prof. Dr. Marcelo Marques - Universidade Estadual de Maringá

Prof $^{a} \operatorname{Dr}^{\mathrm{a}}$ Neiva Maria de Almeida - Universidade Federal da Paraíba

Prof $^{a}$ Dr $^{a}$ Natiéli Piovesan - Instituto Federal do Rio Grande do Norte

Prof ${ }^{a}$ Dr $^{\text {a }}$ Priscila Tessmer Scaglioni - Universidade Federal de Pelotas

Prof. Dr. Takeshy Tachizawa - Faculdade de Campo Limpo Paulista

\section{Linguística, Letras e Artes}

Prof $^{a}$ Dr $^{a}$ Adriana Demite Stephani - Universidade Federal do Tocantins

Prof $^{a}$ Dr $^{a}$ Angeli Rose do Nascimento - Universidade Federal do Estado do Rio de Janeiro

Prof $^{a}$ Dra $^{\text {a }}$ Carolina Fernandes da Silva Mandaji - Universidade Tecnológica Federal do Paraná

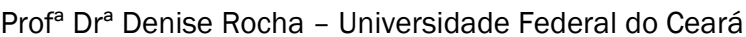

Prof. Dr. Fabiano Tadeu Grazioli - Universidade Regional Integrada do Alto Uruguai e das Missões

Prof. Dr. Gilmei Fleck - Universidade Estadual do Oeste do Paraná

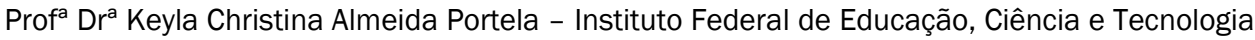
do Paraná

Prof $^{a}$ Dra $^{a}$ Miranilde Oliveira Neves - Instituto de Educação, Ciência e Tecnologia do Pará

Prof $^{a}$ Dr $^{\text {a }}$ Sandra Regina Gardacho Pietrobon - Universidade Estadual do Centro-Oeste

Prof $^{a}$ Dr $^{a}$ Sheila Marta Carregosa Rocha - Universidade do Estado da Bahia

\section{Conselho Técnico Científico}

Prof. Me. Abrãao Carvalho Nogueira - Universidade Federal do Espírito Santo

Prof. Me. Adalberto Zorzo - Centro Estadual de Educação Tecnológica Paula Souza

Prof. Me. Adalto Moreira Braz - Universidade Federal de Goiás

Prof. Dr. Adaylson Wagner Sousa de Vasconcelos - Ordem dos Advogados do Brasil/Seccional Paraíba

Prof. Dr. Adilson Tadeu Basquerote Silva - Universidade para o Desenvolvimento do Alto Vale do Itajaí

Prof. Me. Alexsandro Teixeira Ribeiro - Centro Universitário Internacional

Prof. Me. André Flávio Gonçalves Silva - Universidade Federal do Maranhão

Prof ${ }^{a}$ Ma. Andréa Cristina Marques de Araújo - Universidade Fernando Pessoa

Prof $^{a}$ Dr $^{\text {a }}$ Andreza Lopes - Instituto de Pesquisa e Desenvolvimento Acadêmico

Prof $^{a}$ Dr $^{a}$ Andrezza Miguel da Silva - Faculdade da Amazônia

Profa Ma. Anelisa Mota Gregoleti - Universidade Estadual de Maringá

Prof ${ }^{a}$ Ma. Anne Karynne da Silva Barbosa - Universidade Federal do Maranhão

Prof. Dr. Antonio Hot Pereira de Faria - Polícia Militar de Minas Gerais

Prof. Me. Armando Dias Duarte - Universidade Federal de Pernambuco

Prof $^{a}$ Ma. Bianca Camargo Martins - UniCesumar

Prof $^{a}$ Ma. Carolina Shimomura Nanya - Universidade Federal de São Carlos

Prof. Me. Carlos Antônio dos Santos - Universidade Federal Rural do Rio de Janeiro

Prof. Ma. Cláudia de Araújo Marques - Faculdade de Música do Espírito Santo

Prof $^{a}$ Dr $^{a}$ Cláudia Taís Siqueira Cagliari - Centro Universitário Dinâmica das Cataratas

Prof. Me. Clécio Danilo Dias da Silva - Universidade Federal do Rio Grande do Norte

Prof. Me. Daniel da Silva Miranda - Universidade Federal do Pará

Prof $^{a}$ Ma. Daniela da Silva Rodrigues - Universidade de Brasília

Prof $^{\mathrm{a}}$ Ma. Daniela Remião de Macedo - Universidade de Lisboa

Prof $^{a}$ Ma. Dayane de Melo Barros - Universidade Federal de Pernambuco

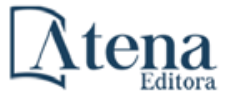


Prof. Me. Douglas Santos Mezacas - Universidade Estadual de Goiás

Prof. Me. Edevaldo de Castro Monteiro - Embrapa Agrobiologia

Prof. Me. Eduardo Gomes de Oliveira - Faculdades Unificadas Doctum de Cataguases

Prof. Me. Eduardo Henrique Ferreira - Faculdade Pitágoras de Londrina

Prof. Dr. Edwaldo Costa - Marinha do Brasil

Prof. Me. Eliel Constantino da Silva - Universidade Estadual Paulista Júlio de Mesquita

Prof. Me. Ernane Rosa Martins - Instituto Federal de Educação, Ciência e Tecnologia de Goiás

Prof. Me. Euvaldo de Sousa Costa Junior - Prefeitura Municipal de São João do Piauí

Prof $^{a}$ Ma. Fabiana Coelho Couto Rocha Corrêa - Centro Universitário Estácio Juiz de Fora

Prof. Dr. Fabiano Lemos Pereira - Prefeitura Municipal de Macaé

Prof. Me. Felipe da Costa Negrão - Universidade Federal do Amazonas

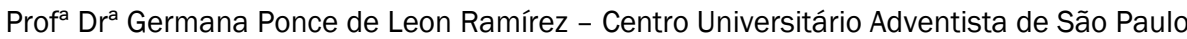

Prof. Me. Gevair Campos - Instituto Mineiro de Agropecuária

Prof. Me. Givanildo de Oliveira Santos - Secretaria da Educação de Goiás

Prof. Dr. Guilherme Renato Gomes - Universidade Norte do ParanáProf. Me. Gustavo Krahl Universidade do Oeste de Santa Catarina

Prof. Me. Helton Rangel Coutinho Junior - Tribunal de Justiça do Estado do Rio de Janeiro

Prof $^{a}$ Ma. Isabelle Cerqueira Sousa - Universidade de Fortaleza

Prof $^{a}$ Ma. Jaqueline Oliveira Rezende - Universidade Federal de Uberlândia

Prof. Me. Javier Antonio Albornoz - University of Miami and Miami Dade College

Prof. Me. Jhonatan da Silva Lima - Universidade Federal do Pará

Prof. Dr. José Carlos da Silva Mendes - Instituto de Psicologia Cognitiva, Desenvolvimento Humano e Social

Prof. Me. Jose Elyton Batista dos Santos - Universidade Federal de Sergipe

Prof. Me. José Luiz Leonardo de Araujo Pimenta - Instituto Nacional de Investigación Agropecuaria Uruguay

Prof. Me. José Messias Ribeiro Júnior - Instituto Federal de Educação Tecnológica de Pernambuco

Prof $^{a}$ Dr $^{a}$ Juliana Santana de Curcio - Universidade Federal de Goiás

Prof $^{\mathrm{a}}$ Ma. Juliana Thaisa Rodrigues Pacheco - Universidade Estadual de Ponta Grossa

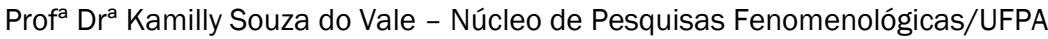

Prof. Dr. Kárpio Márcio de Siqueira - Universidade do Estado da Bahia

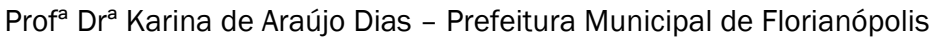

Prof. Dr. Lázaro Castro Silva Nascimento - Laboratório de Fenomenologia \& Subjetividade/UFPR

Prof. Me. Leonardo Tullio - Universidade Estadual de Ponta Grossa

Prof ${ }^{\mathrm{a}} \mathrm{Ma}$. Lilian Coelho de Freitas - Instituto Federal do Pará

Prof $^{a}$ Ma. Liliani Aparecida Sereno Fontes de Medeiros - Consórcio CEDERJ

Prof $^{a}$ Dr $^{\mathrm{a}}$ Lívia do Carmo Silva - Universidade Federal de Goiás

Prof. Dr. Lucio Marques Vieira Souza - Secretaria de Estado da Educação, do Esporte e da Cultura de Sergipe

Prof. Me. Luis Henrique Almeida Castro - Universidade Federal da Grande Dourados

Prof. Dr. Luan Vinicius Bernardelli - Universidade Estadual do Paraná

Prof. Dr. Michel da Costa - Universidade Metropolitana de Santos

Prof. Dr. Marcelo Máximo Purificação - Fundação Integrada Municipal de Ensino Superior

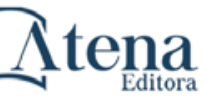

Ano 2020 
Prof. Me. Marcos Aurelio Alves e Silva - Instituto Federal de Educação, Ciência e Tecnologia de São Paulo

Prof ${ }^{a}$ Ma. Maria Elanny Damasceno Silva - Universidade Federal do Ceará

Prof ${ }^{a}$ Ma. Marileila Marques Toledo - Universidade Federal dos Vales do Jequitinhonha e Mucuri

Prof. Me. Ricardo Sérgio da Silva - Universidade Federal de Pernambuco

Prof ${ }^{a}$ Ma. Renata Luciane Polsaque Young Blood - UniSecal

Prof. Me. Robson Lucas Soares da Silva - Universidade Federal da Paraíba

Prof. Me. Sebastião André Barbosa Junior - Universidade Federal Rural de Pernambuco

Prof $^{a}$ Ma. Silene Ribeiro Miranda Barbosa - Consultoria Brasileira de Ensino, Pesquisa e Extensão

Prof $^{a}$ Ma. Solange Aparecida de Souza Monteiro - Instituto Federal de São Paulo

Prof. Me. Tallys Newton Fernandes de Matos - Faculdade Regional Jaguaribana

Prof $^{a}$ Ma. Thatianny Jasmine Castro Martins de Carvalho - Universidade Federal do Piauí

Prof. Me. Tiago Silvio Dedoné - Colégio ECEL Positivo

Prof. Dr. Welleson Feitosa Gazel - Universidade Paulista 


\section{Atividades científicas e tecnológicas no campo da engenharia mecânica}

Editora Chefe: Prof $^{\mathrm{a}} \mathrm{Dr}^{\mathrm{a}}$ Antonella Carvalho de Oliveira

Bibliotecária: Janaina Ramos

Diagramação: Luiza Alves Batista

Correção: Emely Guarez

Edição de Arte: Luiza Alves Batista

Revisão: Os Autores

Organizadores: Henrique Ajuz Holzmann

João Dallamuta

Dados Internacionais de Catalogação na Publicação (CIP)

A872 Atividades científicas e tecnológicas no campo da engenharia mecânica / Organizadores Henrique Ajuz Holzmann, João Dallamuta. - Ponta Grossa - PR: Atena, 2020.

Formato: PDF

Requisitos de sistema: Adobe Acrobat Reader

Modo de acesso: World Wide Web

Inclui bibliografia

ISBN 978-65-5706-486-3

DOI 10.22533/at.ed.863202610

1. Engenharia mecânica. I. Holzmann, Henrique Ajuz (Organizador). II. Dallamuta, João (Organizador). III. Título. CDD 621

Elaborado por Bibliotecária Janaina Ramos - CRB-8/9166

Atena Editora

Ponta Grossa - Paraná - Brasil Telefone: +55 (42) 3323-5493 www.atenaeditora.com.br contato@atenaeditora.com.br 


\section{APRESENTAÇÃO}

Em um cenário cada vez mais competitivo, desenvolver novas maneiras de melhoria nos processos industriais, bem como para o próprio dia a dia da população é uma das buscas constantes das áreas de engenharia.

Desta forma buscar evitar ou prever falhas em sistemas é de vital importância, destacando-se o desenvolvimento de novos materiais, bem como de métodos analíticos e práticos para detecção. Entre os materiais os compósitos veem ganhado cada vez mais espaço devido a sua versatilidade, aliando resistência e peso.

Já para detecção de falhas os métodos de análise de vibrações é quase que unanimidade quando se quer um pleno funcionamento dos equipamentos. $O$ estudo das análises de vibrações em sistemas vem ganhando cada vez mais espaço nos projetos, pois a redução dessas na maioria dos casos acarreta em uma maior vida útil ou um melhor funcionamento dos conjuntos.

Neste livro são apresentados trabalhos relacionados a engenharia mecânica, dentro de uma vertente teórico/prática onde busca-se retratar assuntos atuais e de grande importância para estudante, docentes e profissionais.

Boa leitura!

Henrique Ajuz Holzmann João Dallamuta 


\section{SUMÁRIO}

CAPÍTULO 1

ABORDAGEM DE DETECÇÃO DE AVARIAS EM SISTEMA DINÂMICO UTILIZANDO TÉCNICA DE INTELIGÊNCIA ARTIFICIAL

João Marcelo Abreu Bernardi

Edson Hideki Koroishi

DOI 10.22533/at.ed.8632026101

CAPÍTULO 2

UTILIZAÇÃO DE ATUADORES ELETROMAGNÉTICOS PARA O CONTROLE DE VIBRAÇÃ̃O EM UMA VIGA DE MATERIAL COMPÓSITO

Andrei Santos Oliveira

Camila Albertin Xavier da Silva

Edson Hideki Koroishi

Romeu Rony Cavalcante da Costa

Marco Túlio Santana Alves

DOI 10.22533/at.ed.8632026102

CAPÍTULO 3

CONTROLE ATIVO DE VIBRAÇÕES APLICADO A UMA VIGA FLEXÍVEL UTILIZANDO ATUADORES ELETROMAGNÉTICOS

Matheus Rincon Modesto Maroni

Edson Hideki Koroishi

DOI 10.22533/at.ed.8632026103

CAPÍTULO 4

SUPRESSÃO DO FENÔMENO DE FLUTTEREM PAINÉIS COMPÓSITOS AERONÁUTICOS VIA TÉCNICA DE CONTROLE PASSIVO

Lorrane Pereira Ribeiro

Antônio Marcos Gonçalves de Lima

DOI 10.22533/at.ed.8632026104

CAPÍTULO 5

FABRICAÇÃO DE UM MANIPULADOR ROBÓTICO BASEADO EM UM GUINDASTE

Ana Carolina Dantas Rocha

Eduardo Victor Lima Barboza

José Leonardo Nery de Souza

Otávio Clarindo Lopes Filho

Adriano Marinheiro Pompeu

Dheiver Francisco Santos

DOI 10.22533/at.ed.8632026105

CAPÍTULO 6.

GANHO DE RESISTÊNCIA À COMPRESSÃO POR ENRIJECEDOR EM CHAPA DOBRADA A FRIO

João Paulo Marques de Aquino

João de Jesus dos Santos 
Lais Amaral Alves

DOI 10.22533/at.ed.8632026106

CAPÍTULO 7

PADRONIZAÇÃO DE MATERIAIS COMO MEIO DE ECONOMIA EM SUPRIMENTO DE BENS: UM ESTUDO DE CASO

Patrícia Aparecida Casteluber Nascimento

Gabrielle Silva Ribeiro

Beatriz Marvila Borges

Letícia dos Santos Sciortino

DOI 10.22533/at.ed.8632026107

CAPÍTULO 8 77

A GENERALIZED INTEGRAL TRANSFORMED TECHNIQUE: LITERATURE REVIEW AND COMPARATIVE RESULTS WITH FINITE VOLUME METHOD

Hildson Rodrigues de Queiroz

Flavio Maldonado Bentes

Marcelo de Jesus Rodrigues da Nóbrega

Fabiano Battemarco da Silva Martins

DOI 10.22533/at.ed.8632026108

CAPÍTULO 9 101

UTILIZAÇÃO DE WC NA MOAGEM DE ALTA ENERGIA DE CAVACOS DE AÇO ALTO CROMO

Roberta Alves Gomes Matos

Bruna Horta Bastos Kuffner

Gilbert Silva

DOI 10.22533/at.ed.8632026109

SOBRE OS ORGANIZADORES 108

ÍNDICE REMISSIVO 109 
Data de aceite: 01/10/2020

João Marcelo Abreu Bernardi

Universidade Tecnológica Federal do Paraná

Cornélio Procópio - Paraná

Edson Hideki Koroishi

Universidade Tecnológica Federal do Paraná

Cornélio Procópio - Paraná

RESUMO: Esse trabalho tem como intuito identificar avarias e mensurar os valores das propriedades físicas de um sistema dinâmico de dois graus de liberdade utilizando inteligência artificial. Inicialmente a rede neural artificial (RNA) foi utilizada para identificar se o sistema está com alteração, a partir do deslocamento no tempo, e posteriormente como ponto de partida para que a evolução diferencial (ED) encontre os valores dos parâmetros. O principal objetivo é auxiliar nas tomadas de decisão no gerenciamento de ativos.

PALAVRAS CHAVE: Sistema Dinâmico, Inteligência Artificial, Rede Neural Artificial (RNA) e Evolução Diferencial (ED).

ABSTRACT: This work aims to identify malfunctions and measure the values of the physical properties of a dynamic system of two degrees of freedom using artificial intelligence. First, the artificial neural network (ANN) will be used to identify whether the system is modified, from time displacement, and later as a starting point for the differential evolution (ED) to find the parameter values. The main objective is to assist in asset management decision making.

KEYWORDS: Dynamic System, Artificial Intelligence, Artificial Neural Network (ANN) e Differential Evolution (ED).

\section{I INTRODUÇÃO}

O diagnóstico de avarias vem recebendo atenção de pesquisadores por suas várias aplicações. Com isso métodos inteligentes foram integrados com métodos de processamento de sinal para automatizar o diagnóstico de avarias. A lógica fuzzy, redes neurais, máquina de vetores de suporte e sistemas imunológicos artificiais são técnicas empregadas em problemas de detecção de avarias para motores de indução. Um sistema inteligente reconhece os recursos gerados no estágio de pré-processamento através de um método de processamento de sinal e os usa com uma assinatura on-line para identificar o tipo de avaria (AYDIN, KARAKOSE e AKIN, 2013).

O conceito de sistemas inteligentes é um desejo de muito tempo que tem como objetivo sistemas mecânicos independentes. Com isso em mente as redes neurais artificiais (RNA) tem campo de pesquisa em diversas áreas de aplicações, tais como: Análise de imagens, escritas e áudios e controle de sistemas. (DA SILVA, SPATTI e FLAUZINO, 2010). 
As técnicas de inteligência artificial, como pode ser visto, tem uma grande área de aplicação nas mais diversas áreas sendo uma delas a de detecção de avarias, neste projeto será apresentada uma abordagem na qual se utilizara de redes neurais artificiais e evolução diferencial para que se identifique avarias e os parâmetro um determinado sistema.

\section{I PROCEDIMENTO EXPERIMENTAL}

Segundo Silva, Spatti e Flauzino (2010), a RPM é uma evolução da rede perceptron, sendo que a principal diferença estrutural está no número de camadas intermediárias de neurônios, que fica entre a camada de entrada e a de saída. Como pode ser visto na Figura 1.

Como é notada na figura 1 os sinais externos, originados da aplicação, são propagados uma a uma em direção à camada neural de saída do RPM. As saídas da primeira camada escondida são as próprias entradas dos neurônios da segunda camada escondida, por consequência esta saída corresponde as entradas da camada neural de saída.

No caso das redes RPM o processo de treinamento da rede é feito utilizando o algoritmo backpropagation, também conhecido como regra de Delta generalizada. Tendo identificado os parâmetros da estrutura se utilizando da RPM o próximo passo é usar a Evolução Diferencial (ED) para refinar os valores.

O algoritmo da ED é uma otimização simples no âmbito de aplicações não lineares com variáveis contínuas que é o caso dos sistemas dinâmicos. Tendo sua primeira publicação feita por Storm e Price (1995), ele foi ganhando seu espaço e mostrando a robustez do método nas mais diversas aplicações. (GUIMARÃES, 2009)

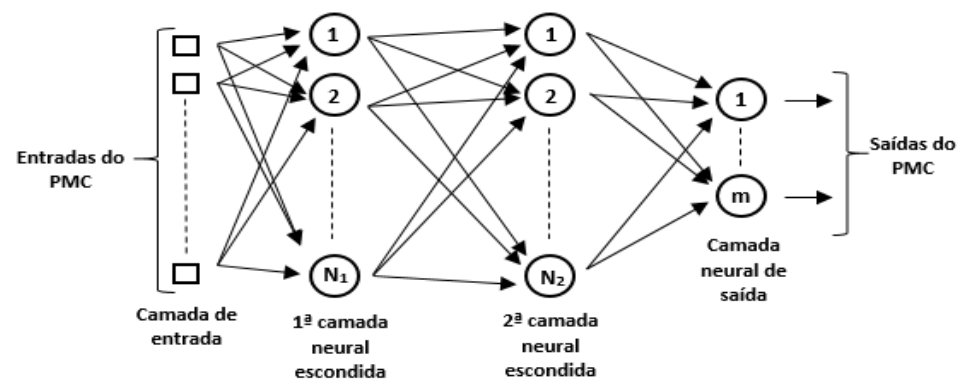

Figura 1 - Ilustração de rede Perceptron múltiplas camadas. (SILVA, SPATTI e FLAUZINO, 2010) 
Tendo como base a combinação dos operadores de mutação e cruzamento para selecionar candidatos potenciais procurando solucionar questões no âmbito da otimização (BANERJEE e ABU-MAHFOUZ, 2014)

O método segue um esquema de solução com algumas etapas bases, sendo elas: mutação, cruzamento e seleção. Sendo essas mesmas testadas por exaustão até se chegar ao critério de parada, conforme mostra a Figura 2.

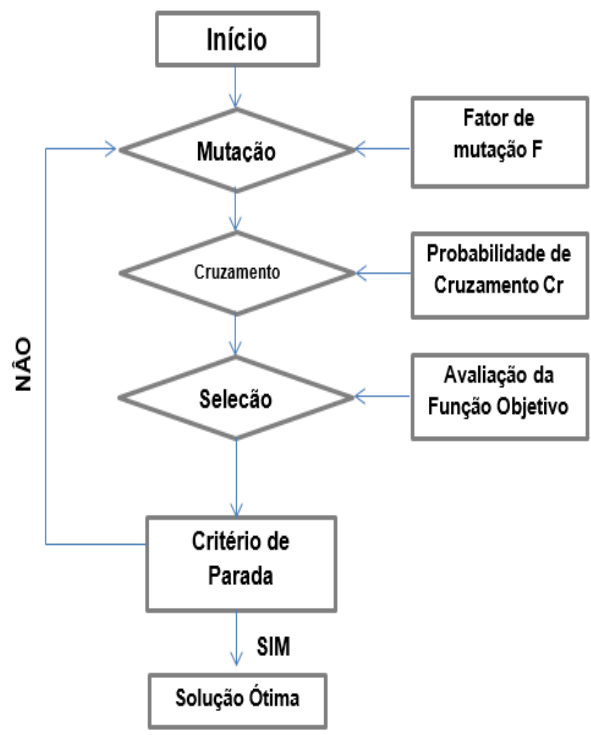

Figura 2 - Etapas do algoritmo ED.

Fonte: Autoria própria

As técnicas descritas acima foram utilizadas de duas formas no estudo, sendo na identificação de avarias em um sistema com dois graus de liberdade (Figura 3) e depois na identificação dos parâmetros do sistema. 

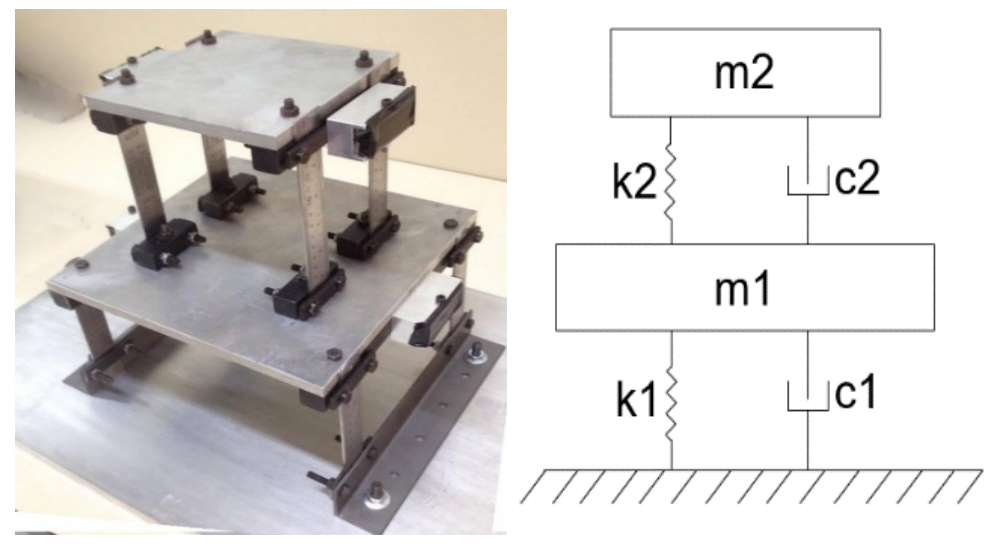

Figura 3 - Representação sistema de dois graus de liberdade

Fonte: Autoria própria.

\section{I METODOLOGIA}

Simulações para um sistema com dois graus de liberdade, conforme figura 3 e tabela 1 e utilizando-se do software Matlab ${ }^{\circledR}$, foram feitas para avaliar o comportamento sem e com algumas alterações nos seus parâmetros. As simulações com modificações do sistema foram feitas acrescentando e reduzindo cerca de $20 \%$ do valor original do sistema para as propriedades de massa e rigidez para as mais diversas intensidades de excitação.

\begin{tabular}{cc}
\hline \multicolumn{3}{c}{ Valores dos parâmetros } \\
\hline Massa 1 $\left(\mathbf{m}_{\mathbf{1}}\right)$ & $4,38262 \mathrm{~kg}$ \\
\hline Massa 2 $\left(\mathbf{m}_{\mathbf{2}}\right)$ & $1,93959 \mathrm{~kg}$ \\
\hline Rigidez 1 $\left(\mathbf{k}_{\mathbf{1}}\right)$ & $22492,50 \mathrm{~N} / \mathrm{m}$ \\
\hline Rigidez 2 $\left(\mathbf{k}_{\mathbf{2}}\right)$ & $14646,96 \mathrm{~N} / \mathrm{m}$ \\
\hline Amortecimento 1 $\left(\mathbf{c}_{1}\right)$ & $21,66 \mathrm{~N} . \mathrm{s} / \mathrm{m}$ \\
\hline Amortecimento 2 $\left(\mathbf{c}_{2}\right)$ & $0,607 \mathrm{~N} . \mathrm{s} / \mathrm{m}$ \\
\hline
\end{tabular}

Tabela 1 - Valores dos parâmetros utilizados nas simulações

Fonte: REPINALDO, 2018

Na sequência utilizou-se a resposta do deslocamento em relação ao tempo para a construção de uma RNA de forma a determinar em qual parâmetro do sistema houve alteração caso tenha havido. Isso vai ser feito atribuindo valores de saída 0 e 1 para os seguintes casos: Caso A - Perca na massa, Caso B - Perca na rigidez, Caso C - Ganho na massa, Caso D - Ganho na rigidez e Caso E - Sem alteração nos parâmetros. 
Em casos em que tiveram mudanças nos parâmetros a simulação foi feita de forma a variar individualmente um por vez. Para esta questão de identificação e quantificação dos parâmetros tanto a RNA e a evolução diferencial foram utilizadas.

\section{I RESULTADOS}

Os resultados dos estudos são divididos nas seguintes partes: Aplicação da rede neural na identificação de falha, da rede neural na identificação dos parâmetros e da evolução diferencial na identificação dos parâmetros.

\subsection{Aplicação da rede neural na identificação de falha}

Foram realizados 100 casos simulados para cada um dos seguintes casos: Perca e ganho de massa em $m_{1}, m_{2}$ e $m_{1}$ e $m_{2}$, perca e ganho de rigidez em $k_{1}$, $k_{2}$ e $k_{1}$ e $k_{2}$ e sem perca nos valores das propriedades.

Para todos os casos, utilizou-se forças impulsivas que variaram no intervalo de acordo com a formula $\mathrm{F}=100^{*}(0.1+$ rand $)$, sendo rand um número aleatório de 0 a 1 , e para os casos de perca e ganho houve limitações de valores de $20 \%$ no parâmetro para mais e para menos.

No total, obteve-se 1300 casos gerados de forma aleatória tanto para as mudanças nas propriedades quanto nas forças impulsivas para que se pudesse pegar os sinais. Desses sinais $10 \%$ de cada um deles foram separados para a validação após a construção da RNA.

O passo seguinte foi considerar $90 \%$ dos casos gerados a partir dos quais fez-se uma normalização utilizando a equação 1, para melhoramento de processamento, e foi construído uma rede neural contendo 5 camadas e 10 neurônios em cada uma delas, isso se deu pela quantidade de acertos obtidos, pelo tempo que se levou para que se pudesse gerar uma diferença de $1 \times 10^{-8}$ entre os valores dos treinamentos e pelas quantidades de saídas que foram consideradas.

$$
x_{\text {norm }}=\frac{\left(x_{i}-x_{\text {minimo }}\right)}{x_{\text {maximo }}-x_{\text {minimo }}}
$$

No qual, $x_{\text {norm }}$ - Valor normalizado; $x_{i}$ - Valor a ser normalizado; $x_{\text {mínimo }}-$ Menor valor do sinal e $x_{\text {máximo }}-$ Maior valor do sinal.

Como dito na metodologia, a construção da primeira RNA tem como intuito determinar apenas se houve alterações nas propriedades tanto de ganho ou de perca, caso haja, foi considerado 5 saídas apenas, para os casos já citados.

As figuras 4 e 5 apresentam as diferenças entre os valores esperados e os encontrados. A partir destes resultados, observa-se que a quantidade de acerto para os dados utilizados na construção do RNA conseguiu classificar todos os 1170 casos, já nos separados para a validação ele obteve sucesso em 127 dos casos avaliados de 130 considerados. 


\subsection{Aplicação da rede neural na identificação dos parâmetros do sistema}

Esta parte do estudo teve como intuito o levantamento dos parâmetros através da rede neural. Sendo construída uma rede neural para determinar a massa, a rigidez e o amortecimento.

O procedimento de teste e validação seguiu os mesmos passos da sessão anterior onde $90 \%$ dos dados foram utilizados para a construção das redes neurais e $10 \%$ para a validação, como foi feito no caso anterior. Os resultados estão sendo mostrados a seguir, sendo apresentados em teste e validação.

\subsubsection{Resultados obtidos nos testes}

O teste foi feito para analisar se as redes neurais construídas a partir dos mesmos dados testados estavam retornando bons resultados. A tabela 2 apresenta a média do erro do valor real e o encontrado.

Analisando a tabela 2 é possível ver que os valores menores, que são os valores de massa e amortecimento, apresentam uma maior dispersão em relação à média. Quanto ao valor de rigidez ele apresentou uma dispersão muito pequena.
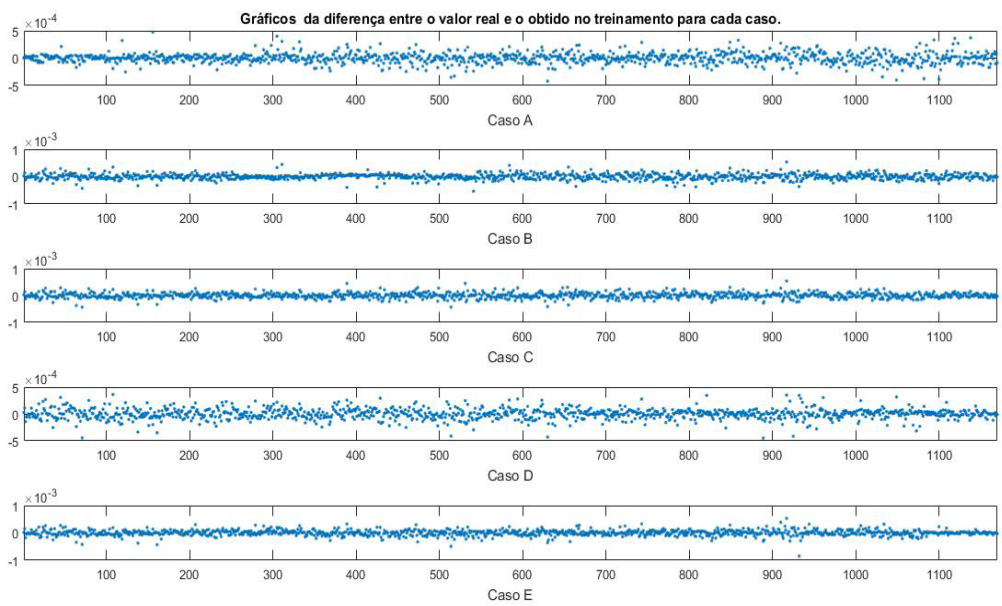

Figura 4 - Diferença entre os valores reais e os obtidos na saída para os valores utilizados na construção da RNA. 

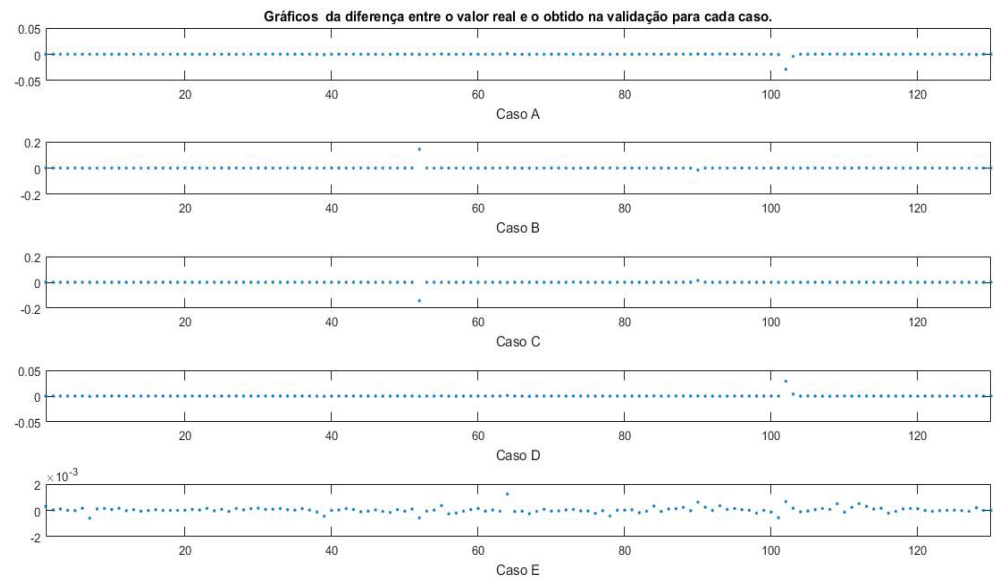

Figura 5 - Diferença entre os valores reais e os obtidos na saída para os valores utilizados separados para avaliação do RNA.

\begin{tabular}{ccccc}
\hline & $\begin{array}{c}\text { Ganho de massa } \\
(\%)\end{array}$ & $\begin{array}{c}\text { Perca de massa } \\
(\%)\end{array}$ & $\begin{array}{c}\text { Ganho de rigidez } \\
(\%)\end{array}$ & $\begin{array}{c}\text { Perca de rigidez } \\
(\%)\end{array}$ \\
\hline Massa 1 & $1,7658 \pm 1,7275$ & $5,3146 \pm 3,6465$ & $3,8789 \pm 2,5010$ & $0,4531 \pm 0,3696$ \\
\hline Massa 2 & $2,1578 \pm 1,8311$ & $5,9893 \pm 5,1329$ & $4,1598 \pm 2,8900$ & $0,5965 \pm 0,5141$ \\
\hline Rigidez 1 & $0,0003 \pm 0,0002$ & $0,0006 \pm 0,0005$ & $0,0001 \pm 0,0001$ & $0,0001 \pm 0,0001$ \\
\hline Rigidez 2 & $0,0004 \pm 0,0004$ & $0,0012 \pm 0,0011$ & $0,0006 \pm 0,0011$ & $0,0008 \pm 0,0016$ \\
\hline Amortecimento 1 & $0,0612 \pm 0,0192$ & $0,0477 \pm 0,0289$ & $1,1614 \pm 0,9074$ & $0,3860 \pm 0,3483$ \\
\hline Amortecimento 2 & $1,5500 \pm 1,3483$ & $4,1680 \pm 1,4853$ & $11,1423 \pm 9,2339$ & $2,8744 \pm 2,2341$ \\
\hline
\end{tabular}

Tabela 2 - Média dos erros dos resultados dos testes

\subsubsection{Resultados obtidos na validação}

Quanto aos resultados obtidos na validação, que tem como intuito validar as redes neurais construídas, ele é exposto na tabela 3.

\begin{tabular}{ccccc}
\hline & $\begin{array}{c}\text { Ganho de massa } \\
(\%)\end{array}$ & $\begin{array}{c}\text { Perca de massa } \\
(\%)\end{array}$ & $\begin{array}{c}\text { Ganho de rigidez } \\
(\%)\end{array}$ & $\begin{array}{c}\text { Perca de rigidez } \\
(\%)\end{array}$ \\
\hline Massa 1 & $3,6625 \pm 5,2133$ & $5,7708 \pm 3,7423$ & $3,8835 \pm 2,2062$ & $0,6090 \pm 0,5212$ \\
\hline Massa 2 & $4,1715 \pm 6,8203$ & $5,6171 \pm 5,1749$ & $4,268 \pm 2,2835$ & $0,6481 \pm 0,5322$ \\
\hline Rigidez 1 & $0,0005 \pm 0,0006$ & $0,0007 \pm 0,0005$ & $\begin{array}{c}0,00009 \pm \\
0,00007\end{array}$ & $0,0001 \pm 0,0001$ \\
\hline Rigidez 2 & $0,0012 \pm 0,0019$ & $0,0015 \pm 0,0013$ & $0,7146 \pm 0,9800$ & $1,7883 \pm 4,2333$ \\
\hline Amortecimento 1 & $0,0586 \pm 0,0307$ & $0,0575 \pm 0,0478$ & $1,6943 \pm 1,3584$ & $0,8411 \pm 0,8463$ \\
\hline Amortecimento 2 & $1,7204 \pm 1,6318$ & $4,7350 \pm 1,8494$ & $11,0899 \pm 9,5020$ & $3,2915 \pm 2,5470$ \\
\hline & & & &
\end{tabular}

Tabela 3 - Média dos erros dos resultados da validação 
Pode se notar que a variação dos resultados obtidos não se difere muito ao que foi apresentado nos testes (tabela 2), apresentando maiores erros nos valores menores e maior dispersão em relação ao valor real.

\subsection{Aplicação da evolução diferencial identificar os parâmetros do sistema}

A aplicação da evolução diferencial tem como objetivo identificar os valores dos parâmetros físicos do sistema, para os casos A, B, C e D. Em todos os casos foram feitas 30 iterações com três tamanhos de população diferentes. As populações iniciais foram formadas a partir de valores simulados, como se fossem obtidos na etapa anterior do estudo (RNA), um valor limite superior e outro inferior, levando em consideração a porcentagem do erro para cada um dos casos. O restante da população seria dividido em metade entre o valor médio e o limite superior e a outra do valor médio ao limite inferior, resultando assim nas quantidades iniciais de indivíduos de 33, 63 e 93.

O intuito de delimitar o número de iterações e variar a quantidade de população foi avaliar o comportamento da busca e a convergência com o aumento populacional. Os resultados são apresentados pelas tabelas 5 e 6 . As figuras 6, 7, 8 e 9 mostram a resposta impulsiva medida na massa $\mathrm{m}_{2}$ e sua FFT.

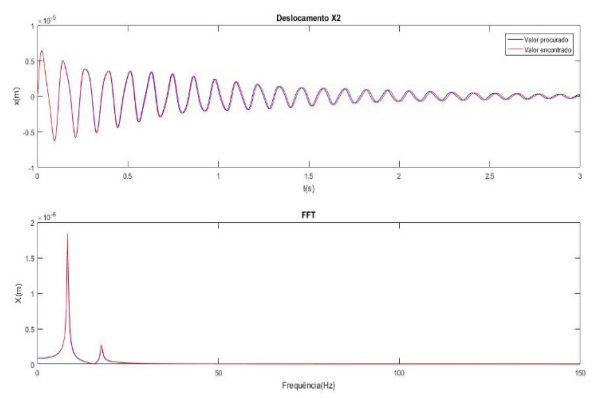

Figura 6 - Comportamento da m2 encontrado na análise de Ganho de Massa (Caso C)

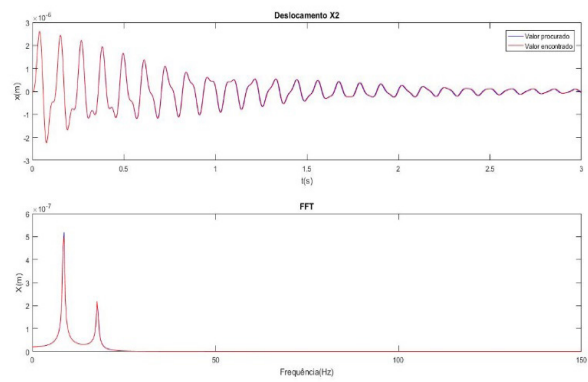

Figura 7 - Comportamento da m2 encontrado na análise de Ganho de Rigidez (Caso D) 


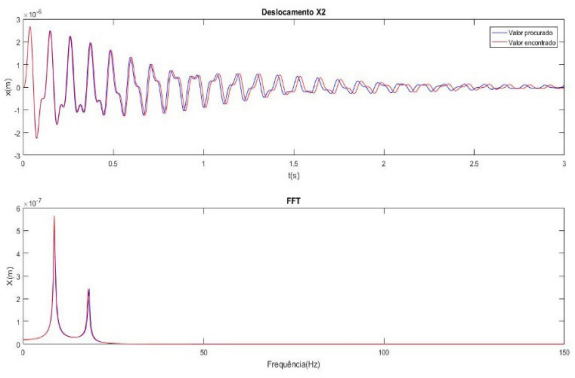

Figura 8 - Comportamento da m2 encontrado na análise de Perca de Massa (Caso A)

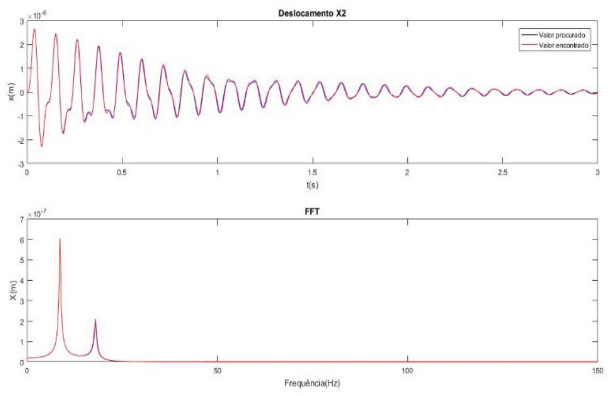

Figura 9 - Comportamento da m2 encontrado na análise de Perca de Massa (Caso B)

Ao analisar os resultados nota-se que os resultados obtidos com uma população inicial de 33 indivíduos já se encontram excelentes resultado com um gasto computacional muito menor, já que o tempo de processamento foi duas vezes maior para 63 e três vezes para 93 indivíduos. Se analisarmos os erros comparado ao que deveria ser encontrado os erros são muito baixos em todos os 3 tamanhos de população para os 4 casos, sendo os melhores resultados obtidos, nas maiorias dos casos, na menor população.

\section{I CONSIDERAÇÕES FINAIS}

No primeiro estudo vimos que na validação tivemos valores de acertos em $97,69 \%$ para identificação de avarias em sistemas, ao se aplicar o mesmo método para identificação de parâmetros não se tivemos o mesmo sucesso. Pode se notar que de forma geral os valores de erros foram altos para as massas e amortecimento, sendo que em houve erro próximo a $11 \%$.

Mesmo o resultado não ter demonstrado promissor ele serve como um ótimo limitador de intervalos para se utilizar a ED que necessita de uma memória computacional muito grande. Quando aplicado a ED os valores de erros não passaram de $0,2 \%$, sendo esse valor também para . 


\begin{tabular}{|c|c|c|c|c|c|c|c|}
\hline & \multirow{2}{*}{$\begin{array}{l}\text { Tamanho da } \\
\text { população }\end{array}$} & \multicolumn{6}{|c|}{ Parâmetros do sistema } \\
\hline & & M1 & M2 & K1 & K2 & C1 & $\mathrm{C} 2$ \\
\hline \multirow{3}{*}{$\begin{array}{c}\text { Ganho } \\
\text { de } \\
\text { massa }\end{array}$} & 33 & $4,4838 \pm 0,2589$ & $2,1528 \pm 0,1507$ & $22492,3500 \pm 0,1678$ & $14647,1712 \pm 0,3191$ & $21,6551 \pm 0,0130$ & $0,5969 \pm 0,0139$ \\
\hline & 63 & $4,3965 \pm 0,1678$ & $2,0097 \pm 0,0657$ & $22492,6762 \pm 0,1148$ & $14646,9261 \pm 0,2013$ & $21,6627 \pm 0,0096$ & $0,6174 \pm 0,0074$ \\
\hline & 93 & $4,7946 \pm 0,2285$ & $1,7663 \pm 0,0994$ & $22492,5125 \pm 0,1428$ & $14646,6913 \pm 0,2874$ & $21,6769 \pm 0,0109$ & $0,5872 \pm 0,0123$ \\
\hline \multirow{3}{*}{$\begin{array}{c}\text { Ganho } \\
\text { de } \\
\text { rigidez }\end{array}$} & 33 & $4,6605 \pm 0,1283$ & $1,9581 \pm 0,05662$ & $22492,5309 \pm 0,0179$ & $14466,6409 \pm 108,1719$ & $21,0399 \pm 0,3490$ & $0,6332 \pm 0,0655$ \\
\hline & 63 & $4,7599 \pm 0,1557$ & $2,1546 \pm 0,0736$ & $22492,4824 \pm 0,0277$ & $14603,0406 \pm 182,3668$ & $22,1313 \pm 0,4298$ & $0,7285 \pm 0,0943$ \\
\hline & 93 & $4,6579 \pm 0,1846$ & $1,9043 \pm 0,0694$ & $22492,4758 \pm 0,0172$ & $14487,5156 \pm 144,0588$ & $22,0579 \pm 0,3540$ & $0,6631 \pm 0,07926$ \\
\hline \multirow{3}{*}{$\begin{array}{c}\text { Perca } \\
\text { de } \\
\text { massa }\end{array}$} & 33 & $4,8571 \pm 0,2664$ & $1,7827 \pm 0,1230$ & $22492,5369 \pm 0,2078$ & $14646,7836 \pm 0,2944$ & $21,6851 \pm 0,0169$ & $0,5725 \pm 0,0262$ \\
\hline & 63 & $4,4141 \pm 0,2222$ & $1,9111 \pm 0,1126$ & $22492,3073 \pm 0,1514$ & $14647,2301 \pm 0,2688$ & $21,6735 \pm 0,0136$ & $0,6059 \pm 0,0229$ \\
\hline & 93 & $4,0368 \pm 0,1596$ & $1,7664 \pm 0,0922$ & $22492,2636 \pm 0,1465$ & $14646,8158 \pm 0,2709$ & $21,6759 \pm 0,0136$ & $0,5626 \pm 0,0207$ \\
\hline \multirow{3}{*}{$\begin{array}{c}\text { Perca } \\
\text { de } \\
\text { rigidez }\end{array}$} & 33 & $4,3674 \pm 0,0298$ & $1,9377 \pm 0,0138$ & $22492,4931 \pm 0,0281$ & $14107,6367 \pm 605,6298$ & $21,6223 \pm 0,2452$ & $0,5989 \pm 0,0216$ \\
\hline & 63 & $4,3438 \pm 0,0217$ & $1,9409 \pm 0,0096$ & $22492,4851 \pm 0,0198$ & $13265,2056 \pm 238,2688$ & $21,3071 \pm 0,1292$ & $0,5908 \pm 0,0119$ \\
\hline & 93 & $4,4239 \pm 0,0374$ & $1,9172 \pm 0,0157$ & $22492,4964 \pm 0,0331$ & $13860,3202 \pm 687,9061$ & $21,9433 \pm 0,2749$ & $0,5669 \pm 0,0252$ \\
\hline
\end{tabular}

Tabela 5 - Valores dos parâmetros encontrados no estudo da evolução diferencial

\begin{tabular}{|c|c|c|c|c|c|c|c|}
\hline & \multirow{2}{*}{$\begin{array}{c}\text { Tamanho da } \\
\text { população }\end{array}$} & \multicolumn{7}{|c|}{ Erro (\%) } \\
\cline { 2 - 7 } & 33 & 0,0041 & 0,0137 & $2,1502 \times 10^{-07}$ & $1,6056 \times 10^{-06}$ & $2,8280 \times 10^{-05}$ & 0,0017 \\
\hline \multirow{3}{*}{$\begin{array}{c}\text { Ganho de } \\
\text { massa }\end{array}$} & 63 & 0,0755 & 0,0979 & $9,3022 \times 10^{-06}$ & $2,6573 \times 10^{-05}$ & 0,0007 & 0,0294 \\
\cline { 2 - 8 } & 93 & 0,0126 & 0,0123 & $5,1597 \times 10^{-07}$ & $1,3936 \times 10^{-06}$ & $7,9838 \times 10^{-05}$ & $1,1538 \times 10^{-05}$ \\
\hline \multirow{3}{*}{$\begin{array}{c}\text { Ganho de } \\
\text { rigidez }\end{array}$} & 33 & 0,0028 & 0,0041 & $4,9509 \times 10^{-09}$ & 0,0003 & 0,0014 & 0,0007 \\
\cline { 2 - 7 } & 63 & 0,0427 & 0,0462 & $6,3418 \times 10^{-07}$ & 0,0056 & 0,0159 & 0,1074 \\
\hline \multirow{3}{*}{$\begin{array}{c}\text { Perca de } \\
\text { massa }\end{array}$} & 93 & 0,0041 & 0,0100 & $1,8538 \times 10^{-07}$ & 0,0005 & 0,0006 & 0,0195 \\
\cline { 2 - 8 } & 33 & 0,0203 & 0,0196 & $4,7198 \times 10^{-07}$ & $3,2676 \times 10^{-06}$ & 0,0001 & 0,0076 \\
\hline & 93 & 0,0007 & 0,0030 & $2,1731 \times 10^{-06}$ & $2,7023 \times 10^{-06}$ & 0,0002 & 0,0085 \\
\hline \multirow{3}{*}{$\begin{array}{c}\text { Perca de } \\
\text { rigidez }\end{array}$} & 33 & 0,0035 & 0,0059 & $2,4942 \times 10^{-06}$ & $5,1017 \times 10^{-06}$ & 0,0002 & 0,0084 \\
\cline { 2 - 7 } & 63 & 0,0004 & 0,0001 & $1,6794 \times 10^{-07}$ & 0,0126 & 0,0009 & 0,0029 \\
\cline { 2 - 7 } & 93 & 0,0051 & 0,0042 & $1,0751 \times 10^{-06}$ & 0,0443 & 0,0088 & 0,0337 \\
\hline
\end{tabular}

Tabela 6 - Erro entre o valor de entrada e a média das 30 buscas realizada com a evolução diferencial

\section{AGRADECIMENTOS}

Agradecemos ao apoio da UTFPR pelo suporte e material que possibilitou a realização deste trabalho. O presente trabalho foi realizado com o apoio do Conselho Nacional de Desenvolvimento Científico e Tecnológico CNPq - Brasil (Processo 402581/2016-4). 


\section{REFERÊNCIAS}

AYDIN, I.; KARAKOSE, M.; AKIN E. An approach for automated fault diagnosis based on a fuzzy decision tree and boundary analysis of a reconstructed phase space. ISA Transactions, volume 53 , p. 220-229, dez. 2013.

BANERJEE, A.; ABU-MAHFOUZ, I. A comparative analysis of particle swarm optimization and differential evolution algorithms for parameter estimation in nonlinear dynamic systems. Chaos, Solitons \& Fractals, v.58, p.65-83, 2014.

DA SILVA, I.N.; SPATTI, D.H.; FLAUZINO, R.A. Redes Neurais Artificiais Para Engenharia e Ciências Aplicadas, Artliber Editora Ltda., 2010.

GUIMARÃES, F. Algoritmos de Evolução Diferencial. Manual de Algoritmos Evolutivos e Metaheuristicas, Minas Gerais, 2009

REPINALDO, J.P. Controle modal aplicado a uma estrutura de $\mathbf{2}$ graus de liberdade utilizando atuadores eletromagnéticos. Dissertação (Mestrado) - Universidade Tecnológica Federal do Paraná, Programa de Pós-Graduação em Engenharia Mecânica.

STORN, R., PRICE, K. V. Differential evolution - a simple and efficient heuristic for global optimization over continuous spaces. Journal of Global Optimization 11, 341-359, 1995. 


\section{CAPÍTULO 2 \\ UTILIZAÇÃO DE ATUADORES ELETROMAGNÉTICOS PARA O CONTROLE DE VIBRAÇÃO EM UMA VIGA DE MATERIAL COMPÓSITO}

Data de aceite: 01/10/2020

Data de submissão: 07/07/2020

\section{Andrei Santos Oliveira}

Universidade Tecnológica Federal do Paraná, Cornélio Procópio, Paraná, Brasil http://lattes.cnpq.br/3799718172614106

Camila Albertin Xavier da Silva Universidade Tecnológica Federal do Paraná, Cornélio Procópio, Paraná, Brasil http://lattes.cnpq.br/3600998711160920

\section{Edson Hideki Koroishi}

Universidade Tecnológica Federal do Paraná,

Cornélio Procópio, Paraná, Brasil http://lattes.cnpq.br/9465293262026260

\section{Romeu Rony Cavalcante da Costa}

Universidade Tecnológica Federal do Paraná, Cornélio Procópio, Paraná, Brasil http://lattes.cnpq.br/6785202465903803

Marco Túlio Santana Alves Universidade Federal da Bahia, Salvador, Bahia, Brasil http://lattes.cnpq.br/9520270393660729

RESUMO: O presente trabalho tem como objetivo o controle ativo de vibrações em uma estrutura de material compósito utilizando atuadores eletromagnéticos. O método de identificação do modelo do sistema foi o algoritmo ERA/OKID, que consiste em um método de identificação de estruturas complexas a partir de dados de entrada e saída do sistema. A técnica de controle utilizada foi o controle ótimo, a partir do uso de Regulador Linear Quadrático (LQR). O sistema de controle é responsável por calcular os esforços de controle necessários para alimentar os atuadores eletromagnéticos. Os atuadores eletromagnéticos por sua vez, atuam sobre a estrutura compósita aplicando a força eletromagnética, resultando na atenuação de vibração da estrutura. Os resultados obtidos se mostraram satisfatórios, apresentando um tempo de acomodação pequeno e redução da amplitude no primeiro modo de vibrar. A fim de validar os resultados numéricos, foram obtidos os resultados experimentais, validando assim a metodologia proposta.

PALAVRAS-CHAVE: LQR, Controle Ativo de Vibrações, Material Compósito, ERA/OKID.

\section{USE OF ELECTROMAGNETIC ACTUATORS TO VIBRATION CONTROL IN A COMPOSITE MATERIAL BEAM}

ABSTRACT: The present work aims to active vibration control in a composite material structure using electromagnetic actuators. The identification method of system model was the ERA / OKID algorithm, which consists of a method of identifying complex structures from the input and output data of the system. The control technique used was the optimal control, based on the use of Linear Quadratic Regulator (LQR). The control system is responsible for calculating the control efforts required to power the electromagnetic actuators. The electromagnetic actuators, in turn, act on the composite structure from the electromagnetic force, resulting in the attenuation of the structure's vibration. The results obtained 
were satisfactory, with a short accommodation time and reduced amplitude in the first mode of vibration. In order to validate the numerical results, experimental results were obtained, thus validating the proposed methodology.

KEYWORDS: LQR, Active Vibrations Control, Composite Material, ERA/OKID.

\section{I INTRODUÇÃO}

Em um ambiente industrial existem inúmeras fontes de vibrações que podem causar desgastes excessivos em mancais, falhas estruturais e mecânicas, manutenção frequente, afrouxamento de parafusos, trincas, fraturas em juntas soldadas, entre outros problemas na indústria. Assim sendo, estudar o comportamento dessas vibrações é fundamental parar eliminar ou reduzir os níveis vibracionais (OGATA, 2003).

Segundo (BORGES, 2016), o controle ativo é o método mais avançado para atenuações de vibrações, é constituído, geralmente, por sensores, atuadores e uma unidade de controle. Os sensores possuem a função de fornecer informações sobre as variáveis a serem controladas. A unidade de controle processa as informações obtidas pelos sensores, de forma a aplicar os algoritmos de controle correspondentes, produzindo os sinais de comando. Os atuadores, por fim, convertem os sinais de comando emitidos, pela unidade de controle, em ações efetivas sobre o sistema.

O controle ativo é uma técnica em que consiste na aplicação de forças contrárias ao movimento da estrutura. $O$ resultado dessas duas forças opostas é a anulação das forças e assim a vibração da estrutura cessa (XINKE, 2007). Este tipo de controle vem apresentando aplicações bem-sucedidas em diversa áreas, e uma área de grande interesse atualmente, é o estudo de material compósito, materiais os quais possuem arranjo inovador, caracterizados por sua leveza, resistência mecânica e possibilidade de otimização de condições de funcionamento específico (REDDY, 1997).

Dentro deste contexto o presente trabalho dedica-se a implementar o controle ativo de vibração em uma viga de material compósito livre-engastada, utilizando Regulador Linear Quadrático (LQR- Linear Quadratic Regulator) a fim de atenuar a vibração da viga de material compósito. Neste projeto, foram utilizados atuadores eletromagnéticos para aplicação da força de controle sobre a estrutura.

\section{I MATERIAS E MÉTODOS}

A bancada experimental consiste em uma viga engastada de material compósito, dois atuadores eletromagnéticos, perfis de alumínio, um acelerômetro, uma placa de aquisição, dois amplificadores e um fonte de alimentação. A Figura 1 apresenta a bancada experimental e os seus respectivos elementos.

A viga compósita apresentada na Figura 1 apresenta $310[\mathrm{~mm}]$ de comprimento, $59,3[\mathrm{~mm}]$ de largura e $2[\mathrm{~mm}]$ de espessura, e é formada por resina epóxi, fibra de vidro e tela de aço 1045. 
Dois atuadores eletromagnéticos são posicionados na estrutura, para a aplicação do controle experimental. Cada atuador possui um gap (lacuna) de 1,5 [mm] da viga.

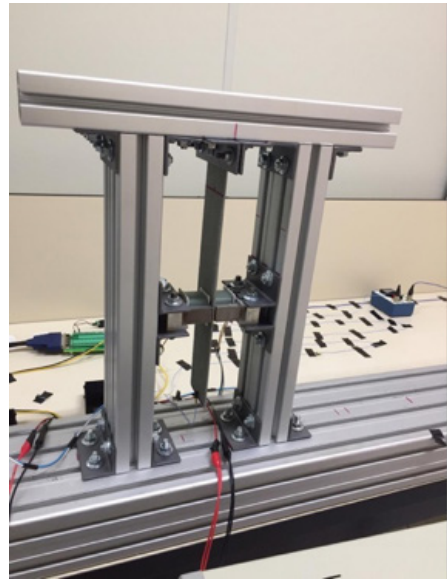

(a)

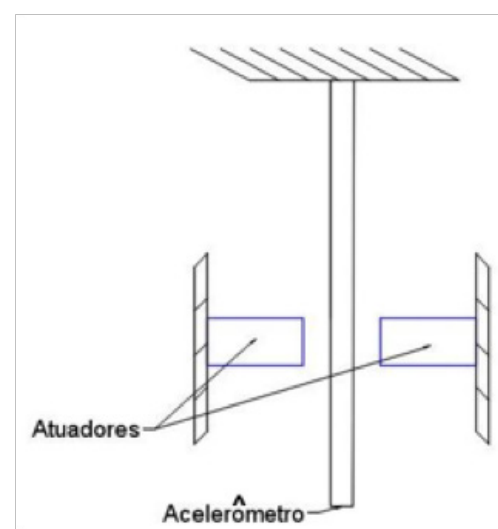

(b)

Figura 1: (a) Bancada (b) Representação esquemática da bancada.

A Figura 2 apresenta a representação esquemática do sistema de controle.

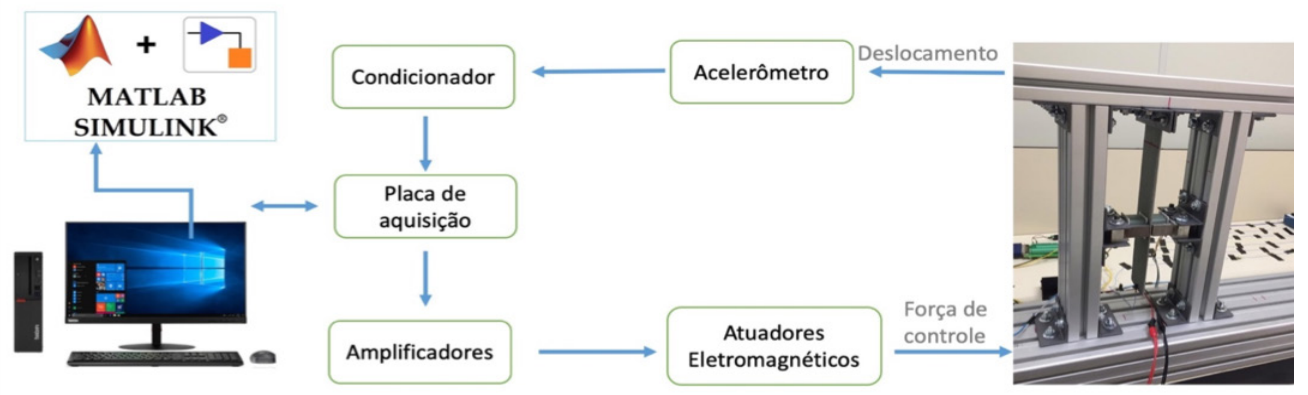

Figura 2: Representação esquemática do sistema de controle.

De acordo com a segunda lei de Newton, pode-se descrever o movimento de uma estrutura pela Equação (1).

$$
[\mathrm{M}]\{\ddot{\mathrm{x}}(\mathrm{t})\}+\left[\mathrm{C}_{\mathrm{a}}\right]\{\dot{\mathrm{x}}(\mathrm{t})\}+[\mathrm{K}]\{\mathrm{x}(\mathrm{t})\}=\{\mathrm{F}(\mathrm{t})\}
$$

A matriz $[\mathrm{M}]$ representa a matriz de massa, $\left[\mathrm{C}_{\mathrm{a}}\right]$ de amortecimento, $[\mathrm{K}]$ de rigidez, $\{\mathrm{X}\}$ o vetor deslocamento e $\{F\}$ a força de excitação. Através da representação de espaço de estados a Equação (1) pode ser rescrita conforme as Equações (2) e (3). 


$$
\begin{gathered}
\{\dot{\mathrm{x}}(\mathrm{t})\}=[\mathrm{A}]\{\mathrm{x}(\mathrm{t})\}+\left[\mathrm{B}_{\mathrm{u}}\right]\{\mathrm{u}(\mathrm{t})\}+\left[\mathrm{B}_{\mathrm{w}}\right]\{\mathrm{w}(\mathrm{t})\} \\
\{\mathrm{y}(\mathrm{t})\}=[\mathrm{C}]\{\mathrm{x}(\mathrm{t})\}
\end{gathered}
$$

onde, $\{\dot{x}(t)\}$ corresponde ao vetor de estado, $[\mathrm{A}]$ a matriz dinâmica, $\left[\mathrm{B}_{\mathrm{w}}\right]$ a matriz de entrada de excitação, $\left[\mathrm{B}_{\mathrm{u}}\right]$ corresponde a matriz de controle, $[\mathrm{C}]$ a matriz de saída, $\{\mathrm{u}(\mathrm{t})\}$ a força de entrada e $\{y(t)\}$ o vetor de saída. As matrizes que correspondem ao comportamento dinâmico do sistema: $[A],\left[B_{w}\right],\left[B_{u}\right],[C]$, sendo todas no domínio modal, foram obtidas através do algoritmo de identificação ERA/OKID que, segundo (ALVES, 2005), é um algoritmo de identificação capaz de determinar as matrizes que representam o comportamento dinâmico do sistema em espaço de estados.

Para controle do sistema foi projetado o regulador linear quadrático (LQR - do inglês, Linear Quadratic Regulator) a partir do software MATLAB ${ }^{\circledR}$. O controlador é a parte fundamental para o controle de vibração, onde o algoritmo específico de controle é implementado para garantir a atenuação de vibração do sistema (ZIPPO, 2015).

O LQR é uma estratégia de controle ótimo e amplamente utilizado em controle ativo de vibrações, baseado em retroalimentação no sistema (LIANG, 2018). O controle da realimentação é dado pela Equação (4):

$$
\{\mathrm{u}(\mathrm{t})\}=-\left[\mathrm{K}_{\mathrm{G}}\right]\{\mathrm{x}(\mathrm{t})\}
$$

Onde a matriz de ganho $\left[\mathrm{K}_{\mathrm{G}}\right]$ é determinada com minimização do desempenho dado pela Equação (5).

$$
\mathrm{J}=\int\left[\{\mathrm{x}(\mathrm{t})\}^{\top}\left[\mathrm{Q}_{\mathrm{lqr}}\right]\{\mathrm{x}(\mathrm{t})\}\right]+\left[\{\mathrm{u}(\mathrm{t})\}^{\top}\left[\mathrm{R}_{\mathrm{lqr}}\right]\{\mathrm{u}(\mathrm{t})\}\right] \mathrm{dt}
$$

Onde $\left[Q_{1 q r}\right]$ é uma matriz hermitiana definida positiva (ou semi-definida positiva) ou real simétrica das cargas de cada estado e $\left[R_{\mathrm{lqr}}\right]$ é uma matriz hermitiana definida positiva ou real simétrica do consumo de energia dos sinais de controle (ASSUNÇÃO, 2001). Para o projeto do controlador, as matrizes $Q_{\mathrm{lqr}}$ e $R_{\mathrm{lqr}}$ utilizadas são apresentadas na Equação 6 .

$$
\left[Q_{\mid q r}\right]=2500 *\left[\begin{array}{llll}
1 & 0 & 0 & 0 \\
0 & 1 & 0 & 0 \\
0 & 0 & 1 & 0 \\
0 & 0 & 0 & 1
\end{array}\right] \text { e }\left[R_{\mathrm{lqr}}\right]=[10]
$$

Com o modelo da estrutura compósita identificado e com o controlador projetado, obteve-se os resultados numéricos e experimentais.

\section{I RESULTADOS}

Os resultados numéricos foram obtidos através de simulação numérica computacional realizada no software $M A T L A B^{\circledR}$, a Figura 3 representa a resposta do deslocamento em função do tempo para o sistema com e sem controle. 


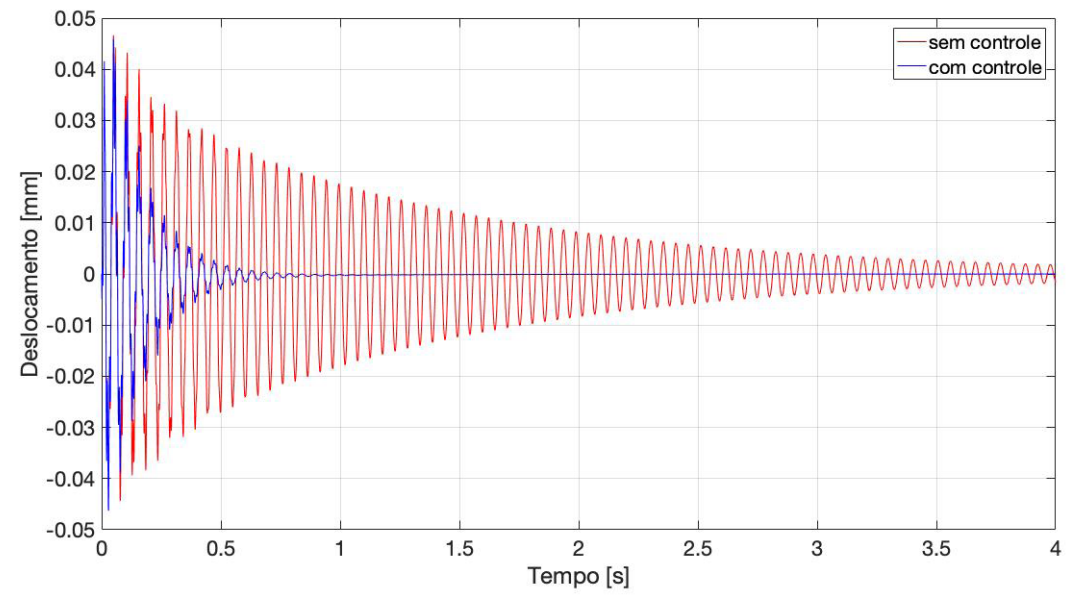

Figura 3: Resposta determinística do deslocamento em função do tempo.

A partir deste resultado, nota-se que houve uma atenuação da vibração na viga de material compósito, apresentando um tempo de acomodação menor quando apresentado sem controle, em que, em menos de 1 [s] atinge a estabilidade, ao passo que a resposta sem controle leva aproximadamente 5 [s].

As respostas do sistema sem e com controle também foram analisadas no domínio da frequência, sendo apresentadas pela Figura 4.

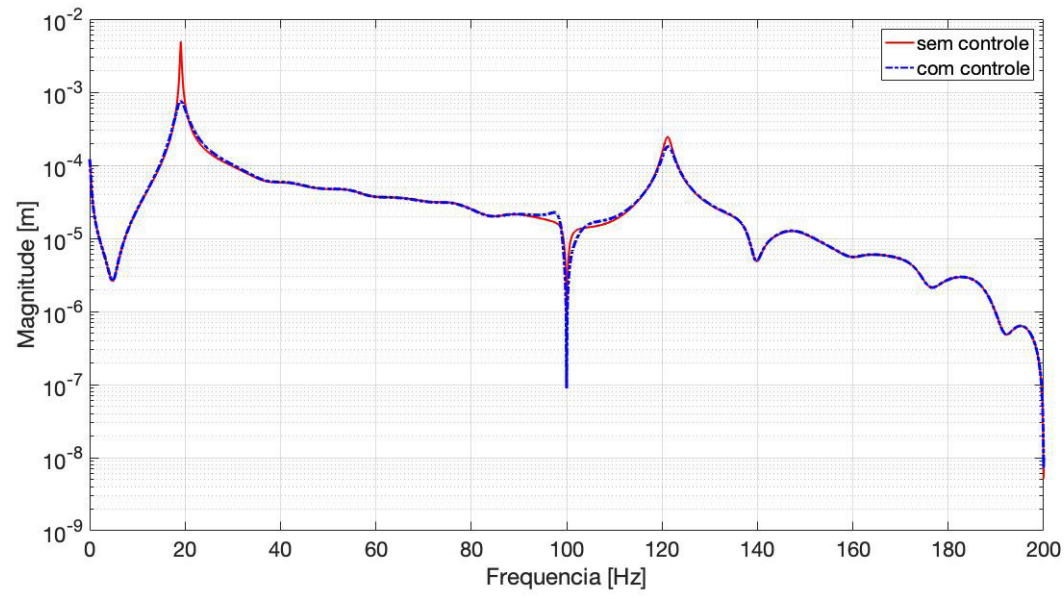

Figura 4: Resposta do sistema em relação a frequência do sistema sem controle e com controle. 
Nota-se a atenuação nos dois modos de vibrar da viga compósita, o primeiro localizado aproximadamente em 19 [Hz] e o segundo em 121 [Hz]. Quantitativamente, o primeiro modo de vibrar é atenuado de 4,9 [mm] para 0,75 [mm], representando uma redução de 4,15 [mm], aproximadamente. Já o segundo modo de vibrar passou de 0,24 [mm] para 0,18 [mm], redução de 0,06 [mm].

Por fim, foi analisado a corrente elétrica utilizada pelos dois atuadores eletromagnéticos, representando o esforço que o controlador teve para atenuar a vibração. O gráfico apresenta a corrente elétrica utilizada em cada atuador, como mostra a Figura 5.
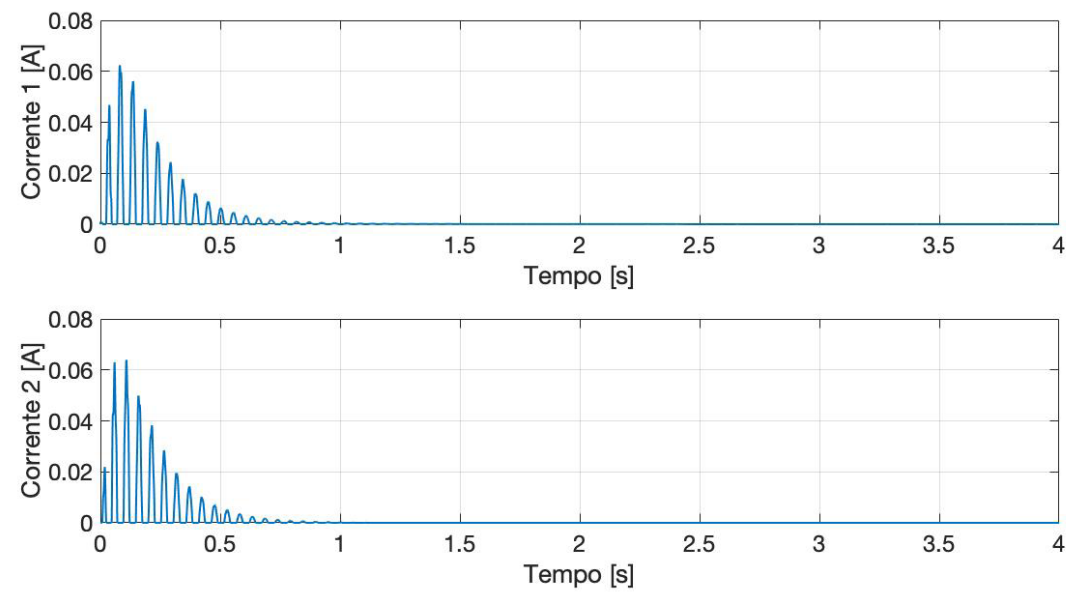

Figura 5: Corrente elétrica em função do tempo.

Conforme a Figura 5, nota-se os maiores picos da corrente elétrica nos primeiros instantes, uma vez que as forças para atenuar a vibração são maiores em consequência que neste intervalo de tempo é onde se encontra as maiores amplitudes de deslocamento.

Com a utilização da bancada experimental foram obtidos os resultados experimentais, a partir da malha de controle apresentada na Figura 2, a fim de validar os resultados obtidos nas simulações numéricas.

Foram obtidas as mesmas respostas da simulação numérica, para fins de comparação e validação, e são apresentados na Figura 6, 7 e 8. 


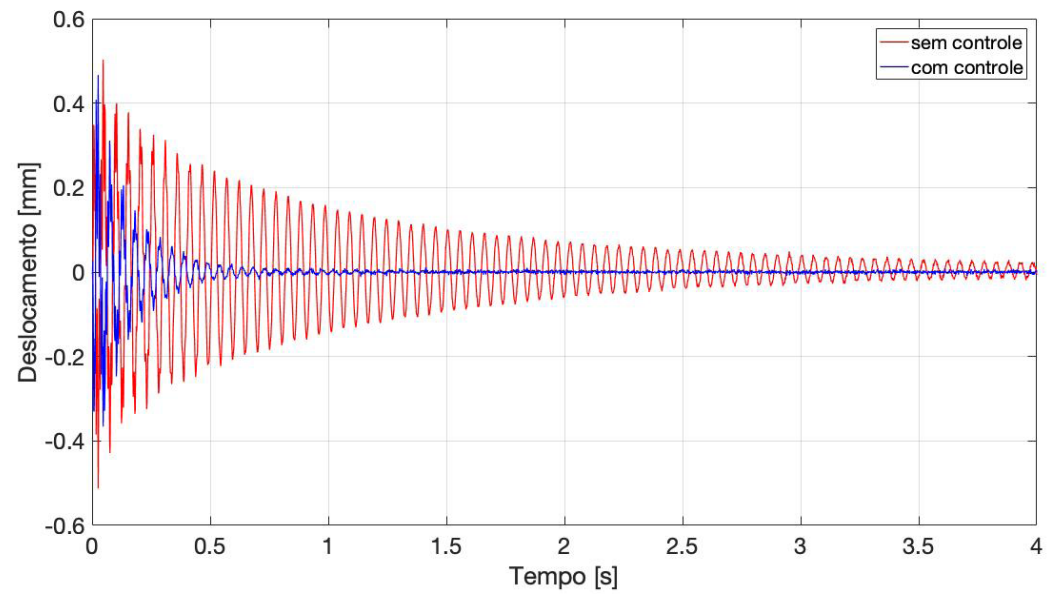

Figura 6: Resposta determinística do deslocamento em função do tempo experimental.

Como visto na Figura 6, a resposta do deslocamento em função do tempo apresenta resultados similares aos resultados obtidos numericamente, apresentando a atenuação da vibração em aproximadamente, em menos de 1 [s] com a aplicação controle do controle experimental.

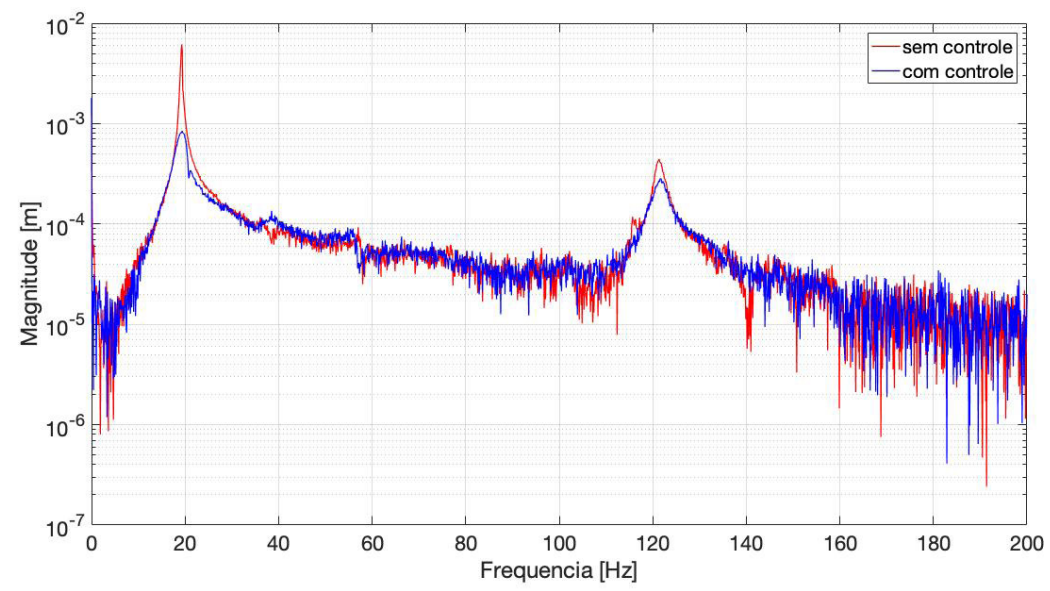

Figura 7: Função resposta em frequência (FRF) do sistema sem controle e com controle experimental.

A Figura 7 apresenta a redução da amplitude de vibração nos dois primeiros modos cujas frequências ocorrem, respectivamente, em 19,4 [Hz] e 121,9 [Hz]. No primeiro modo apresenta-se uma redução de aproximadamente $5,36[\mathrm{~mm}]$ no primeiro modo e 0,15 [mm] 
no segundo modo de vibrar. Comparativamente, as reduções de deslocamento no primeiro e segundo modo de vibrar apresentaram valores próximos aos valores simulados.

Por fim, a Figura 8 representa a utilização de corrente de cada atuador, experimentalmente encontra-se valores maiores que os valores simulados, uma vez que na simulação o pico de utilização de corrente elétrica representa 0,07 [A] enquanto que na pratica obteve-se um pico de 0,14 [A] aproximadamente.
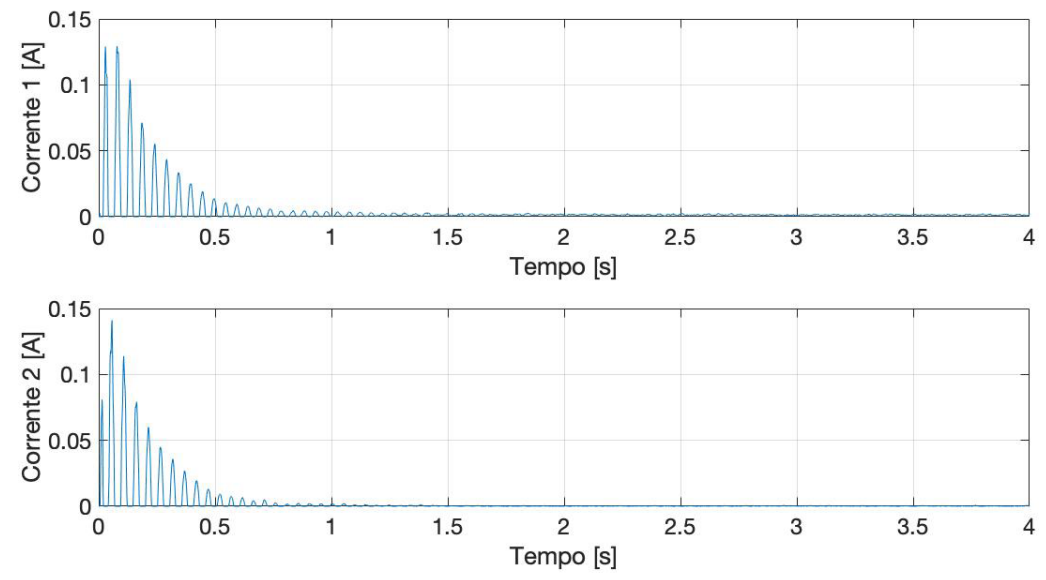

Figura 8: Corrente elétrica em função do tempo experimental.

\section{I CONCLUSÕES}

No presente trabalho foi possível avaliar a partir dos resultados de simulação computacional a notável relevância de um sistema de controle para atenuações de vibrações em vigas compósitas.

Nos resultados obtidos, foi possível verificar a atenuação de vibração da viga de material compósito, apresentando um tempo de acomodação em cerca de 0,5 a 1 [s]. Em contrapartida os resultados obtidos sem a aplicação de controle apresentaram a atenuação da viga em aproximadamente 6 [s].

Para a validação dos resultados numéricos, obteve-se respostas experimentais, e como foi disposto no presente trabalho, conclui-se que a metodologia de controle ativo de vibrações proposta é válida, visto que os resultados numéricos e experimentais demonstraram a validade da metodologia proposta. 


\section{AGRADECIMENTOS}

Agradecemos ao apoio da UTFPR pelo suporte e material que possibilitou a realização deste trabalho. O presente trabalho foi realizado com o apoio do Conselho Nacional de Desenvolvimento Científico e Tecnológico CNPq - Brasil (Processo 402581/2016-4).

\section{REFERÊNCIAS}

ALVES, MARCO TÚLIO SANTANA. Avaliação numérica e experimental dos métodos ERA e ERA OKID para a identificação de sistemas mecânicos. Marco Túlio Santana Alves - 2005.

ASSUNÇÃO, E.; TEIXEIRA, M. C. M. Projeto de sistemas de controle via LMIS usando o MATLAB. Aplicações em Dinâmica e Controle, São Carlos, p. 350-368, 2001.

BORGES, A.S. Controle Modal de Rotores com Mancais Magnéticos - Projeto Robusto. $197 \mathrm{f}$. Tese de Doutorado, Universidade Federal de Uberlândia, Uberlândia, 2016.

OGATA, K. Engenharia de Controle Moderno, Prentice-Hall do Brasil, São Paulo, Brazil, p. $788,2003$.

REDDY, J.N., Mechanics of Laminated Composite Plates: Theory and Analysis, Second Edition, CRC Press, London, UK, 1997.

XINKE, G. and HAIMIN, T. Active vibration control of a cantilever beam using bonded piezoelectric sensors and actuators. In: Electronic Measurement and Instruments, 2007. ICEMI'07. 8th International Conference on. IEEE, p. 4-85-4-88, 2007.

ZIPPO, A. Active vibration control of a composite sandwich plate. Composite Structures v.128, 100-114, 2015. 
Matheus Rincon Modesto Maroni Universidade Tecnológica Federal do Paraná UTFPR - Campus Cornélio Procópio Cornélio Procópio - Paraná

\section{Edson Hideki Koroishi} Universidade Tecnológica Federal do Paraná UTFPR - Campus Cornélio Procópio Cornélio Procópio - Paraná

RESUMO: $O$ presente trabalho apresenta uma técnica de controle ativo de vibrações aplicado a uma viga flexível utilizando atuadores eletromagnéticos. Para isso, a estrutura foi montada e seus parâmetros foram identificados. $\mathrm{Na}$ sequência, realizou-se a modelagem matemática do sistema dinâmico, e com base no modelo, o controlador LQR foi projetado. A metodologia foi analisada numérica e experimentalmente. $O$ controle numérico foi projetado com auxílio do software MatLab/Simulink e o controle experimental realizado em uma bancada de testes. Tanto os resultados numéricos quanto os experimentais apresentaram resultados satisfatórios, validando assim a metodologia proposta.

PALAVRAS-CHAVE: Viga Flexível, Controle Ativo de Vibrações, Atuador Eletromagnético, LQR.

\section{ACTIVE VIBRATION CONTROL APPLIED TO A FLEXIBLE BEAM USING ELECTROMAGNETIC ACTUATORS}

ABSTRACT: The present contribution is dedicated to active vibration control in a flexible beam using electromagnetic actuators. For this, the structure was built and its parameters were identified. After that, the mathematical modeling of the physical system was done, and from this model, the controller LQR was designed. The methodology was analyzed numerical and experimentally. The numerical control was projected using software MatLab/Simulink and the e xperimental control was performed in a test bench. Both the numerical and experimental results presented satisfactory results and proved the validity of the proposed methodology.

KEYWORDS: Flexible Beam, Active Vibration Control, Electromagnetic Actuator, LQR.

\section{I INTRODUÇÃO}

Em todos os campos da engenharia, a busca pela otimização dos processos vem crescendo cada dia mais. Os elementos de viga são de grande importância tanto no campo da construção civil quanto mecânica, já que são comumente usados em estruturas e máquinas. Em particular, devido à grande dinâmica de operação na área mecânica, muitas máquinas e equipamentos geram um elevado nível de vibrações, que muitas vezes podem levar a consequências prejudiciais à estrutura. Portanto, algumas técnicas foram criadas para 
controlar as vibrações nas estruturas. Entre elas, o Controle Modal tem-se destacado, principalmente porque reduz consideravelmente o custo computacional necessário. Isso se deve ao fato de que essa técnica emprega um modelo matemático reduzido que representa a estrutura, que tem seu comportamento dinâmico descrito satisfatoriamente pelo uso de um número limitado de modos que compõem seu modelo matemático (KOROISHI, 2013).

O presente trabalho foi desenvolvido para estudar técnicas de controle ativo de vibração, numérica e experimentalmente, utilizando atuadores eletromagnéticos em uma viga flexível.

\section{I METODOLOGIA}

Este trabalho visa estudar técnicas de controle ativo de vibração em uma viga flexível, mostrado na Fig. 1 (a), utilizando atuadores eletromagnéticos, iniciando pela montagem da estrutura, modelo matemático, identificação de parâmetros, controle numérico e finalmente controle experimental. A Figura 1 (b) apresenta o modelo esquemático da viga.

A viga possui dimensões de $300 \mathrm{~mm}$ de comprimento, $26,5 \mathrm{~mm}$ de largura e $1 \mathrm{~mm}$ de espessura, e conforme mostra a Figura 1 (b), a viga flexível foi dividida em 20 elementos finitos discretizados com $15 \mathrm{~mm}$ de comprimento cada. Cada nó possui dois graus de liberdade, o primeiro relacionado ao deslocamento e o segundo a rotação, sendo o primeiro nó restrito a estes movimentos devido ao engaste. A parte "l" do atuador eletromagnético está situado no nó 9 e possui uma massa concentrada (considerando o suporte) de 264,07g. Uma corrente elétrica impulsiva foi aplicada nos atuadores, a qual resultava numa força impulsiva sobre a viga e a resposta foi capturada por um acelerômetro posicionado no nó 21.

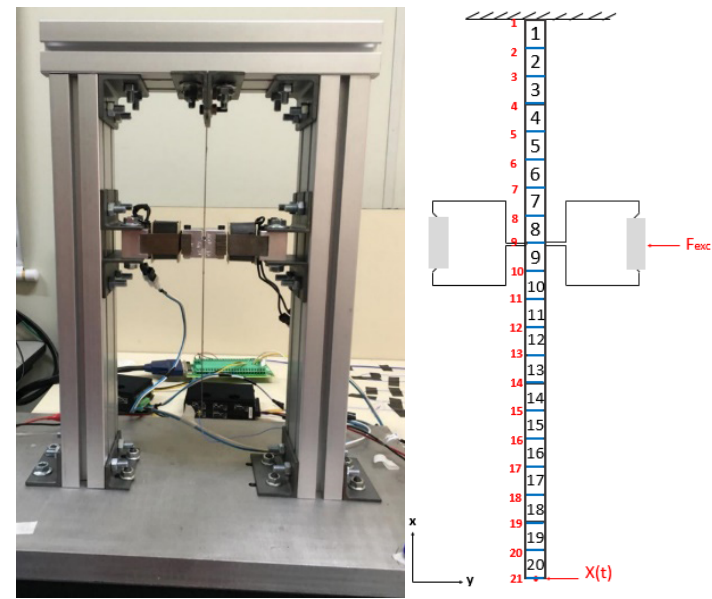

(a)

(b)

Figura 1. (a) Viga Flexível. (b) Modelo Esquemático. 


\subsection{Modelagem Do Sistema}

Aplicando a Segunda Lei de Newton, a equação de movimento que descreve o comportamento dinâmico do sistema é apresentada pela equação (1).

$$
\left[\mathrm{M}_{\mathrm{g}}\right]\{\ddot{\mathrm{x}}(\mathrm{t})\}+\left[\mathrm{C}_{\mathrm{ag}_{\mathrm{g}}}\right]\{\dot{\mathrm{x}}(\mathrm{t})\}+\left[\mathrm{K}_{\mathrm{g}}\right]\{\mathrm{x}(\mathrm{t})\}=\{\mathrm{F}(\mathrm{t})\}
$$

em que $\left[\mathrm{K}_{\mathrm{g}}\right],\left[\mathrm{M}_{\mathrm{g}}\right]$ e $\left[\mathrm{C}_{\mathrm{a}_{\mathrm{g}}}\right]$ são, respectivamente, as matrizes globais de rigidez, massa e amortecimento e $\{x\}$ o vetor deslocamento.

Utilizando os métodos dos elementos finitos e o modelo de Euler-Bernoulli para vigas, as matrizes elementares $[K],[M]$ e $\left[C_{a}\right]$ e, de acordo com (AZEVEDO, 2003), são representadas pela equação (2).

$$
\begin{aligned}
& {[\mathrm{K}]=\frac{E I}{L}\left[\begin{array}{cccc}
12 & 6 L & -12 & 6 L \\
6 L & 4 L^{2} & -6 L & 2 L^{2} \\
-12 & -6 L & 12 & -6 L \\
6 L & 2 L^{2} & -6 L & 4 L^{2}
\end{array}\right]} \\
& {[\mathrm{M}]=\frac{\rho S L}{420}\left[\begin{array}{cccc}
156 & 22 L & 54 & -13 L \\
22 L & 4 L^{2} & 13 L & -3 L^{2} \\
54 & 13 L & 156 & -22 L \\
-13 L & -3 L^{2} & -22 L & 4 L^{2}
\end{array}\right]} \\
& {\left[\mathrm{C}_{\mathrm{a}}\right]=\alpha[\mathrm{M}]+\beta[\mathrm{K}]}
\end{aligned}
$$

As matrizes $[\mathrm{K}]$ e $[\mathrm{M}]$ dependem apenas do módulo de elasticidade $E$, do momento de inércia $I$, da massa específica $p$, da seção transversal $S$, e do comprimento $L$, enquanto a matriz depende ainda de $a$ e $\beta$, que são escalares reais, e correspondem as constantes de proporcionalidade de massa e rigidez, respectivamente. No entanto, os parâmetros $E$, $p, a$ e $\beta$ não podem ser calculados diretamente. Assim sendo, faz-se necessário o uso de métodos de otimização para aproximar os valores de tais parâmetros. Foi utilizado do Algoritmo Genético como meio de otimização, considerando com Função Objetivo a minimização entre as Funções Resposta em Frequência numérica e experimental. A Tabela (1) apresenta o espaço do projeto. $O$ algoritmo de otimização GA foi executado 200 vezes para os seguintes tamanhos populacionais: 50, 100, 150 e 200.

\begin{tabular}{|c|c|c|}
\hline Parâmetros & Limite Inferior & Limite Superior \\
\hline Módulo de Elasticidade[E] & $1 \times 10^{12}$ & $1 \times 10^{13}$ \\
\hline Massa Específica [p] & $1 \times 10^{3}$ & $1 \times 10^{5}$ \\
\hline Constante de Proporcionalidade $[\mathrm{a}]$ & 0 & 1 \\
\hline Constante de Proporcionalidade $[\beta]$ & 0 & 1 \\
\hline
\end{tabular}

Tabela 1. Espaço de projeto. 
A Figura (2) apresenta a comparação entre a FRF experimental e as médias das FRFs identificadas para diferentes tamanhos de populações, enquanto a Figura (3) apresenta uma aproximação nos picos.

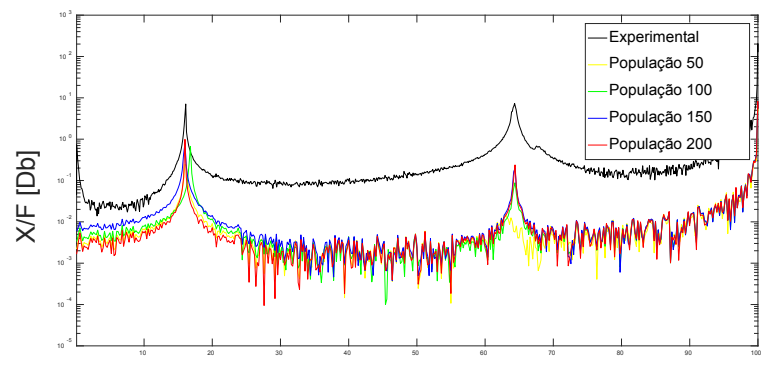

Frequência $[\mathrm{Hz}]$

Figura 2. FRFs experimental e identificadas.
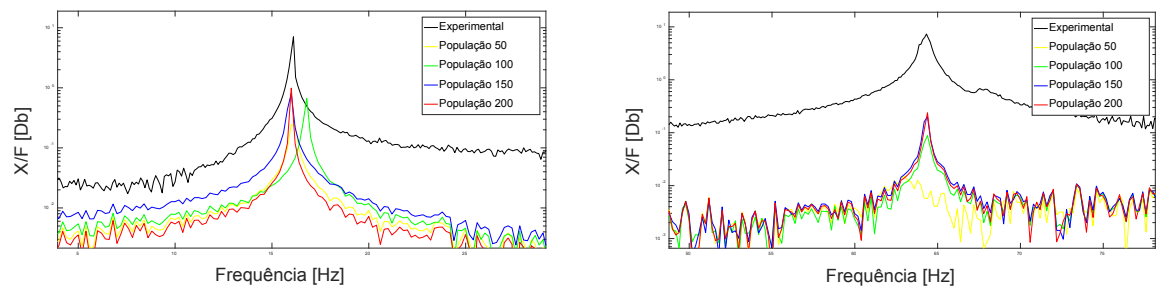

Figura 3. Picos das FRFs experimental e identificadas.

A Tabela (2) apresenta a média dos valores identificados e seus respectivos desvios padrões.

\begin{tabular}{|c|c|c|}
\hline Tamanho da população & Módulo de Elasticidade[E] & Massa Específica [p] \\
\hline 50 & $1.9766 \times 10^{12} \pm 6.99 \times 10^{10}$ & $1.7018 \times 10^{4} \pm 8.99 \times 10^{3}$ \\
\hline 100 & $1.5851 \times 10^{12} \pm 7.49 \times 10^{10}$ & $1.0434 \times 10^{4} \pm 459.91$ \\
\hline 150 & $1.0801 \times 10^{12} \pm 3.81 \times 10^{10}$ & $5.6601 \times 10^{4} \pm 436.47$ \\
\hline 200 & $1.0995 \times 10^{12} \pm 2.91 \times 10^{10}$ & $5.8008 \times 10^{4} \pm 256.20$ \\
\hline
\end{tabular}

\begin{tabular}{|c|c|c|}
\hline Tamanho da população & Constante de Proporcionalidade [a] & Constante de Proporcionalidade [ $\boldsymbol{\beta}]$ \\
\hline 50 & $0.3444 \pm 0.1287$ & $6.1432 \times 10^{-5} \pm 2.8 \times 10^{-5}$ \\
\hline 100 & $0.2188 \pm 0.2208$ & $9.4849 \times 10^{-6} \pm 1.45 \times 10^{-5}$ \\
\hline 150 & $0.3077 \pm 0.3348$ & $1.7718 \times 10^{-6} \pm 3.58 \times 10^{-6}$ \\
\hline 200 & $0.2825 \pm 0.3697$ & $1.9256 \times 10^{-6} \pm 5.96 \times 10^{-6}$ \\
\hline
\end{tabular}

Tabela 2. Média e desvio padrão dos parâmetros. 
Observa-se que conforme a população aumenta, a curva identificada mais se aproxima do pico da curva experimental. Assim, nota-se que a curva identificada que mais se aproximou foi a curva em vermelho, com população de 200 . No entanto o desvio padrão foi relativamente alto, já que nem todas as curvas convergiram. Assim sendo, foi escolhida a curva que melhor se aproximou com população de 200 e seus parâmetros são apresentados pela Tabela (3).

\begin{tabular}{|c|c|c|c|}
\hline \multicolumn{4}{|c|}{ Parâmetros } \\
\hline $\mathrm{E}(\mathrm{Pa})$ & $\mathrm{p}\left(\mathrm{Kg} / \mathrm{m}^{3}\right)$ & $\mathrm{a}$ & $\beta$ \\
\hline $2,3971 \times 10^{12}$ & $2,2442 \times 10^{4}$ & 0,2964 & $2,9873 \times 10^{-5}$ \\
\hline
\end{tabular}

Tabela 3. Parâmetros identificados.

\subsection{Técnicas de Controle}

Os sistemas de controle lidam basicamente com a manutenção de quantidades como temperatura e pressão nos valores operacionais desejados ou a condução de uma determinada variável para determinados valores (PINHEIRO, 2009). A técnica de controle utiliza os dados das saídas do sistema para que o controlador calcule o esforço de controle necessário. Em seguida, o controlador envia os comandos necessários ao atuador, que ajusta uma ação para corrigir o erro, a fim de melhorar o desempenho do sistema e obter uma saída variável o mais próxima possível (REPINALDO, 2018).

O controlador ótimo Regulador Quadrático Linear é cada vez mais difundido na literatura, devido ao seu desempenho e facilidade de implementação (PURNAWAN, 2017).

Considerando a equação de estados e a realimentação de estados apresentados pela equação (4).

$$
\begin{aligned}
& \{\dot{x}\}=[A]\{x(t)\}+[B]\{u(t)\} \\
& \{u(t)\}=-[G]\{x(t)\}
\end{aligned}
$$

o ganho $\left[K_{g}\right]$ do controlador, de acordo com Ogata (2003),é determinado através da minimização de uma função custo, dada pela Equação (5).

$$
\mathrm{J}=\int_{0}^{\infty}\left(\{\mathrm{x}(\mathrm{t})\}^{\top}[\mathrm{Q}]\{\mathrm{x}(\mathrm{t})]+\left[\{\mathrm{u}(\mathrm{t})\}^{\top}[\mathrm{R}]\{\mathrm{u}(\mathrm{t})\}\right) d \mathrm{t}\right.
$$

em que [Q]é uma matriz hermitiana definida positiva (ou semidefinida positiva) ou real simétrica e $[R]$ é uma matriz hermitiana definida positiva ou real simétrica. As matrizes $[Q]$ e $[R]$ determinam a importância relativa do erro e o consumo dessa energia (OGATA, 2003).

Considerando o sistema representado pela equação e resolvendo o problema de minimização da equação (5), o ganho do controlador é obtido. 


\subsection{Atuador Eletromagnético}

A metodologia para obtenção do modelo de atuador eletromagnético foi previamente apresentada por (MORAIS, 2013). Segundo Morais (2013), a força de atração entre os dois núcleos ferromagnéticos é dada pela equação (6).

$$
\mathrm{F}_{\mathrm{AEM}}=\frac{N^{2} I^{2} \mu_{0} a f}{2\left((e \pm \delta)+\frac{b+c+d-2 a}{\mu_{r}}\right)^{2}}
$$

em que $N$ é o número de espiras, I a corrente elétrica do atuador, $\mu_{0}$ a permeabilidade magnética do vácuo, $\mu_{\mathrm{r}}$ a permeabilidade relativa, "e" o gap, $\delta$ representa o deslocamento da viga no nó do atuador eletromagnético, $a, b, c, d$ e $f$ são constantes que representam os parâmetros geométricos do atuador. Como o AEM aplica apenas força de atração, deve ser entendido como: o valor "+" para $\delta>0$; e "-" para $\delta<0$.

Os parâmetros do atuador eletromagnético, extraídos por (KOROISHI, 2015) são apresentados na Tabela. 4 .

\begin{tabular}{|c|c|}
\hline Parâmetro & Valor \\
\hline$\mu_{0}(\mathrm{H} / \mathrm{m})$ & $4 \pi_{10}^{-7}$ \\
\hline $\mathrm{N}$ (espiras) & 250 \\
\hline $\mathrm{a}(\mathrm{mm})$ & 9.5 \\
\hline $\mathrm{b}(\mathrm{mm})$ & 38 \\
\hline $\mathrm{c}(\mathrm{mm})$ & 28.5 \\
\hline $\mathrm{d}(\mathrm{mm})$ & 9.5 \\
\hline $\mathrm{e}(\mathrm{mm})$ & 1.5 \\
\hline $\mathrm{f}(\mathrm{mm})$ & 19.5 \\
\hline
\end{tabular}

Tabela 4. Parâmetros dos AEM's.

A Tabela (5) apresenta os valores de permeabilidade relativa para cada AEM, os quais foram determinados experimentalmente por (COLOMBO, 2017).

\begin{tabular}{|c|c|c|c|}
\hline AEM & Mediana & Média & Desvio padrão \\
\hline 1 & 727.90 & 662.57 & $9.36 \%$ \\
\hline 2 & 397.65 & 468.46 & $8.57 \%$ \\
\hline
\end{tabular}

Tabela 5. Parâmetros identificados dos AEMs. 
O fio de cobre padrão das bobinas do atuador foi o AWG24, cujas características são mostradas na Tabela (6).

\begin{tabular}{|c|c|c|c|}
\hline Diametro $(\mathrm{mm})$ & Area $\left(\mathrm{mm}^{2}\right)$ & $\begin{array}{c}\text { Resistencia a20 } \\
\left(\frac{\text { Ohm }}{m}\right)\end{array}$ & Corrente Máxima $(\mathrm{A})$ \\
\hline 0.511 & 2.205 & 0.0842 & 3.5 \\
\hline
\end{tabular}

Tabela 6. Parâmetros do fio de cobre da bobina.

\subsection{Bancada De Testes}

O controle experimental foi realizado em uma bancada de testes conforme apresentado na Figura (4).

O sinal de deslocamento é medido pelo acelerômetro modelo PCB Piezotronics ${ }^{\circledR}$. Este sinal é transmitido para um condicionador de sinal, a fim de melhorar a precisão dos valores medidos que são conduzidos para a placa de aquisição. O modelo do condicionador é o PCB Piezotronics ${ }^{\circledR}$ 480E09. A função dos amplificadores é converter o sinal de tensão de saída da placa em corrente elétrica que alimentará os atuadores. O modelo é um servoamplificador Maxon Motor ${ }^{\circledR}$ 4-Q-DC. A aquisição de dados é realizada através da placa National Instrument PCl-6221, que possui taxa de aquisição de 100 [Hz] e 10 [ms] de tempo de resposta.

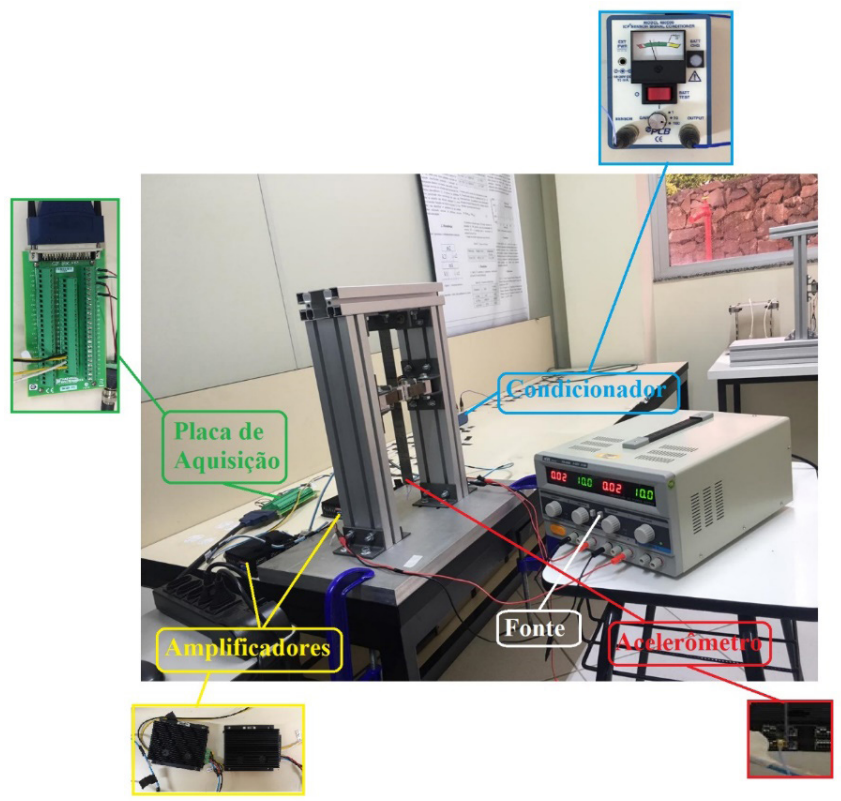

Figura 4. Bancada de testes. 
A figura (5) ilustra o modelo do sistema de controle experimental.

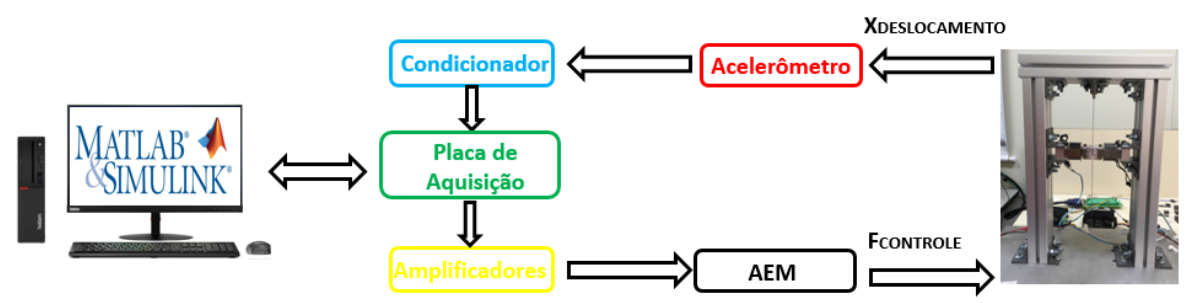

Figura 7. Modelo esquemático de controle.

\section{I RESULTADOS E DISCUSSÕES}

\subsection{Controle Numérico}

O controle numérico foi realizado no software MatLab/Simulink e seus resultados são apresentados pelas Figuras (6) a (8).

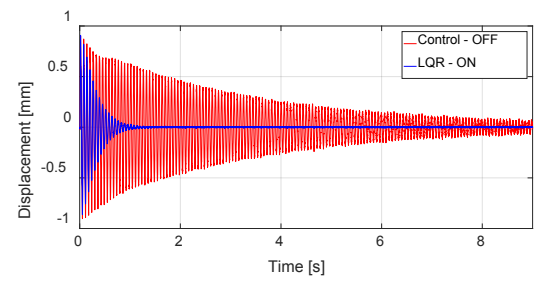

Figura 6. Deslocamento Numérico.

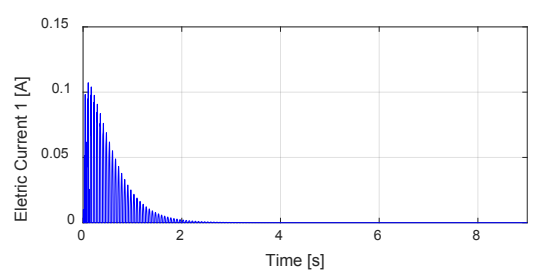

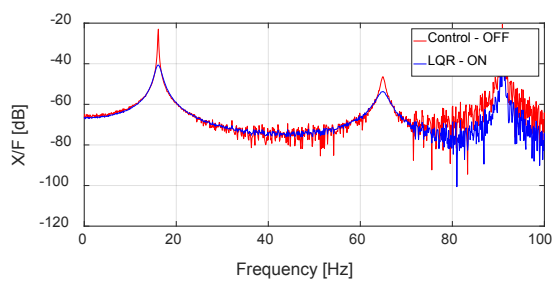

Figura 7. FRF Numérica.

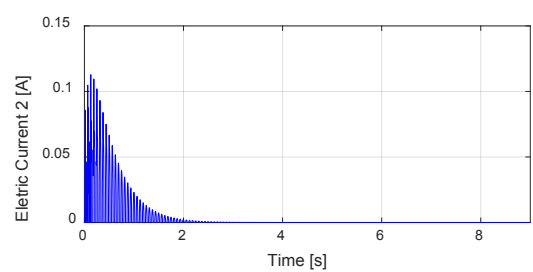

Figura 8. Corrente Elétrica Numérica.

Conforme pode ser observado pelos gráficos, o controlador LQR apresentou um ótimo desempenho numérico. Observa-se que apresentou um tempo de acomodação de cerca de 0,85s. e uma redução de $7,45 \mathrm{~dB}$ no primeiro modo e de $17,68 \mathrm{~dB}$ no segundo modo, enquanto o pico máximo de corrente elétrica foi de $0,1108 \mathrm{~A}$. 


\subsection{Controle Experimental}

O controle experimental foi realizado na bancada de testes apresentada na Figura (6) e seus resultados são apresentados pelas Figuras (9) a (11).

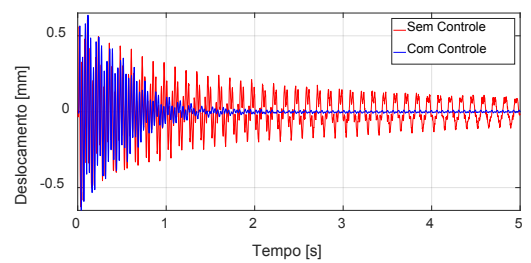

Figura 9. Deslocamento Experimental.

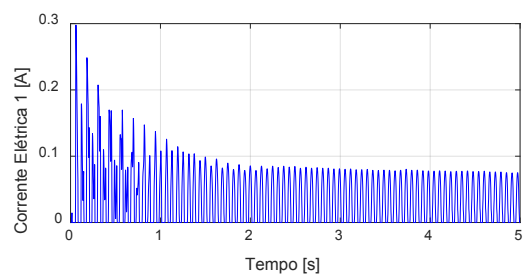

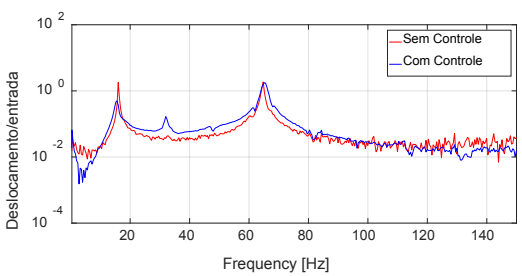

Figura 10. FRF Experimental.

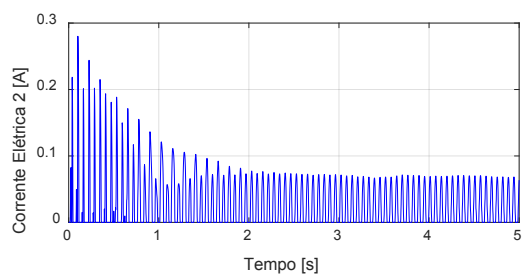

Figura 11. Corrente Elétrica Experimental.

Observando os resultados do controle experimental, nota-se que o controlador LQR apresentou ótimo desempenho. O tempo de acomodação foi de cerca de 1,28s e uma redução nos picos da FRF de 1,2956 dB, enquanto o pico máximo de corrente elétrica foi de $0,2978 \mathrm{~A}$.

\section{I CONCLUSÕES}

O presente trabalho teve como objetivo a montagem, identificação, modelagem, controle numérico e experimental de vibrações em uma estrutura flexível utilizando atuadores eletromagnéticos. Primeiramente, os parâmetros físicos da estrutura foram identificados através da metodologia do problema inverso e do Algoritmo Genético. Em seguida, realizou-se a modelagem dinâmica do sistema e o projeto do controlador LQR e, finalmente, foram realizadas simulações numéricas e controle experimental. O controlador apresentou desempenho satisfatório tanto numericamente quanto experimentalmente.

Em geral, pode-se concluir que a metodologia proposta e as ferramentas utilizadas apresentaram resultados satisfatórios, possibilitando seu uso para melhorar o desempenho do controle ativo de vibração nas estruturas flexíveis. 


\section{AGRADECIMENTOS}

Agradecemos ao apoio da UTFPR pelo suporte e material que possibilitou a realização deste trabalho. O presente trabalho foi realizado com o apoio do Conselho Nacional de Desenvolvimento Científico e Tecnológico CNPq - Brasil (Processo 402581/2016-4).

\section{REFERÊNCIAS}

Azevedo, A. F. M., 2003, Método dos Elementos Finitos. $1^{\mathrm{a}}$ ed., Faculdade de Engenharia da Universidade de Porto, Portugal.

Colombo, D. A.; Taketa, E.; Repinaldo, J. P., 2017, Identificação de parâmetros através de Técnicas Heurísticas de Otimização. In: CONFERÊNCIA BRASILEIRA DE DINÂMICA, CONTROLE E APLICAÇÕES - DINCON.

Koroishi, E. H., 2013, Controle de Vibrações em Máquinas Rotativas utilizando Atuadores Eletromagnéticos, Tese de Doutorado, Universidade Federal de Uberlândia, Uberlândia - MG.

Morais, T S; Hagopian, J. D. ; Steffen Jr, V. ; MAHFOUD, J., 2013, Modeling and Identification of Electromagnetic Actuator for the Control of Rotating Machinery. Shock and Vibration, v. 20, p. 171-179

Pinheiro, B., 2009, Sistema de controle tempo real embarcado para automação de manobra de estacionamento. Dissertação (Mestrado) - Universidade Federal de Santa Catarina.

Purnawan, H.; Mardlijah; Purwanto, E. B., 2017, Design of linear quadratic regulator (LQR) control system for flight stability of LSU-05. Journal of Physics: Conference Series, v. 890.

Repinaldo, Silva, C. A. X.; Santos, W. F. ; Koroishi, E. H., 2018, Identificação de Parâmetros e Controle de um Sistema de Dois Graus de Liberdade. In: X Congresso Nacional de Engenharia Mecânica, 2018, Salvador. Anais do X Congresso Nacional de Engenharia Mecânica. 


\section{SUPRESSÃO DO FENÔMENO DE FLUTTER EM PAINÉIS COMPÓSITOS AERONÁUTICOS VIA TÉCNICA DE CONTROLE PASSIVO}

Data de aceite: 01/10/2020

Data submissão: 06/07/2020

\section{Lorrane Pereira Ribeiro}

Universidade Federal de Uberlândia, Faculdade de Engenharia Mecânica, Campus

Santa Mônica

Uberlândia, Minas Gerais, Brasil https://orcid.org/0000-0001-7317-9599

\section{Antônio Marcos Gonçalves de Lima}

Universidade Federal de Uberlândia, Faculdade de Engenharia Mecânica, Campus

Santa Mônica

Uberlândia, Minas Gerais, Brasil https://orcid.org/0000-0003-0170-6083

RESUMO: A utilização de materiais compósitos tem sido cada vez mais comum na indústria aeronáutica para a construção de estruturas cada vez mais leves e com melhores propriedades mecânicas. Entretanto, problemas como vibrações e ruído indesejáveis são potencializados com o emprego de tais materiais para atender aos interesses de construção de estruturas leves e com aumento das velocidades de operação. Portanto, torna-se necessário o uso de estratégias de controle eficazes para atacar tais problemas. Este trabalho demonstra a viabilidade do uso de uma ferramenta de controle passivo do flutter de painéis compósitos através do emprego dos circuitos elétricos shunt multimodais.

PALAVRAS-CHAVE: Aerelasticidade, Controle passivo de vibrações, Materiais compósitos, Circuitos shunt multimodais.

\section{SUPPRESSION OF THE FLUTTER}

PHENOMENON IN COMPOSITE AERONAUTICAL PANELS BY PASSIVE CONTROL TECHNIQUE

ABSTRACT: The use of composite materials has been increasingly in aeronautical industries for the construction of lighter structures with better mechanical properties. However, problems such as vibrations and noise are augmented significantly by the use of such materials due to the construction of lighter structures with increasing their operating speeds. Therefore, it is necessary to use efficient control strategies to deal with such problems. This work demonstrates the feasibility of using a passive composite panel flutter control tool via multimodal shunt electrical circuits.

KEYWORDS: Aeroelasticity, Passive vibration control, Composite materials, Multimodal shunt circuits.

\section{1| INTRODUÇÃO}

Em aplicações aeronáuticas e automotivas, o uso dos materiais compósitos permitiu a concepção de estruturas cada vez mais leves, flexíveis e eficientes (REDDY, 1997). No entanto, a flexibilidade combinada com os efeitos de anisotropia de tais materiais representam vários desafios para os engenheiros e projetistas que devem considerar tais efeitos ao dimensionar uma estrutura compósita. Além disso, o interesse em alcançar a estabilidade dinâmica de tais sistemas é de 
suma importância em aplicações aeronáuticas, uma vez que as amplitudes de vibrações estão diretamente relacionadas às instabilidades aeroelásticas e, consequentemente, à fadiga (PALMERI e RICCIARDELLI, 2006). Esta é a razão pela qual, mais recentemente, estratégias de controle de vibrações e ruído vem sendo aplicadas em sistemas aeroelásticos para prevenir o fenômeno do flutter que pode ser catastrófico (ALMEIDA, 2011).

O flutter é uma instabilidade aeroelástica auto excitada causada pela interação de forças elásticas, aerodinâmicas e inerciais, resultando em grandes amplitudes de vibrações que modificam o modo como as cargas aerodinâmicas atuam na estrutura num processo oscilatório iterativo e auto excitado. Nesta condição de instabilidade, altas tensões internas podem surgir de forma a limitar as amplitudes de vibrações de painéis aeronáuticos e levar a fadiga estrutural (DOWELL, 1975).

Melhorias no desempenho dinâmico e aeroelástico de estruturas compósitas de interesse aeronáutico sujeitas ao flutter podem ser alcançadas por meio de estratégias de controle passivo ou ativo de vibrações, empregando-se os materiais inteligentes (VIANA, 2005). Neste caso, as chamadas técnicas de controle passivo têm sido incorporadas em muitos sistemas industriais devido às inúmeras vantagens quando comparadas com as técnicas de controle ativo, como por exemplo, baixo custo efetivo e de fácil manutenção e aplicação. Além disso, tais técnicas não necessitam de nenhuma fonte externa de energia, fato que garante inerente estabilidade ao sistema e as tornam mais bem adaptadas aos sistemas aeroelásticos. Tipicamente, o controle passivo de vibrações pode ser obtido com a utilização de materiais piezelétricos acoplados a circuitos elétricos shunt (HAGOOD e VON FLOTOW, 1991; RIBEIRO et al., 2020). Portanto, a partir da combinação da estrutura compósita em regime de escoamento supersônico com materiais piezelétricos acoplados de circuitos elétricos shunt, torna-se de especial interesse o amortecimento das vibrações devidas às cargas aerodinâmicas e, por consequência, a supressão do flutter (LEÃO et al., 2016; RIBEIRO, 2019).

\section{I MODELAGEM AEROELETROMECÂNICA-SHUNT}

Esta seção é dedicada à modelagem de uma placa plana retangular compósita, que incorpora uma camada piezelétrica acoplada de circuito shunt, cuja placa está sujeita a um escoamento de ar supersônico. Na sequência é apresentado apenas um resumo da modelagem. O desenvolvimento completo pode ser encontrado nos trabalhos de Ribeiro (2019) e Ribeiro et al. (2020).

A função de resposta em frequência (FRF) para um sistema eletromecânico-shunt, levando-se em consideração a impedância do circuito shunt, $Z(\omega)$, é dada na Eq. (1).

$$
\mathbf{H}(\omega)=\left[-\omega^{2} \mathbf{M}_{u u}+\mathbf{K}_{u u}-\mathbf{K}_{u \phi}\left(\mathbf{K}_{\phi \phi}-\frac{1}{j \omega} \mathbf{Z}^{-1}(\omega)\right)^{-1} \mathbf{K}_{\phi u}\right]^{-1}
$$


onde $\mathrm{M}_{\mathrm{uu}}, \mathrm{K}_{\mathrm{uu}}, \mathrm{K}_{\mathrm{u} \varnothing}$ e $\mathrm{K}_{ø \varnothing}$ são as matrizes globais de massa, rigidez mecânica, rigidez eletromecânica e rigidez elétrica, respectivamente.

Para o circuito multimodal com configuração em paralelo e para o controle de dois modos de forma simultânea proposto por Wu (1998), a impedância equivalente total é composta por resistores $\left(R_{n}\right)$, indutores $\left(L_{n}\right)$ e capacitores $\left(C_{n}\right)$, como apresentado na Eq. (2).

$$
Z(\omega)=\frac{R_{1} L_{1} \omega\left[\frac{\bar{L}_{1}}{\bar{C}_{1}\left(\bar{L}_{1} \omega j-\frac{j}{\bar{C}_{1} \omega}\right)}+\frac{L_{2}^{\prime} R_{2}^{\prime} \omega j}{R_{2}^{\prime}+L_{2}^{\prime} \omega j}\right] j}{\left(R_{1}+L_{1} \omega j\right)\left[\frac{\bar{L}_{1}}{\bar{C}_{1}\left(\bar{L}_{1} \omega j-\frac{j}{\bar{C}_{1} \omega}\right)}+\frac{L_{1} R_{1} \omega j}{R_{1}+L_{1} \omega j}+\frac{L_{2}^{\prime} R_{2}^{\prime} \omega j}{R_{2}^{\prime}+L_{2}^{\prime} \omega j}\right]}
$$

onde, para $n=1,2: R_{n}=\sqrt{ } 2 K_{i j} / C_{P Z T} \omega_{n}\left(1+K_{i j}^{2}\right) ; L_{n}=1 / C_{P Z T} \omega_{n}^{2}\left(1+K_{i j}^{2}\right) ; \omega_{n}$ a frequência natural do n-ésimo modo; $\mathrm{K}_{\mathrm{ij}}$ é o fator de acoplamento eletromecânico; $\mathrm{C}_{\mathrm{PZT}}$ a capacitância da pastilha piezelétrica; $\bar{L}_{1}$ e $\bar{C}_{1}$ formam um circuito de bloqueio de maneira que o segundo modo do sistema seja amortecido sem interferência do controle do primeiro modo, sendo que, este circuito de bloqueio cria uma impedância infinita, dada por $\bar{L}_{1} \dot{C}_{1}=1 / \omega_{1}^{2} ; R_{2}^{\prime}=$ $R_{1} R_{2} / R_{1}-R_{2}$ e $L_{2}^{\prime}=L_{1} L_{2}+L_{2} L_{1}-L_{1} \bar{L}_{1}-\omega^{2}{ }_{2} L_{1} L_{2} \bar{L}_{1} \bar{C}_{1} /\left(L_{1} L_{2}\right)\left(1-\omega^{2}{ }_{2} \bar{L}_{1} \bar{C}_{1}\right)$.

Assim, de acordo com a topologia de circuito a ser utilizada para o controle passivo das vibrações mecânicas, a expressão da impedância, $Z(\omega)$, deve ser introduzida na equação da Função de Resposta em Frequência (FRF) do sistema.

\subsection{Adição do escoamento de ar no modelo}

O modelo eletromecânico com circuito shunt multimodal recebe um carregamento aerodinâmico que altera suas respostas dinâmicas à medida em que há uma variação crescente da velocidade do escoamento de ar sobre a estrutura. Assim, com essa variação crescente de velocidade do carregamento, há um deslocamento das frequências naturais, uma em direção à outra, até que haja união das mesmas, denominada coalescência. A partir deste ponto, a estrutura se torna instável, sendo observado um movimento que ocorre de forma acoplada entre dois ou mais modos naturais, que geralmente são de flexão-torção.

Neste trabalho, a Teoria do Pistão (ASHLEY, 1956) foi a utilizada para prever a velocidade de ocorrência do flutter do sistema. Esta teoria considera que o carregamento aerodinâmico sobre o painel eletromecânico pode ser calculado pela variação de sua pressão aerodinâmica. Como este trabalho visa apenas a obtenção da velocidade crítica de ocorrência de flutter, a Teoria do Pistão pode ser truncada em seu termo de primeira ordem, além da desconsideração do amortecimento aerodinâmico, devido a sua pequena contribuição se comparada com o amortecimento inserido. 


$$
\mathrm{p}-\mathrm{p}_{\infty}=\frac{2 q}{\beta} \frac{\partial W}{\partial x}(3)
$$

onde $p_{\infty}$ é a pressão não perturbada (pressão distante do sistema); $q=(1 / 2) p_{a} U_{\infty}^{2}$ é a pressão dinâmica, sendo $\mathrm{p}_{\mathrm{a}}$ a densidade do ar e $U_{\infty}$ é a velocidade do escoamento não perturbado; $\beta=\sqrt{ } \mathrm{M}^{2}{ }_{\infty}-1$, sendo $\mathrm{M}_{\infty} \mathrm{o}$ número de Mach. A direção do escoamento é determinada pela variável em relação à qual é derivado o deslocamento transversal, $\mathrm{W}, \mathrm{da}$ placa que neste caso é em relação à direção $x$.

O modelo descrito pela Eq. (3) recebe o nome de Modelo de Ackeret ou Modelo de Aproximação Quase-Estacionário da Teoria Linear do Escoamento Potencial, sendo este modelo a forma mais simples da Teoria do Pistão, porém, suficiente para prever as respostas do sistema e de acordo com suas restrições, onde considerou-se o uso de painéis compósitos de placas finas e pequenos deslocamentos.

$\mathrm{Na}$ integração do carregamento aerodinâmico ao modelo eletromecânico, foi utilizado o trabalho da força aerodinâmica, como indicado no trabalho de Almeida (2011) e, após manipulações, chega-se à matriz de rigidez aerodinâmica, $\mathbf{K}_{\text {aerod}}$, a qual é então adicionada à rigidez mecânica da estrutura.

$$
W_{\text {aerod. }}^{F}=\int w \frac{2 q}{\beta} \frac{\partial w}{\partial x} d A=\frac{2 q}{\beta} \int \mathbf{N}_{x}^{T}(\xi, \eta) \mathbf{N}(\xi, \eta) d A=\frac{2 q}{\beta} \mathbf{K}_{\text {aerod. (4) }}
$$

onde $\mathbf{N}$ são as funções de forma e $\mathbf{N}_{\mathrm{x}}$ a derivada das funções de forma em relação a $x$.

A Teoria do Pistão adiciona o carregamento aerodinâmico na forma de uma matriz de rigidez aerodinâmica que é então somada à rigidez mecânica da estrutura. Assim, obtém-se as equações do movimento do sistema aeroeletromecânico:

$$
\left[\begin{array}{cc}
\mathbf{M} & 0 \\
0 & 0
\end{array}\right]\left\{\begin{array}{l}
\ddot{\mathbf{u}}(t) \\
\ddot{\boldsymbol{\Phi}}(t)
\end{array}\right\}+\left[\begin{array}{cc}
\mathbf{K}_{u u}+\frac{2 q}{\beta} \mathbf{K}_{\text {aerod. }} & \mathbf{K}_{u \Phi} \\
\mathbf{K}_{\Phi u} & \mathbf{K}_{\Phi \Phi}+\frac{1}{j \omega} Z^{-1}(\omega)
\end{array}\right]\left\{\begin{array}{l}
\mathbf{u}(t) \\
\boldsymbol{\Phi}(t)
\end{array}\right\}=\left\{\begin{array}{l}
\mathbf{f}(t) \\
\mathbf{q}(t)
\end{array}\right\}(5)
$$

onde $\mathbf{u}(\mathrm{t})$ são os graus de liberdade (gdls) mecânicos de toda estrutura (globais); $\Phi(t)$ os gdls elétricos (potenciais elétricos) globais; $f(t)$ o vetor de excitação mecânica e q(t) o vetor de cargas elétricas.

Predição do flutter: após a construção das equações do movimento para o problema aeroeletromecânico acoplado, recai-se em um problema não-linear de resolução de autovalor. O problema é não linear porque a impedância elétrica, $Z(\omega)$, é dependente da frequência e, desta maneira, a matriz de rigidez associada a ela também. Todo algoritmo de resolução deste problema cuja solução se dá por meio de um método iterativo pode ser encontrado em Ribeiro (2019). 


\section{I APLICAÇÕES NUMÉRICAS E DISCUSSÕES}

Nesta seção, são apresentados os resultados das simulações numéricas para uma placa de material compósito quadri-apoiada contendo uma camada de PZT acoplada de shunt multimodal, como ilustrado na Fig. 1.

Cada camada do compósito de configuração, $\left[0^{\circ} / 75^{\circ} / 75^{\circ} 0^{\circ}\right]$, possui $0,30 \mathrm{~mm}$ de espessura e a camada piezelétrica possui espessura de $0,50 \mathrm{~mm}$. A densidade do compósito é $1578 \mathrm{Kg} / \mathrm{m}^{3}$ e a do PZT é $7700 \mathrm{Kg} / \mathrm{m}^{3}$. A placa foi discretizada em uma malha regular de 12x12 EF's.

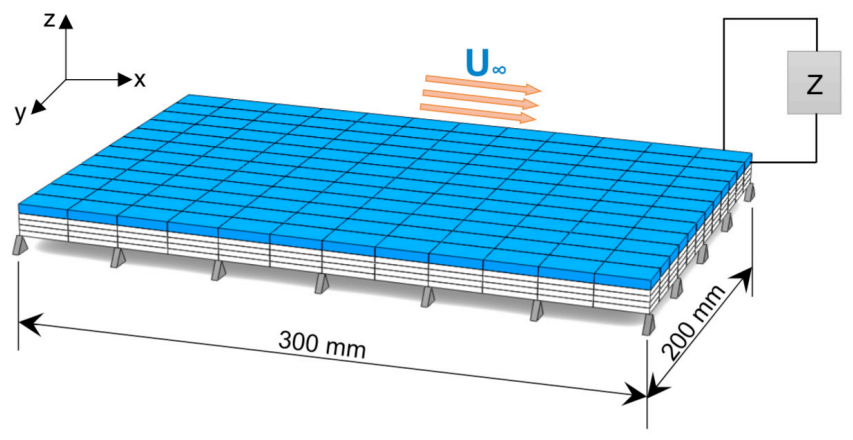

Fig. 1. Placa compósita (quatro camadas - branco) com camada piezelétrica (azul) acoplada de circuito shunt multimodal sujeita a um fluxo supersônico.

A Tabela 1 apresenta as propriedades mecânicas do material compósito e a Tabela 2 as propriedades elétricas e eletromecânicas do PZT G1195.

\begin{tabular}{cccccccccc}
\hline \hline Material & $\mathrm{E}_{1}(\mathrm{GPa})$ & $\mathrm{E}_{2}(\mathrm{GPa})$ & $\mathrm{E} 3(\mathrm{GPa})$ & $\mathrm{G}_{12}(\mathrm{GPa})$ & $\mathrm{G}_{13}(\mathrm{GPa})$ & $\mathrm{G}_{23}(\mathrm{GPa})$ & $\mathrm{v}_{12}$ & $\mathrm{v}_{13}$ & $\mathrm{v}_{23}$ \\
\hline Compósito & 173,06 & 33,09 & 5,17 & 9,38 & 8,27 & 3,24 & 0,04 & 0,25 & 0,17 \\
PZT G1195 & 69,00 & $\mathrm{E}_{1}$ & $\mathrm{E}_{1}$ & 24,2 & $\mathrm{G}_{12}$ & $\mathrm{G}_{12}$ & 0.33 & 0.33 & 0.33 \\
\hline \hline
\end{tabular}

Tabela 1. Propriedades mecânicas do material compósito.

\begin{tabular}{ccccccccc}
\hline \hline Material & $\begin{array}{c}\mathrm{e}_{15} \\
\left(\mathrm{C} / \mathrm{m}^{2}\right)\end{array}$ & $\begin{array}{c}\mathrm{e}_{24} \\
\left(\mathrm{C} / \mathrm{m}^{2}\right)\end{array}$ & $\begin{array}{c}\mathrm{e}_{31} \\
\left(\mathrm{C} / \mathrm{m}^{2}\right)\end{array}$ & $\begin{array}{c}\mathrm{e}_{32} \\
\left(\mathrm{C} / \mathrm{m}^{2}\right)\end{array}$ & $\begin{array}{c}\mathrm{e}_{33} \\
\left(\mathrm{C} / \mathrm{m}^{2}\right)\end{array}$ & $\begin{array}{c}\mathrm{C}_{11} \\
(\mathrm{~F} / \mathrm{m})\end{array}$ & $\begin{array}{c}\mathrm{C}_{22} \\
(\mathrm{~F} / \mathrm{m})\end{array}$ & $\begin{array}{c}\mathrm{C}_{33} \\
(\mathrm{~F} / \mathrm{m})\end{array}$ \\
\hline PZT G1195 & 0.00 & 0.00 & $-18,30$ & $-9,01$ & $-9,01$ & $-1,59 \times 10-8$ & $\mathrm{C}_{11}$ & $\mathrm{C}_{11}$ \\
\hline \hline
\end{tabular}

Tabela 2. Propriedades eletromecânicas e elétricas do PZT. 


\subsection{Verificação da modelagem}

Primeiramente, foi realizada a validação do código numérico computacional implementado em ambiente MATLAB $^{\circledR}$ por confrontação com resultados obtidos pela utilização do software ANSYS ${ }^{\circledR}$. O objetivo foi confrontar as frequências naturais e FRFs obtidas no MATLAB e no ANSYS como apresentado na Tab. 3 e Fig. 2, respectivamente. Neste caso, foi desconsiderada a presença do PZT e shunt na placa da Fig. 1, resultando numa placa compósita de 4 camadas. O EF utilizado na modelagem via ANSYS ${ }^{\circledR}$ foi 0 SHELL181 que é o mais empregado na modelagem de placas compósitas e sanduíches.

\begin{tabular}{ccccccccc}
\hline Freq. Nat. [Hz] & $\mathbf{f}_{1}$ & $\mathbf{f}_{2}$ & $\mathbf{f}_{3}$ & $\mathbf{f}_{4}$ & $\mathbf{f}_{5}$ & $\mathbf{f}_{6}$ & $\mathbf{f}_{7}$ & $\mathbf{f}_{8}$ \\
\hline Matlab $^{\circledast}$ & 43,77 & 117,36 & 127,50 & 174,45 & 254,51 & 274,30 & 286,64 & 311,70 \\
\hline ANSYS $^{\circledast}$ & 43,45 & 116,76 & 128,04 & 173,89 & 255,98 & 279,36 & 287,12 & 314,54 \\
\hline
\end{tabular}

Tabela 3. Comparação frequências naturais modelos em MATLAB ${ }^{\circledR}$ e ANSYS ${ }^{\circledR}$.

Assim, nota-se uma grande proximidade entre os valores obtidos, principalmente, para os dois primeiros modos que são os de interesse devido a sua coalescência quando a estrutura é submetida a carregamento aerodinâmico. Desta maneira, o modelo desenvolvido em Matlab ${ }^{\circledast}$ é considerado suficiente para as análises e simulações aeroelásticas a serem realizadas.

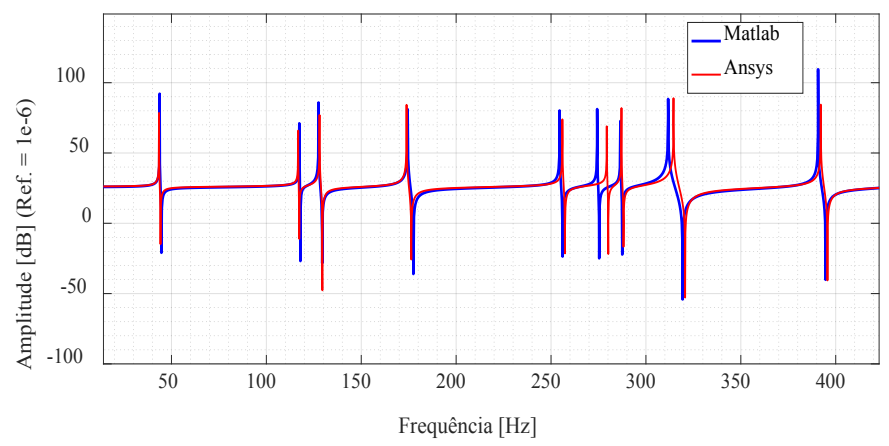

Fig. 2. Comparação entre FRFs dos modelos em MATLAB ${ }^{\circledR}$ e ANSYS ${ }^{\circledR}$.

\subsection{Predição flutter}

Na sequência, foi realizado um estudo visou descobrir, dentre os vários modos de vibrar da estrutura da Fig. 1, quais deles tendem a se coalescer primeiro quando a mesma está sujeita a um fluxo supersônico com velocidade de escoamento crescente. Vale ressaltar que nesta etapa a estrutura compósita foi simulada em conjunto com a camada 
de PZTG1195, mas sem que o mesmo estivesse acoplado de circuito shunt. A Fig. 3 mostra a variação dos quinze primeiros amortecimentos modais $(\mathrm{g})$ em função da velocidade do fluxo. Destaque foi dados aos dois primeiros amortecimentos modais: em azul, referente ao primeiro modo e em verde, referente ao segundo modo. O restante na cor preta.

No caso de uma estrutura sem amortecimento, o valor do amortecimento modal, g, permanece igual a zero até o ponto de flutter. A partir do ponto de coalescência, os valores de $g_{1}$ (amortecimento modal do primeiro modo) e $g_{2}$ (amortecimento modal do segundo modo) não são mais iguais a zero, como pode ser observado na Fig. 3. Assim, nota-se que a velocidade de ocorrência deste fenômeno acontece a $1331 \mathrm{~m} / \mathrm{s}$ e a coalescência se dá entre os dois primeiros modos de vibrar da estrutura.

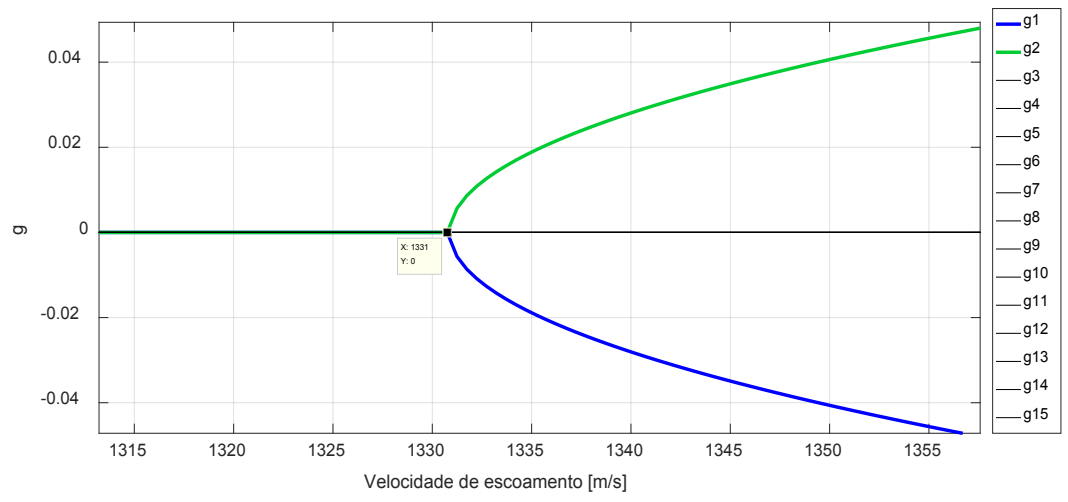

Fig. 3. Amortecimentos modais da placa compósita com PZT sujeita a um fluxo supersônico.

\subsection{Inclusão do circuito elétrico shunt multimodal}

Para fins de atenuação das vibrações e consequente ganho aeroelástico do sistema aeroeletromecânico em questão, utilizou-se do circuito elétrico shunt multimodal em paralelo. Nesta etapa, a sintonização do circuito foi realizada por meio das equações de Hagood e Flotow (1991) combinadas com as equações de Wu (1998).

Esta sintonização é feita na velocidade de ocorrência do flutter para a condição "Open Circuit", que é a situação em que há a presença mecânica do material piezelétrico sobre a placa, mas não há atuação elétrica. Assim, os valores dos parâmetros do circuito foram calculados de acordo com o exposto na seção 2. Os valores destes parâmetros são apresentados na Tab. 4. 


\begin{tabular}{ccccccc}
\hline $\begin{array}{c}\text { Parâmetros ótimos via } \\
\text { Hagood e Von Flotow } \\
\text { (1991) e Wu (1998) }\end{array}$ & $\mathrm{R}_{1}[\Omega]$ & $\mathrm{L}_{1}[\mathrm{H}]$ & $\mathrm{R}_{21}[\Omega]$ & $\mathrm{L}_{21}[\mathrm{H}]$ & $\mathrm{L}_{1 \mathrm{~b}}[\mathrm{H}]$ & $\mathrm{C}_{1 \mathrm{~b}}[\mathrm{nF}]$ \\
\cline { 2 - 7 } & 243,84 & 0,21 & 13933,79 & 42,11 & 1,28 & 470,00 \\
\hline
\end{tabular}

Tabela 4. Parâmetros nominais do circuito elétrico shunt utilizado.

Pela análise da Tab. 4, nota-se um alto valor para a indutância $L_{21}$. Assim, para uma montagem experimental seria necessário o uso de impedâncias sintéticas dos tipos Riordan e Antoniou como investigadas no trabalho de Viana (2005).

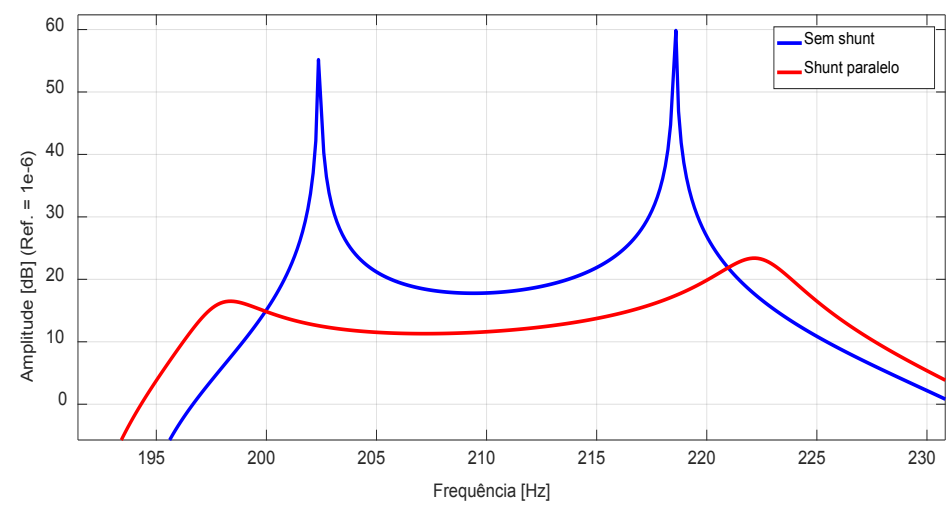

Fig. 4. FRFs para a velocidade de escoamento de $1300 \mathrm{~m} / \mathrm{s}$.

Pela análise da Fig. 4, nota-se claramente a grande capacidade de atenuação passiva dos níveis de vibrações proporcionada pelo circuito multimodal paralelo para os dois primeiros modos de vibração da estrutura.

\begin{tabular}{cccc}
\hline & $\begin{array}{c}\text { Velocidade } \\
\text { flutter }[\mathbf{m} / \mathbf{s}]\end{array}$ & $\begin{array}{c}\text { Amplitude [dB] } \\
\mathbf{1}^{\mathbf{0}} \text { modo }\end{array}$ & $\begin{array}{c}\text { Amplitude [dB] } \\
\mathbf{2}^{\mathbf{0}} \text { modo }\end{array}$ \\
\hline Sem shunt & 1331 & 55,17 & 59,84 \\
\hline Shunt paralelo & $\mathbf{1 3 4 8}$ & 16,49 & 23,39 \\
\hline
\end{tabular}

Tabela 5. Comparação resultados sistema sem amortecimento versus amortecimento via shunt. 


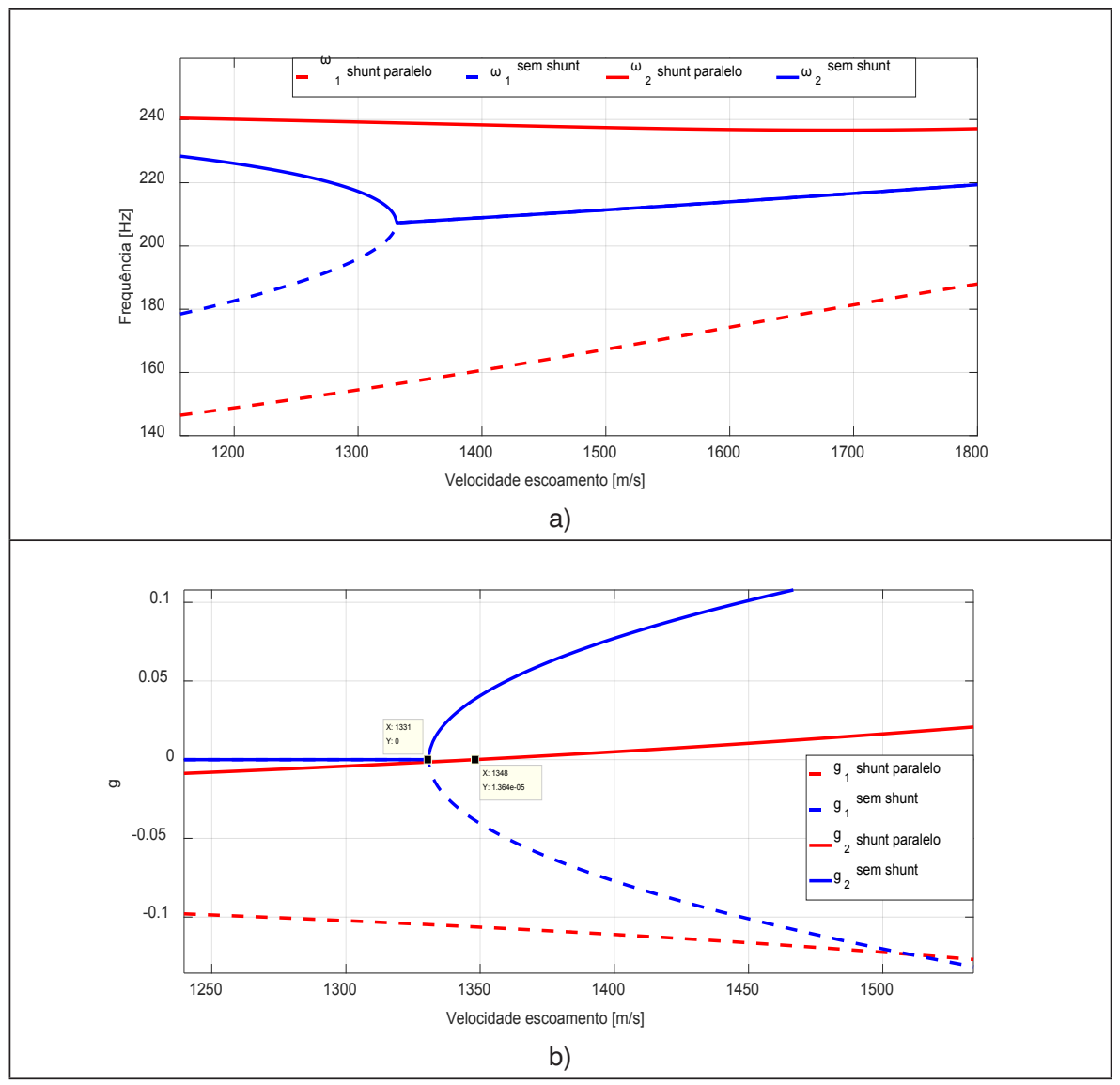

Fig. 5. Diagrama V-g: a) Duas primeiras frequências naturais variando com a velocidade; b) Amortecimentos modais para os dois primeiros modos.

Em se tratando de ganho aeroelástico, os resultados sintetizados na Tabela 5 e ilustrados na Fig. 5 mostram ganhos mais modestos. A velocidade crítica de ocorrência do flutter passou de $1331 \mathrm{~m} / \mathrm{s}$, sem nenhum tipo de amortecimento, para $1348 \mathrm{~m} / \mathrm{s}$ para o sistema aeroeletromecânico amortecido via shunt. Este pequeno ganho aeroelástico pode ser explicado pela sintonização do circuito, de forma que, as equações para o cálculo de seus parâmetros foram obtidas na literatura (HAGOOD e VON FLOTOW, 1991; WU, 1998) com o intuito de atenuar somente as vibrações, não considerando a coalescência dos modos como sendo também um objetivo.

\section{4 | CONCLUSÕES FINAIS}

A grande contribuição deste trabalho diz respeito à comprovação da viabilidade de utilização de circuitos elétricos shunt acoplados a elementos piezelétricos no que tange ao aumento da estabilidade aeroelástica de painéis compósitos. Assim, se tem hoje 
disponível uma ferramenta numérico-computacional para tratar os problemas da dinâmica e aerodinâmica de sistemas aeroeletromecânicos.

A partir dos resultados obtidos, evidencia-se as seguintes conclusões específicas:

$\left.1^{\mathrm{a}}\right)$ Os procedimentos de modelagem desenvolvidos demonstraram ser representativos para a caracterização do comportamento aeroelástico de sistemas estruturais compósitos incorporando elementos piezelétricos acoplados de circuitos elétricos shunt multimodais;

$2^{a}$ ) Nota-se a grande capacidade de atenuação dos níveis de vibrações proporcionada pelo circuito multimodal paralelo para os dois primeiros modos de vibração da estrutura quando a mesma é submetida à carregamento aerodinâmico. O ganho em estabilidade aeroelástica foi modesto, visto que, a sintonização do circuito shunt nominal foi realizada por meio de expressões disponíveis na literatura, as quais tem como intuito a sintonização para atenuação de vibrações somente, não considerando o aumento da velocidade de flutter como sendo também um objetivo a ser alcançado.

Salienta-se, portanto, a necessidade da utilização de ferramentas de otimização para que se possa obter melhores respostas em termo de ganho aeroelástico, buscando-se o melhor compromisso entre as funções objetivo de redução de amplitude de vibrações e aumento da velocidade de ocorrência do fenômeno de flutter. O procedimento de otimização será realizado em trabalhos futuros.

\section{AGRADECIMENTOS}

Os autores gostariam de agradecer à CAPES, ao CNPq, à FAPEMIG e ao Programa de Pós-graduação em Engenharia Mecânica - FEMEC/UFU pelo suporte no desenvolvimento do presente trabalho.

\section{REFERÊNCIAS}

ALMEIDA, A. E. O Efeito de Enrijecimento por Tensão Piezeletricamente Induzida na Estabilidade Aeroelástica de Painéis Aeronáuticos. 100f. Tese de Mestrado em Ciências. Instituto Tecnológico de Aeronáutica, 2011.

ASHLEY, H.; ZARTARIAN, G. Piston Theory: a New Aerodynamic Tool for the Aeroelastician. Journal of the Aeronautical Sciences, v. 23, n. 12, p. 1109-1918, 1956. doi:10.2514/8.3740.

DOWELL, E. H. Aeroelasticity of plates and shells. Princetown. New York, USA: Noordhoff International Publishing, 1975.

HAGOOD, N. W. e VON FLOTOW, A. Damping of Structural Vibrations with Piezoelectric Materials and Passive Electrical Networks. Journal of Sound and Vibration, v. 146, n. 2, p. 243-268, 1991.

LEÃO, L. S. et al. Dynamic aeroelastic behavior of composite plates with multimode resonant shunted piezoceramics in series. Composite Structures, v. 153, p. 815-824, 2016. doi: 10.1016/j. compstruct.2016.07.010. 
PALMERI, A.; RICCIARDELLI, F. Fatigue analyses of buildings with viscoelastic dampers. Journal of Wind Engineering and Industrial Aerodynamics, v.94, p. 377-395, 2006. doi:10.1016/j. jweia.2006.01.005

REDDY, J. N. Mechanics of Laminated Composite Plates: Theory and Analysis. 2. ed. Florida: CRC Press, 1997.

RIBEIRO, L. P. Metodologia ótima robusta para o projeto de uma técnica de controle passivo de supressão do fenômeno de flutter em painéis compósitos de interesse aeronáutico. 2019. 143f. Tese de Doutorado, Universidade Federal de Uberlândia, 2019.

RIBEIRO, L. P., DE LIMA, A. M. G. e SILVA, V. A. C. Robust project of resonant shunt circuit for passive vibration control of composite structures. J Braz. Soc. Mech. Sci. Eng., v. 42, p. 342, 2020.

VIANA, F. A. C. Amortecimento de vibrações usando pastilhas piezoelétricas e circuitos shunt ressonantes. 105f. Dissertação de Mestrado, Universidade Federal de Uberlândia, 2005.

WU, S. Y. Method for multiple mode shunt damping of structural vibration using a single PZT transducer. Smart. Struct. Mater., v. 159, p. 159-68, 1998. 


\section{FABRICAÇÃO DE UM MANIPULADOR ROBÓTICO BASEADO EM UM GUINDASTE}

Data de aceite: 01/10/2020

Data de submissão: 02/09/2020

Ana Carolina Dantas Rocha

Centro Universitário Tiradentes - UNIT Maceió - AL

http://lattes.cnpq.br/4137796291693168

Eduardo Victor Lima Barboza

Centro Universitário Tiradentes - UNIT Maceió - AL http://lattes.cnpq.br/5445899817559566

José Leonardo Nery de Souza

Centro Universitário Tiradentes - UNIT Maceió - AL http://lattes.cnpq.br/0054352433552979

Otávio Clarindo Lopes Filho

Centro Universitário Tiradentes - UNIT Maceió - AL

http://lattes.cnpq.br/6257422413896502

Adriano Marinheiro Pompeu

Centro Universitário Tiradentes - UNIT Maceió - AL

http://lattes.cnpq.br/1514565770443198

Dheiver Francisco Santos

Universidade Federal de Alagoas - Instituto de

Computação

Maceió - AL

http://lattes.cnpq.br/3797115046847189
RESUMO: Os conceitos de automação industrial têm se expandido na atualidade, devido à crescente demanda impulsionada pela indústria 4.0, tais conceitos estão diretamente relacionados a integração de conhecimentos teóricos e práticos, vivenciados nos campos acadêmicos e profissionais. A aplicação da robótica viabiliza desenvolvimento e ensaios de equipamentos em pequena escala, que contribuem com análises precisas, a fim de fomentar e viabilizar a construção de máquinas de grande escala, altamente tecnológicas e automatizadas. Com o intuito da aplicação dos conceitos de controle e automação, este trabalho objetivou projetar um manipulador robótico, baseado em um guindaste, visando a evolução do desenvolvimento de novas soluções para a área da automação industrial. Como metodologia, foi realizada uma pesquisa experimental, uma vez que foram realizados experimentos em laboratórios de automação para o desenvolvimento do projeto do manipulador. Os materiais utilizados objetivaram a utilização de estruturas metálicas, placas de MDF e manipuladores robóticos de baixo custo, juntamente com motores de passo que oferecem precisão maior aos ensaios. Os resultados obtidos consolidaram os conceitos de fabricação e desenvolvimento de manipulador robótico, que pode ser utilizado como parâmetro para construção de guindastes automatizados.

PALAVRAS-CHAVE: Automação Industrial, Microcontroladores, Mecatrônica. 


\section{MANUFACTURING OF A ROBOTIC MANIPULATOR BASED ON A CRANE}

ABSTRACT: The concepts of industrial automation have been currently expanding due to the growing demand driven by industry 4.0. Such concepts are directly related to the integration of theoretical and practical knowledge, experienced in academic and professional fields. The application of robotics enables the development and testing of small-scale equipment, which contributes to accurate analysis, in order to encourage and enable the construction of large-scale, highly technological and automated machines. In order to apply the concepts of control and automation, this work aimed to design a robotic manipulator, based on a crane, seeking the evolution of the development of new solutions for the industrial automation area. As methodology, an experimental research was carried out, since the experiments were conducted in automation laboratories for the development of the manipulator project. The materials were focused on metallic structures, MDF plates and low cost robotic manipulators, along with stepper motors that offer greater precision to the tests. The results obtained consolidated the concepts of manufacturing and development of robotic manipulators, which can be used as a parameter for the construction of automated cranes.

KEYWORDS: Industrial Automation, Microcontrollers, Mechatronics.

\section{I INTRODUÇÃO}

Desde a origem da humanidade, o homem vem tentando progressivamente buscar alternativas para diminuir $\mathrm{o}$ trabalho braçal, objetivando a agilidade nos processos com 0 auxílio de ferramentas e equipamentos. A partir da revolução industrial, há uma crescente substituição da força humana por máquinas mais eficazes, que podem ser tanto teleoperadas por pessoas, ou até mesmo automáticas, que fazem todo o trabalho de forma autônoma. Sem dúvida tal busca pela diminuição de seu trabalho trouxe consigo o desenvolvimento da revolução tecnológica, tão necessária na atualidade.

As funções de elevação de grandes volumes de cargas, pressionou as empresas e indústrias a se atualizarem e desenvolverem máquinas e equipamentos que possibilitam elevar materiais e matérias primas com enorme peso. Aos poucos os processos mecânicos foram abrindo espaço para os processos eletrônicos e robóticos, que atualmente estão inseridos em máquinas industriais, como por exemplo guindastes pórticos de elevação.

Com isso, percebe-se o quão eficiente pode ser um manipulador robótico, quando aplicado em um guindaste, o que permite a elevação de objetos extremamente pesados. Esta, é uma alternativa para melhor desempenho e eficiência no deslocamento de cargas e, logicamente leva-se em consideração, a ampliação expansão da força humana, permitindo que se tenha mais horas de trabalho, que justificariam o gasto de energia e manutenções preventivas.

A razão pela qual os manipuladores robóticos são tão importantes para a indústria, além da melhoria da eficiência, é a quantidade de carga que este consegue suportar, assim como a habilidade de manusear materiais com geometria complexa. Desse modo, a indústria consegue aumentar exponencialmente a velocidade e qualidade de todas as 
etapas envolvidas no desenvolvimento de determinado produto, desde a obtenção da matéria prima até a distribuição. Hoje, as empresas que utilizam mão de obra humana para determinado fim não conseguem competir diretamente com empresas do mesmo ramo que utilizam mão de obra automatizada.

Entretanto, o crescimento da fabricação de manipuladores robóticos móveis é bastante expressivo, o produto não para de crescer e desenvolve-se, visando a necessidade do ser humano por tecnologia. Logo, os manipuladores robóticos industriais são minoria, existe uma mínima variedade entre eles, segundo (COCOTA, et. al., 2013).

Dentro dessa lógica, é nítido que os manipuladores vão substituir grande parte dos trabalhos braçais, visto que a repetição do mesmo movimento pode ocasionar em doenças como tendinite. Os mesmos podem conseguir exercer até a perfeição da atividade por mais tempo, visto que os trabalhos estão sujeitos à fadiga, que diminuiria a eficiência no trabalho, o que pode comprometer a produção.

O objetivo deste trabalho é projetar um modelo demonstrativo de um manipulador robótico capaz de erguer grandes cargas, podendo ele ser tanto teleoperado, quanto automatizado. Com o intuito de possibilitar o controle remotamente, será utilizada a radiofrequência, onde um emissor enviará sinais para um receptor, que será lido pelo microcontrolador, e assim, fazendo o manipulador operar de forma automatizada, onde o microcontrolador gravará movimentos feitos pelo usuário, e então repetirá esses movimentos da forma que o operador programar.

\section{I REFERENCIAL TEÓRICO}

\subsection{Eletrônica e Microcontroladores}

Em 1951, foi inventado o transistor de junção, um dispositivo semicondutor capaz de amplificar o sinal de rádio. Este deu origem a muitas outras invenções, como os circuitos integrados, dispositivos compactos que tem milhares de transistores (MALVINO, BATES, 2016).

Os Microcontroladores são basicamente pequenos computadores em circuitos integrados bem singulares, pois os mesmos têm a possibilidade de executar códigos na memória de entrada e saída com tarefas bastante específicas. Eles são utilizados em diversos tipos de automação, os mesmos são programados por computadores ou discos de memória. Sendo assim existem aparelhos utilizados com o objetivo de transmissão do código que realizam a transferência de dados para o microcontrolador (FERREIRA, 1998).

O microcontrolador Controlador de Interface Programável (PIC) possui trinta e cinco orientações ordenadas em três diferentes formatos. A totalidade das instruções consomem apenas um formato, sendo consumido também apenas um ciclo de relógio, com ressalva das instruções de desvios que consomem apenas dois ciclos. O PIC é um microcontrolador com um Conjunto Reduzido de Instruções (RISC), baseado em acumulador, que adota uma 
arquitetura Harvard. As palavras de dados e de instruções possuem tamanhos de oito e catorze bits, respectivamente (TAGLETTI, et, al., 2005).

Entretanto, para que os manipuladores consigam produzir movimentos desejados, é necessário implementar habilidades sensoriais semelhantes às do homem. Ainda que os manipuladores atuais tenham uma inúmera quantidade de sensores avançados tecnologicamente, não é possível que um manipulador reproduza com perfeição tudo que o ser humano consegue realizar (ROSÁRIO, 2010).

O motor de passo é utilizado onde o controle do número de rotações é muito importante, como em impressoras, drivers de CD e sistemas de automação industrial e robótica. O passo que esse motor dá equivale ao menor deslocamento angular para o qual fora programado. Hoje existem controladores de modulação de pulso capazes de conseguir uma resolução de posicionamento infinitamente preciso (PATSKO, 2006).

\subsection{Caixas de Redução}

Segundo Sulato (2014), uma caixa de redução trata-se de um arranjo mecânico de eixos com engrenagens de diversos tipos cuja função é reduzir a velocidade angular do sistema de acionamento de equipamentos que utilizam motores. Por consequência da diminuição da velocidade tem-se o aumento no torque transmitido, ou seja, é uma relação inversamente proporcional. Eles foram desenvolvidos pois, em algumas ocasiões, os motores não podem ser acoplados diretamente no dispositivo que irá utilizá-lo, havendo a necessidade de alterar velocidade e torque.

As caixas de redução também são chamadas de variador de velocidades e dividemse em redutores e ampliadores. Os redutores aumentam o torque fornecido pelo motor em detrimento da velocidade angular no eixo do mesmo. Já os ampliadores aumentam a velocidade angular em detrimento do torque fornecido por ele. Nas caixas de redução o diâmetro da engrenagem acoplada ao motor deve ser maior do que a acoplada ao eixo do equipamento que o utiliza, enquanto as ampliadoras operam de forma inversa (CASER, SERAPHIM, 2014).

Um redutor é capaz de fornecer ao equipamento um torque tantas vezes maior do que o fornecido pelo motor em seu eixo, desconsiderando as perdas na caixa. Com isso, motores menores e mais simples podem ser empregados em máquinas muito robustas permitindo o funcionamento das mesmas por conta do torque agregado, o que torna processo muito mais vantajoso num ponto de vista técnico e econômico (ANTUNES; FREIRE 2002).

Os motores acoplados às reduções são motores de passo. Tratam-se de motores com alta precisão de deslocamento, designado para equipamentos nos quais o controle de número de rotações é muito importante, como impressoras, sistemas de automação industrial e robótica. O passo do motor trata-se do menor deslocamento angular que o eixo do motor pode exercer e depende da quantidade de polos do mesmo (PATSKO, 2006). 
Além das reduções aplicadas, os motores também contam com recursos designados para aprimorar a relação energia-força. O uso de motores síncronos de ímãs permanentes gera uma eficiência $2 \%$ a $3 \%$ maior que a de motores de indução pois o rotor é formado por ímãs de alta densidade de fluxo, o que permite temperatura e sistema de ventilação menores, tornando o motor mais compacto (FIGUEIREDO, BIM, 2010).

\subsection{Automatização}

Os processos de automatização começaram a crescer a partir da terceira revolução industrial, que também se caracterizou pelo emprego da eletrônica e da tecnologia da informação ( $\mathrm{TI})$, que teve seu início nos anos 70 e ainda é empregada nos dias atuais (AZEVEDO, 2017).

Não se deve confundir o conceito de automação com automatização. A automatização refere-se à realização de movimentos automático, repetitivos e mecânicos, ou seja, é sinônimo de mecanização. Já com a automação é possível construir sistema ativos que se utilizam da informação obtida sobre o meio pelo qual atuam, obtendo uma ótima eficiência. Ou seja, o sistema consegue calcular a correção corretiva mais apropriada, tal como o operador humano, por meio de seus sensores (ROSÁRIO, 2009).

A automatização na indústria tinha como objetivo uma maior produtividade e redução de custos. Mas com o passar do tempo foi revelado que nem sempre isso acontece. Devese levar em conta que o investimento para a instalação de tais processos é alto, e esta nova instalação precisa de recursos, inclusive humanos, para sua manutenção. Atualmente o motivo pelo qual muitas empresas escolhem a automação é a busca de maior qualidade dos processos, com objetivo de reduzir as perdas e a fabricação de produtos que sem ela não seriam produzidos (GUTIERREZ, PAN, 2008).

Segundo Rosário (2010), o processo de automatização dá-se através da elaboração de um processo já existente ou de um novo processo, segundo estudos de viabilidade de ganho e limite de sistemas automatizados. Dentre as principais vantagens, incluir robôs em sistemas de automatização para melhor e mais rápido desenvolvimento do mesmo.

A automatização dos processos industriais permite a projeção virtual de produtos, produção e processos em apenas um processo, obtido pela inter-relação entre produtor e fornecedor, e também permite que a produção de amostras físicas seja reduzida ao mínimo (RIBEIRO; CHAGAS, 2017).

\section{I MATERIAIS E MÉTODO}

Este trabalho trata-se de uma pesquisa experimental, já que serão necessários vários testes em laboratório para checar a eficiência e funcionalidade das partes do projeto. Este tipo tem o objetivo de entender as relações de causa-e-efeito ao eliminar explicações contraditórias (FONSECA, 2002). 
Na projeção de algo como um manipulador é preciso uma certa minuciosidade quanto à escolha dos materiais, pois sabe-se que diferentes materiais se comportam de diferentes maneiras. A estrutura utilizada é feita em aço carbono, também chamado de metalon, visto que, segundo Ramos (2015) é um material resistente, leve e de baixo custo. Não obstante, também é necessária uma boa base para suportar o peso de todo o corpo. Com isso em mente, foi desenhada uma estrutura que se adequasse a essa condição, que então foi feita em placa de fibra de média densidade (MDF) com técnicas de marcenaria, ilustrada na Figura 1.

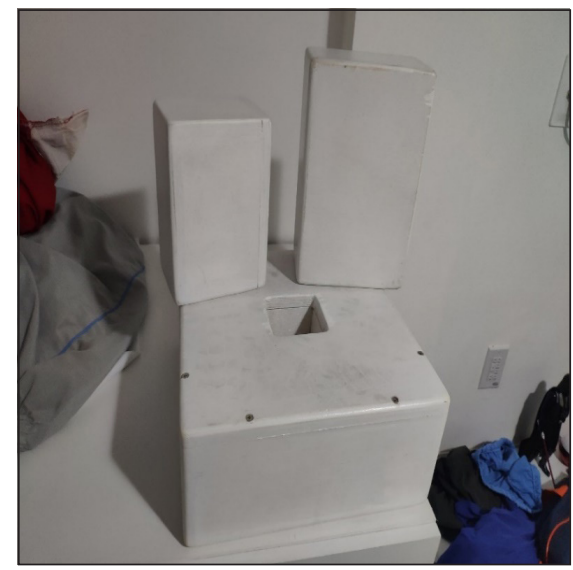

Figura 1: Base

Fonte: Autores, 2020

Além da estrutura, também foram escolhidos motores de passo e um servo motor. Os motores de passo com um bom torque, visando o objetivo de erguer cargas maiores, e o escolhido foi o NEMA 23, evidenciada na Figura 2, cujo torque é de $24 \mathrm{kgf}^{\star} \mathrm{cm}$.

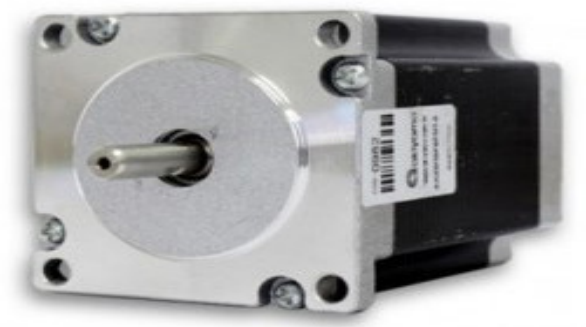

Figura 2: Motor NEMA 23

Fonte: Anúncio da RoboCore ${ }^{1}$

1. Disponível em: <https://www.robocore.net/loja/motores/motor-de-passo-nema23-15kgf_cm>Acesso em 15 de maio de 2019. 
O servo motor com engrenagens de metal possui torque para aguentar peças pesadas. O escolhido foi o Servo Motor Tower Pro Mg-996, cujo torque é de $15 \mathrm{kgf}^{\star} \mathrm{cm}$, e para a sua automatização, isto é, para o movimento contínuo e repetitivo, a escolha foi de drives para motor de passo no modelo DRV8825. A antelação desse modelo foi devido ao drive possuir tensões lógicas de 3,3 até $5 \mathrm{~V}$, suportando controlar motores com alimentação entre $8.2 \mathrm{~V}$ e $45 \mathrm{~V}$, com a facilidade de inserir o código de programação diretamente no drive, o que ocasiona na economia de tempo para a execução do projeto.

O controle por radiofrequência do manipulador foi desenvolvido com base nos componentes de criptografia e decodificação HT12E e HT12D, conforme ilustrado na Figura 3.

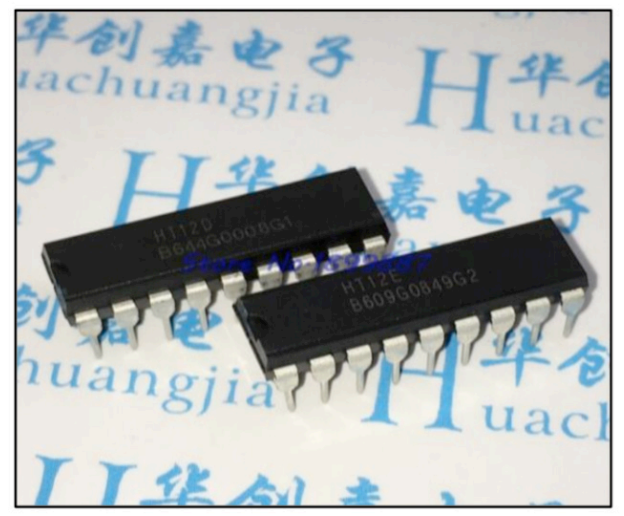

Figura 3: HT12E e HT12D

Fonte: Anúncio do AliExpress ${ }^{2}$

Esses chips foram instalados em conjunto com emissores e receptores de radiofrequência de forma que pudessem acionar individualmente os comandos responsáveis por acionar os periféricos do manipulador. Quando o botão de acionamento no controle remoto é pressionado, são transmitidos 13 bits de dados, sendo o primeiro de sincronização (valor binário) e mais 4 para informar qual botão foi pressionado. O encoder HT12E faz o embaralhamento do sinal de acordo com o clock de sincronização. Quando o sinal é recebido pelo receptor, o mesmo é enviado para o decodificador HT12D que desempenha o trabalho de desembaralhar os sinais e acionar o pino determinado pelo emissor.

Para a complementação do circuito eletrônico, primeiramente serão feitos testes em uma protoboard, uma placa utilizada para testes de circuito eletrônico de fácil montagem e remodelagem, apresentada na Figura 4, para então ser feito numa placa de circuito impresso $(\mathrm{PCl})$.

2. Disponível em: < https://bit.ly/34IMaee> Acesso em 15 de maio de 2019 


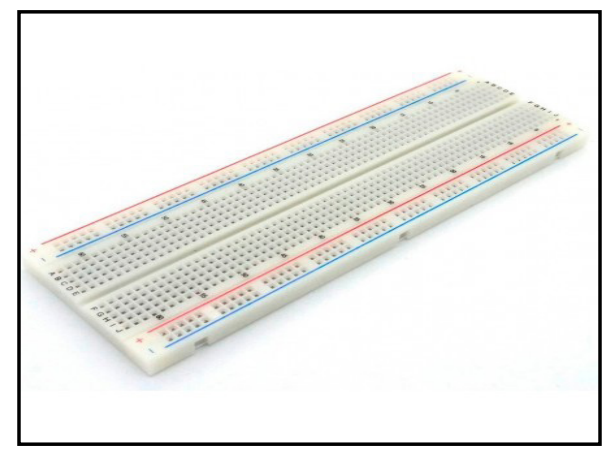

Figura 4: Protoboard

Fonte: Anúncio do Vidadesilicio ${ }^{3}$

Existem vários métodos para confecção de uma $\mathrm{PCl}$, e o utilizado será o método fotográfico, onde as trilhas do circuito será impressa a laser em papel fotográfico. Também será utilizada uma placa virgem, que é uma pci limpa, revestida em cobre, que será limpa e terá o circuito impresso posto sobre ela, que então será transmitido através do calor de um ferro de passar roupa. Com isso as trilhas que antes estariam no papel terão passado para a placa, que então será deixada de molho em percloreto de ferro, para corroer o cobre para obter os trilhos conforme desejado. Então a placa será furada e os componentes soldados.

Para o movimento do eixo principal, será utilizado um cubo de bicicleta, como o tipo comum ilustrado na Figura 5 e nele será acoplada uma engrenagem maior do que a acoplada no motor, conforme exemplo da Figura 6, com o objetivo de aumentar o torque.

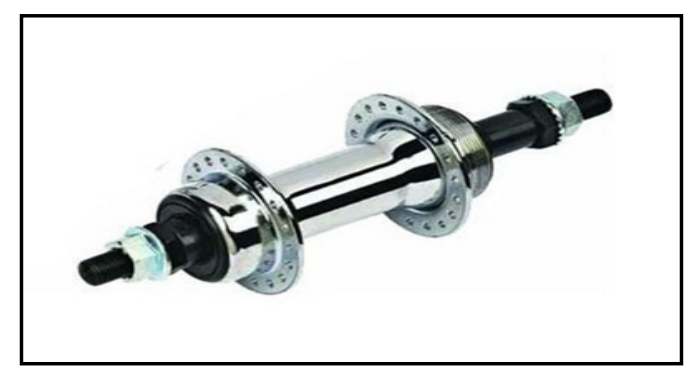

Figura 5: Cubo comum de roda de bicicleta

Fonte: Anúncio do Extra ${ }^{4}$

3. Disponível em: < https://www.vidadesilicio.com.br/protoboard-830> Acesso em 22 de maio de 2019.

4. Disponível em: < https://www.extra.com.br/EsporteLazer/Bicicletas/pecasparabicicleta/cubo-aco-dianteiro-3-8-com-espacador-36f-13685458.html > Acesso em 22 maio de 2019. 


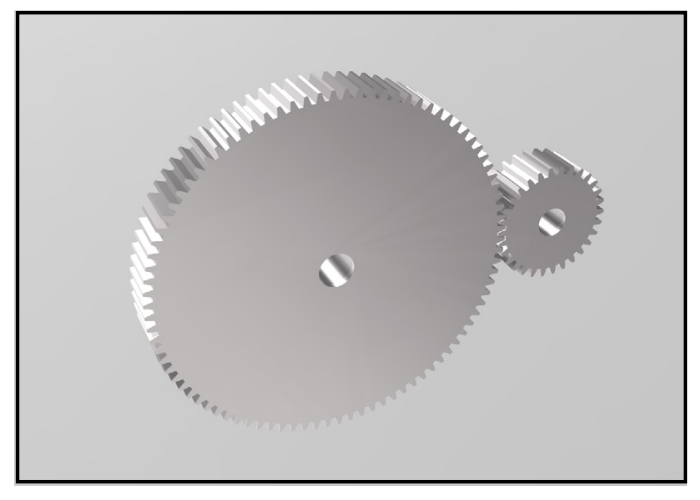

Figura 6: Modelo das engrenagens

Fonte: Autores, 2020

Para fixar o cubo no metalon, primeiramente foi serrada a parte inferior dele, então nele foram fixadas madeira em formato de quadrado, que será parafusada no metalon para evitar flutuação. Sobre a garra, um modelo obtido no GrabCard foi impresso em impressora 3D, em material PLA, apresentado na Figura 7. Depois de impressa, suas partes foram parafusadas, como demostrado na Figura 8 e em seguida será fixado o servo motor, que fará com que a garra abra e feche.

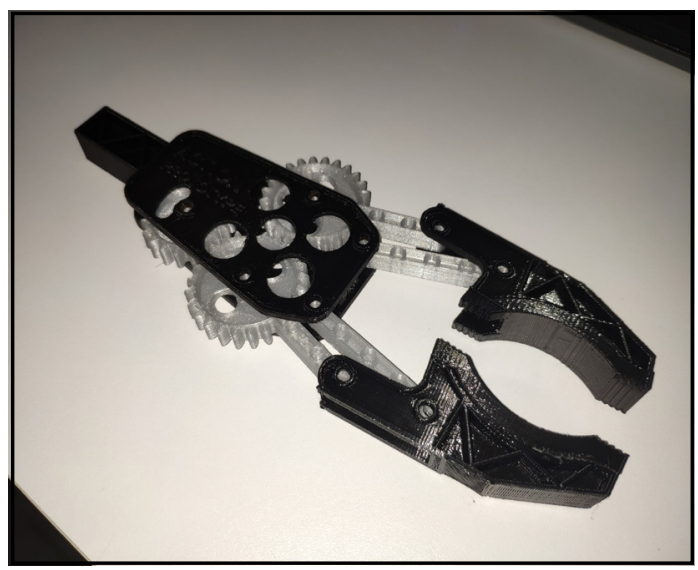

Figura 7: Garra impressa

Fonte: Autores, 2020 


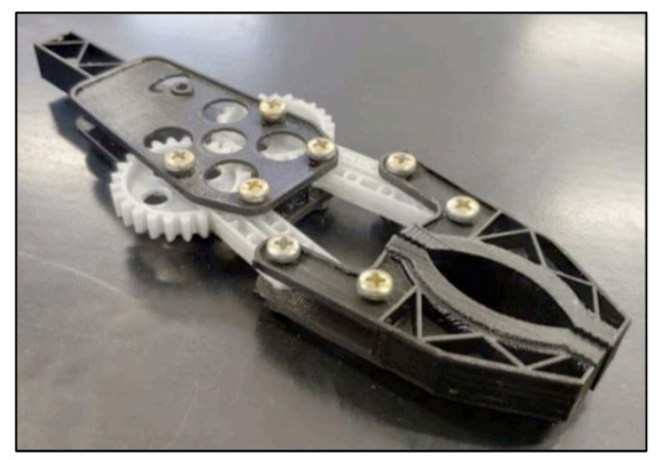

Figura 8: Garra montada

Fonte: Autores, 2020

Mais além, foi desenvolvido um compartimento (Figura 9), onde serão colocados diodos emissores de luz (LEDs), que ficará na base, com o objetivo de dar uma indicação de que estará ligado.

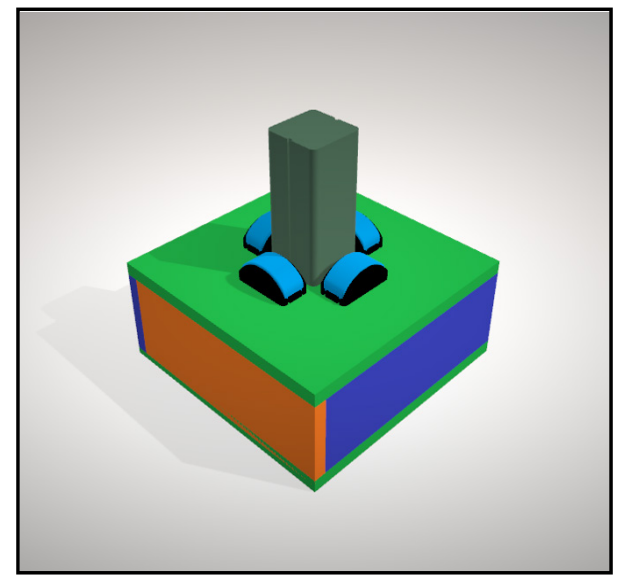

Figura 9: Modelo do spot de LEDs

Fonte: Autores, 2020

\section{I RESULTADOS E DISCUSSÃO}

Foram propostos dois circuitos que se comunicam um com o outro através de radiofrequência. O primeiro circuito trata-se do emissor e o segundo do receptor, ambos trabalham de forma similar, porém em sentidos inversos, enquanto o emissor transforma os sinais analógicos em sinais de radiofrequência o receptor transforma estes em sinais analógicos novamente. 
Para aplicar tais circuitos no manipulador diversos acionadores analógicos foram dispostos no emissor e diversos interpretadores de sinais foram dispostos no receptor. Os acionadores analógicos transformam comandos aplicados manualmente pelo operador em um sinal elétrico que é lido e transformado pelo emissor enquanto o receptor recebe esses sinais e os envia novamente em forma analógica para a controladora principal do manipulador e esta aciona um periférico que desempenha alguma função.

Como resultado dessa aplicação foi idealizado um controle remoto capaz de controlar todas as funções do manipulador robótico a distância e sem fios, facilitando sua operação e permitindo a construção de um controle extremamente funcional, mostrado na Figura 10.

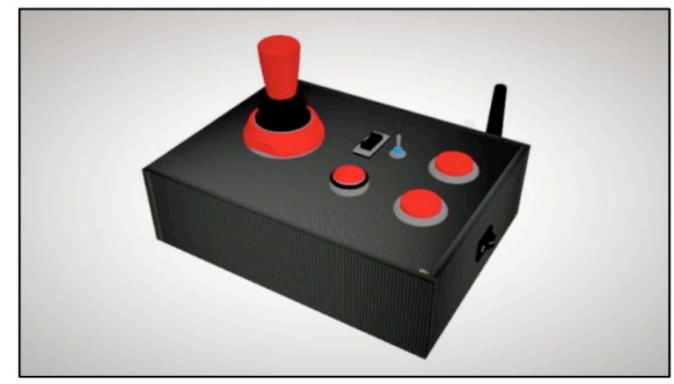

Figura 10: Modelo do controle remoto

Fonte: Autores, 2020

Circuitos eletrônicos que controlam o manipulador indicam um funcionamento previsto, porém ainda não se encontram em seu estado mais avançado. O circuito de acionamento e controle de rotação dos motores de passo mostrado na Figura 11 desempenhou sua função de forma satisfatória. Digitalmente o drive que aciona o motor de passo também funcionou como esperado. A disponibilidade de corrente do drive proporcionou os motores a conseguir trabalhar de forma rápida o suficiente para que sejam acionados quase ao mesmo tempo. A interface de entrada e saída de dados respondeu aos comandos do operador de forma esperada. 


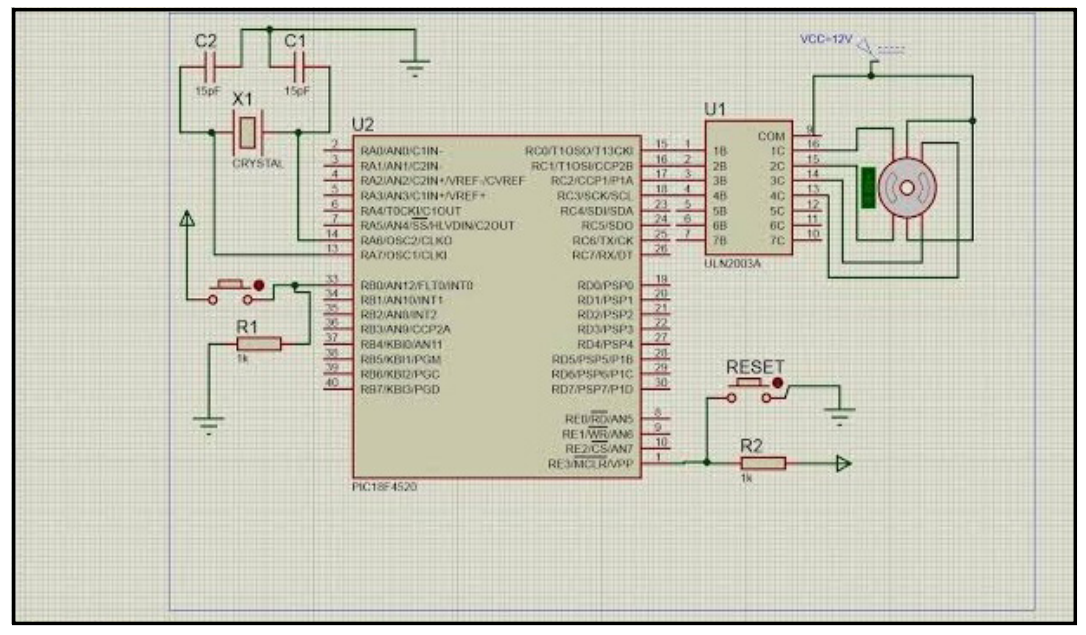

Figura 11: Circuito de acionamento

Fonte: Autores, 2020

Referente a garra, que foi devidamente parafusada e então testado seu movimento, mostrou-se eficiente, já que proporciona uma boa abertura dos dedos, e é firme, o que ajuda a evitar problemas como o objeto escapar de seus dedos, ficando menos dependente do motor que será acoplado a ela.

Por fim, na Figura 12 encontra-se o guindaste montado. Ele é facilmente desmontável, assim facilitando o transporte, o que poderia ser um empecilho, devido ao seu tamanho. Nela é possível ver um dos drivers ligado ao motor do eixo de rotação. Até o momento não foi fixada a garra ao guindaste. A Figura 13 mostra como deverá ficar após sua conclusão, imagem feita no 3D Builder da Microsoft.

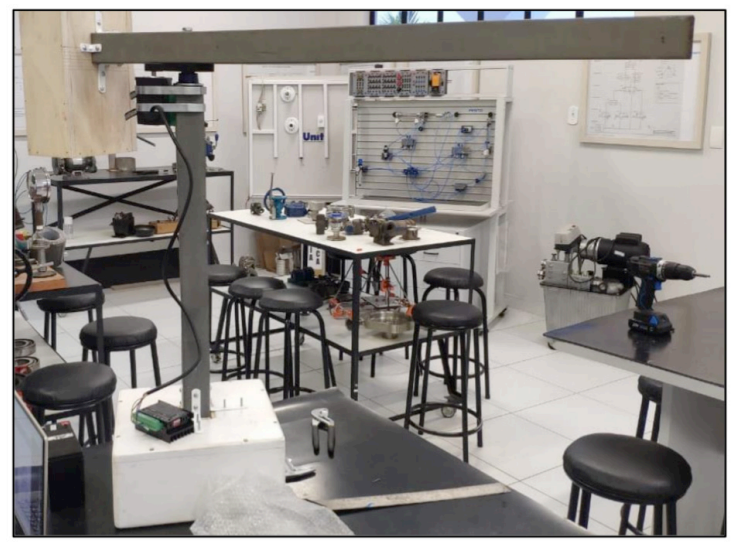

Figura 12: Guindaste em desenvolvimento

Fonte: Autores, 2020 


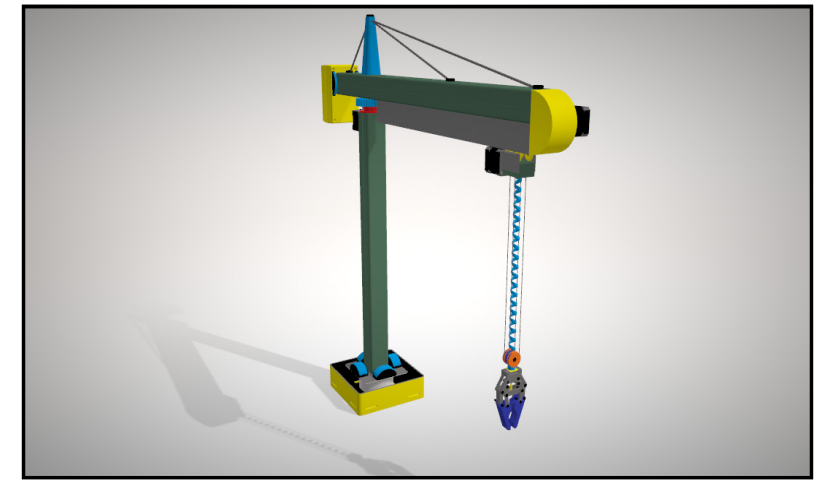

Figura 13: Modelo 3D do guindaste

Fonte: Autores, 2020

\section{I CONCLUSÃO}

O presente trabalho teve como objetivo o desenvolvimento de um manipulador robótico, onde o projeto ocorreu de maneira diferente, no que tange a aplicação dos conceitos de controle e automação. A estrutura do projeto de guindaste, permitiu ensaios de criação a fim de possibilitar o içamento de cargas, que podem ser expandidas em escalas maiores que um manipulador comum.

Além disso, vale destacar que teleoperar e automatizar um manipulador não é uma tarefa fácil, mesmo para programadores mais experientes. Às suas inúmeras funções trouxeram dificuldades em sua transformação para código de programação, que futuramente será elaborada em linguagem $\mathrm{C}$.

Entretanto, tais obstáculos só fomentaram a realização do projeto, uma vez que houve desafios na montagem das partes mecânica da montagem. Com a retirada da parte inferior do cubo de bicicleta, o mesmo ficou sem base de apoio, necessitando a fixação de madeira no formato quadrado para o melhor encaixe no metalon.

O material utilizado para a impressão da garra foi poliácido láctico (PLA), um material resistente visando o custo benefício. Entretanto, os torques dos motores de passo são muito potentes e com a utilização de um material mais resistente na garra, o manipulador conseguiria levantar até mesmo cargas maiores durante os ensaios.

Logo, os resultados atestam a capacidade de movimentação de cargas do manipulador teleoperado e automatizado. A multidisciplinaridade na fabricação desse protótipo demonstra o quanto a Engenharia Mecatrônica está envolvida em diversas áreas e que tem o potencial de buscar soluções práticas referentes à automação. 


\section{REFERÊNCIAS}

ANTUNES, I; FREIRE, M. A. C. Elementos de Máquinas. São Paulo: Érica, 2002.

AZEVEDO, Hélio. Simulador para sistemas cognitivos voltado para robótica social. Automação, [S. I.], p. 1-6, 7 mar. 2017. Disponível em: https://www.ufrgs.br/sbai17/papers/paper_23.pdf. Acesso em: 29 mar. 2019.

CASER, Igor Neves; SERAPHIM, Sylvio Kaschner Costalonga. Projeto de caixa de redução de velocidade por correia sincronizadora para veículo baja SAE®. 2014. Dissertação (Bacharel em Engenharia Mecânica) - Universidade Federal Do Espírito Santo, Espírito Santo.

COCOTA, José. Desenvolvimento de um robô antropomórfico com punho esférico para práticas de robótica com alunos de graduação. Desenvolvimento, [S. I.], p. 1-7, 25 jul. 2013. Disponível em: https://proceedings.sbmac.org.br/sbmac/article/view/139. Acesso em: 19 mar. 2019.

FERREIRA, José. Introdução ao projecto com sistemas digitais e microcontroladores. 1 ed. Faculdade de Engenharia da Universidade do Porto: FEUP editoras, 1998.

FIGUEIREDO, Daniel; BIM, Edson. Controle linear de máximo torque de um motor síncrono de imãs permanentes interiores. Revista Controle \& Automação, Campinas, v. 21, 2010.

FONSECA, João. Metodologia da pesquisa científica. Paraná: Universidade Estadual do Paraná, 2002.

GUTIERREZ, Regina; PAN, Simon. Complexo eletrônico: automação do controle industrial. Automação, [S. I.], p. 1-50, 25 jan. 2008.

MALVINO, Albert; BATES, David. Eletrônica. In: MALVINO, Albert; BATES, David. Eletrônica. 2016: AMGH, 2016.

PATSKO, Luíz Fernando. Tutorial controle de motor de passo. PDF. 18 de dezembro de 2006.

RAMOS, Ademilson. Metalon: o metal versátil e barato. Engenhariae, 2019. Disponível em: <https:// engenhariae.com.br/editorial/colunas/metalon-o-metal-versatil-e-barato>. Acesso em: 4 de jun. de 2019.

RIBEIRO, Laís; CHAGAS, Vanessa. Automação, Desenvolvimento e Implementação de automação e controle de sistema, p. 1-100, 10 abr. 2017. Disponível em: http://bd.centro.iff.edu.br/ handle/123456789/1702. Acesso em: 28 mar. 2019.

ROSÁRIO, J.M. Robótica Industrial I Modelagem, Utilização e Programação. 2010: Baraúna, 2010.

SULATO, Alan. Elementos orgânicos de máquinas: Curso de Engenharia Industrial Madeireira, 2014.

TAGLIETTI, Ângelos. Metal-containing trifurcate receptor that recognizes and senses citrate in water. Metal, 2005, p. 1-7, 4 jun. 2005. Disponível em: https://pubs.acs.org/doi/abs/10.1021/ol0507064. Acesso em: 2 abr. 2019. 


\section{GANHO DE RESISTÊNCIA À COMPRESSÃO POR ENRIJECEDOR EM CHAPA DOBRADA A FRIO}

Data de aceite: 01/10/2020

Data de submissão: 19/08/2020

João Paulo Marques de Aquino Centro Federal de Educação Tecnológica Celso Suckow da Fonseca

Rio de Janeiro - RJ https://orcid.org/0000-0002-1938-1814

João de Jesus dos Santos Centro Federal de Educação Tecnológica Celso Suckow da Fonseca

Rio de Janeiro - RJ https://orcid.org/0000-0003-2875-1511

Lais Amaral Alves Centro Federal de Educação Tecnológica Celso Suckow da Fonseca

Rio de Janeiro - RJ https://orcid.org/0000-0003-0543-2374

RESUMO: No presente trabalho é feito um estudo sobre como o acréscimo de um enrijecedor intermediário no perfil de uma barra de aço dobrada a frio pode influenciar na sua resistência à compressão. Foi escolhido um perfil $\mathrm{U}$ enrijecido nas bordas e foram confeccionadas seis barras de aço com $0,80 \mathrm{~cm}$ de comprimento em média. Três barras receberam o enrijecedor intermediário. Foi calculada teoricamente a resistência à compressão de cada uma das barras pelo método das larguras efetivas. As análises tiveram como base a norma brasileira e NBR14762:2010 - "Dimensionamento de estruturas de aço constituídas por perfis formados a frio - Procedimento". Todas as seis barras foram submetidas a ensaio de compressão feito em laboratório. Pela análise comparativa entre os resultados teóricos e experimentais, percebeu-se um resultado a favor da segurança por parte da Norma brasileira. As resistências à compressão encontradas pelo método das larguras efetivas se mostraram inferiores aos valores obtidos em laboratório. Observouse também que o acréscimo do enrijecedor intermediário causou um aumento em média de $30 \%$ da resistência à compressão da barra quando analisados os resultados experimentais. Porém, de acordo com os resultados teóricos do método das larguras efetivas, o acréscimo de um enrijecedor intermediário resultaria no aumento, em média, de 2,4\% na resistência à compressão, sendo necessário um estudo mais profundo das possíveis causas dessa diferença.

PALAVRAS-CHAVE: Perfis formados a frio, Resistência à compressão, Enrijecedor intermediário, Barras comprimidas.

\section{GAIN RESISTANCE TO COMPRESSION BY STIFFENER IN COLD BENT PLATE}

ABSTRACT: The present study is an evaluation on how the addition of an intermediate stiffener in the profile of a cold formed steel bar can influence its resistance to compression. A rigid $\mathrm{U}$ profile was chosen at the edges and six steel bars $0.80 \mathrm{~cm}$ in length on average were made. Three bars received the intermediate stiffener. The compressive strength of each of the bars was theoretically calculated by the effective width method. The analyzes were based on Brazilian standard NBR14762: 2010 - "Sizing of 
steel structures made up of cold formed profiles - Procedure". All six bars were submitted to a laboratory compression test. By the comparative analysis between the theoretical and experimental results, a work in favor of the security by the Brazilian Standard was perceived. The compressive strengths found by the effective width method were lower than the values obtained in the laboratory. It was also observed that the addition of the intermediate rigifier caused an increase in average of $30 \%$ of the compressive strength of the bar when analyzing the experimental results. However, according to the theoretical results of the effective width method, the addition of an intermediate stiffener would result in an increase of $2.4 \%$ in compressive strength on average, requiring a more in-depth study of the possible causes of this discrepancy.

KEYWORDS: Profiles cold formed, Compression strength, Intermediate stiffener, Compressed bars.

\section{I INTRODUÇÃO}

Os perfis de aço formados a frio se adaptam cada vez mais para serem usados na construção civil, principalmente por causa da rapidez e economia exigidas pelo mercado. Esse elemento estrutural pode ser eficientemente utilizado em galpões de pequeno e médio porte, coberturas, mezaninos, em casas populares e edifícios de pequeno porte. Tem-se observado o crescente uso em light steel framing (LSF) que são painéis estruturados por perfis formados a frio (SILVA et. al, 2012).

Como toda estrutura feita de aço, a construção pré-fabricada com perfis formados a frio possui um tempo reduzido de execução. Sendo compostos por chapas finas, possui leveza, facilidade de fabricação, de manuseio e de transporte, facilitando e diminuindo o custo de sua montagem - menor gasto com transporte, além de não necessitar maquinários pesados para içamento (SILVA et. al, 2012).

Outra característica marcante dos perfis de aço formados a frio é a boa relação resistência/peso, o que o torna fundamental em construções e obras em que exista uma preocupação mútua em relação ao tempo de montagem com um menor custo (COSTA, 2012).

Os perfis formados a frio oferecem uma grande quantidade de opções de seções transversais que podem ser produzidas, o que permite atender uma grande gama de áreas e estruturas. O perfil light steel framing tem sido empregado tanto como peças estruturais (vigas, pilares) como não estruturais (paredes) (COSTA, 2012).

A alteração da geometria de um perfil metálico causa alterações nas suas características, entre elas pode acarretar o ganho de resistência à compressão e trazer vantagens econômicas na execução de uma estrutura metálica.

A Norma brasileira prevê alguns métodos para cálculo e dimensionamento de perfis formados a frio para solicitações do tipo compressão, flexão, flexo-torção e outros. Alguns desses métodos só podem ser realizados através de análises numéricas realizadas por 
modelos computacionais, tornando inviável seu uso analiticamente. A Norma brasileira ABNT NBR 14762:2010 prevê três métodos diferentes que podem ser utilizados para compressão centrada em perfis formados a frio, dentre os quais um será abordado e utilizado no desenvolvimento deste trabalho.

O objetivo deste trabalho é comparar a resistência à compressão de um perfil dobrado a frio antes e após o acréscimo de um enrijecedor intermediário na alma, sendo o cálculo teórico da resistência à compressão centrada pelo método previsto na ABNT NBR 14762:2010, o Método das Larguras Efetivas, obtendo resultados experimentalmente através de ensaios de compressão nos perfis, com e sem o enrijecedor.

\section{I REVISÃO BIBLIOGRÁFICA}

O aço é a mais versátil e a mais importante das ligas metálicas conhecidas pelo ser humano. Trata-se de uma liga de ferro e carbono cujo teor de carbono varia de $0,008 \%$ até 2,11\% (CHIAVERINI, 1996).

O carbono serve para aumentar a resistência do aço, porém, como consequência diminui a sua ductilidade, tornando-o mais frágil e mais suscetível a quebradura. Os aços com baixo teor de carbono têm menor resistência a tração, porém apresentam a vantagem de serem mais dúcteis. Os aços utilizados em estruturas têm as mesmas resistências a ruptura por tração ou compressão que variam entre amplos limites: de $300 \mathrm{MPa}$ até valores acima de $1200 \mathrm{MPa}$ (PFEIL, 2009).

Chiaverini (1996) classifica o aço quanto às suas aplicações. Por exemplo, dos aços destinados para uso estrutural, se requer boa ductilidade, homogeneidade, e soldabilidade, além da necessidade de possuir a tensão de ruptura maior que a tensão de escoamento. A resistência a corrosão pode ser alcançada através da adição de cobre em quantidades que dependem do grau de agressividade do ambiente onde a liga estará inserida. Para atender requisitos como os citados acima, são geralmente utilizados em estruturas os aços-carbono e os aços em baixo teor de liga ou microligados, ambos os tipos classificados com teores baixo e médio de carbono. Outras técnicas empregadas para elevar a resistência de aços estruturais são os processos de conformação (processo mecânico no qual se comprime o metal sólido em moldes e se utiliza da deformação plástica da matéria-prima para o preenchimento das cavidades dos moldes) e tratamentos térmicos (PFEIL, 2009).

\section{I OBJETO DO ESTUDO}

A escolha do perfil metálico e adotado baseou-se em uma peça de drywall, caracterizada pela versatilidade do uso, vasta aplicabilidade e grande comercialização. Com a ideia de reproduzir um perfil com a mesma geometria, o perfil base adotado foi $\cup_{\mathrm{e}} 90 \times 40 \times 10 \times 0,5$. As medidas são as mesmas para o perfil modificado, com a adição 
de um enrijecedor intermediário na alma. Devido a capacidade da prensa mecânica do laboratório disponível para a realização do ensaio de compressão dos corpos de prova, disponibilizados pela metalúrgica Metalfenas, limitou-se o comprimento da barra a $800 \mathrm{~mm}$. As barras foram numeradas de 1 a 6 . Para estudo teórico (o dimensionamento através do MLE), adotou-se uma média das dimensões encontradas conforme a Tabela 1. As barras 1, 2 e 3 não apresentam enrijecedor intermediário, enquanto as demais são acrescidas do elemento.

\begin{tabular}{|c|c|c|c|c|c|}
\hline Barra & $\begin{array}{c}\text { Comprimento } \\
(\mathbf{m m})\end{array}$ & $\begin{array}{c}\text { Largura Alma } \\
\mathbf{( m m})\end{array}$ & $\begin{array}{c}\text { Largura Mesa } \\
\mathbf{( m m})\end{array}$ & $\begin{array}{c}\text { Enrijecedor borda } \\
(\mathbf{m m})\end{array}$ & $\begin{array}{c}\text { Enrijecedor Inter. } \\
(\mathbf{m m})\end{array}$ \\
\hline $\mathbf{1}$ & 818 & 90 & 36,75 & 12,75 & - \\
\hline $\mathbf{2}$ & 823 & 87,5 & 38,75 & 11 & - \\
\hline $\mathbf{3}$ & 819 & 86 & 38,25 & 13,5 & - \\
\hline $\mathbf{4}$ & 826 & 86 & 39 & 11,25 & 6 \\
\hline $\mathbf{5}$ & 822 & 87 & 42,25 & 10,25 & 10 \\
\hline $\mathbf{6}$ & 822 & 88,5 & 41,25 & 9,75 & 7 \\
\hline
\end{tabular}

Tabela 1 - Dimensões médias dos elementos

O item 4.2 da norma ABNT NBR 14762:2010 permite a utilização de aços sem qualificação estrutural para perfis com a condição que o aço apresente propriedades mecânicas requeridas para receber o trabalho a frio. O mesmo item estabelece que os valores adotados nos projetos para resistência ao escoamento $\left(f_{y}\right)$ e a resistência à ruptura $(f)$ não devem ultrapassar 180 MPa e 300 MPa respectivamente. Na Tabela 2, encontramse os valores obtidos para a resistência ao escoamento de cada barra e as médias para as barras 1, 2 e 3 - perfil sem enrijecedor intermediário, e para as barras 4, 5 e 6 - perfil com enrijecedor, além da média total.

\begin{tabular}{|c|c|c|c|}
\hline Barra & $\mathbf{f}_{\mathrm{y}}(\mathrm{MPa})$ & $\mathbf{f}_{\mathrm{y}}$ médio $(\mathrm{MPa})$ & $\mathbf{f}_{\mathrm{y}}$ médio total $(\mathrm{MPa})$ \\
\hline $\mathbf{1}$ & 147,37 & & \\
\hline $\mathbf{2}$ & 139,34 & $\mathbf{1 4 0 , 2 3}$ & \\
\hline $\mathbf{3}$ & 133,98 & & $\mathbf{1 6 1 , 2 2}$ \\
\hline $\mathbf{4}$ & 187,57 & & \\
\hline $\mathbf{5}$ & 182,21 & $\mathbf{1}$ & \\
\hline $\mathbf{6}$ & $176, \mathbf{2 1}$ & \\
\hline
\end{tabular}

Tabela 2 - Resistência ao escoamento $\left(f_{y}\right)$ das barras e valores médios 
A medição da espessura da chapa foi realiza com o uso de um paquímetro com aferição válida. Os valores apresentados a seguir são os valores considerados nos estudos desse trabalho: $\mathrm{t}=0,5 \mathrm{~mm}: f_{y}=161,22 \mathrm{MPa}$ e $f_{u}=300 \mathrm{MPa}$.

\section{I ESTUDO TEÓRICO}

Por apresentarem medidas diferentes, o estudo teórico foi realizado separadamente para cada uma das seis barras, levando-se em consideração a dimensão média para cada elemento. As barras não atendem a condições específicas para relação larguraespessura do elemento mesa. De acordo o dimensionamento estabelecido pela ABNT NBR 14762:2010, o limite da relação é 60. A Tabela 3 mostra essa relação para cada uma das barras. Porém, tal desacordo com a norma não se configurou como impedimento para este estudo, visto que a proposta é avaliar a resistência a compressão do perfil sem atribuir função estrutural ao objeto analisado.

\begin{tabular}{|c|c|c|c|}
\hline Barra & Largura $(\mathbf{m m})$ & Espessura $(\mathbf{m m})$ & Relação largura-espessura \\
\hline $\mathbf{1}$ & 36,75 & 0,5 & 73,5 \\
\hline $\mathbf{2}$ & 38,75 & 0,5 & 77,5 \\
\hline $\mathbf{3}$ & 38,25 & 0,5 & 76,5 \\
\hline $\mathbf{4}$ & 39 & 0,5 & 78 \\
\hline $\mathbf{5}$ & 42,25 & 0,5 & 84,5 \\
\hline $\mathbf{6}$ & 41,25 & 0,5 & 82,5 \\
\hline
\end{tabular}

Tabela 3 - Relação largura-espessura para o elemento mesa das barras estudadas

Os dados relativos a geometria do perfil utilizados nos cálculos de dimensionamento desse capítulo foram obtidos através do programa CameliaX (CTICM, 2013).

\subsection{Limite de esbeltez - verificação}

Após a checagem da relação largura-espessura, calculou-se o índice de esbeltez, um dos limites geométricos impostos pela ABNT NBR 14762:2010. A norma estabelece que peças tracionadas ou comprimidas não devem ter índice de esbeltez superior a 200. Os resultados obtidos permitem classificar as barras estudadas como curtas, pois apresentam um índice médio de esbeltez de 55.

\subsection{Força axial de flambagem elástica}

Para perfis monossimétricos, como os analisados nesse estudo, a força axial crítica de flambagem elástica é o menor valor calculado entre as duas forças citadas na Tabela 4. 


\begin{tabular}{|c|c|c|c|}
\hline Barra & $\mathbf{N}_{\mathrm{ey}} \mathbf{( k N )}$ & $\mathbf{N}_{\mathrm{exz}} \mathbf{( k N )}$ & Força crítica $\mathbf{( k N )}$ \\
\hline $\mathbf{1}$ & 56,198 & 40,887 & 40,887 \\
\hline $\mathbf{2}$ & 58,81 & 38,042 & 38,042 \\
\hline $\mathbf{3}$ & 61,946 & 41,139 & 41,139 \\
\hline $\mathbf{4}$ & 59,975 & 41,231 & 41,231 \\
\hline $\mathbf{5}$ & 70,493 & 46,382 & 46,382 \\
\hline $\mathbf{6}$ & 66,257 & 43,769 & 43,769 \\
\hline
\end{tabular}

Tabela 4 - Forças axiais críticas de flambagem elástica

\subsection{Fator de redução global}

A Tabela 5 apresenta o índice de esbeltez reduzido $\left(\lambda_{0}\right)$ e o fator de redução da força axial de compressão resistente $(\mathrm{x})$.

\begin{tabular}{|c|c|c|}
\hline Barra & Índice de esbeltez reduzido $\left(\boldsymbol{\lambda}_{\mathbf{0}}\right)$ & $\begin{array}{c}\text { Fator de redução da força axial de } \\
\text { compressão resistente }(\mathbf{x})\end{array}$ \\
\hline 1 & 0,607 & 0,857 \\
\hline 2 & 0,625 & 0,849 \\
\hline 3 & 0,605 & 0,858 \\
\hline 4 & 0,608 & 0,857 \\
\hline 5 & 0,589 & 0,865 \\
\hline 6 & 0,598 & 0,861 \\
\hline
\end{tabular}

Tabela 5 - Índice de esbeltez reduzido e fator de redução das barras

\subsection{Método das Larguras Efetivas}

Para o dimensionamento da área efetiva da seção transversal das barras, fezse uso do Método das Larguras Efetiva (MLE). As larguras efetivas foram calculadas separadamente para cada elemento do perfil. Para todas as barras, houve divergência entre as larguras brutas e efetivas. Os resultados encontrados estão na Tabela 6.

\begin{tabular}{|c|c|c|c|c|c|c|}
\hline \multirow{2}{*}{ Barra } & \multicolumn{3}{|c|}{ Largura Bruta } & \multicolumn{3}{c|}{ Largura Efetiva } \\
\cline { 2 - 7 } & $\begin{array}{c}\text { Enrijecedor de } \\
\text { borda (cm) }\end{array}$ & Mesa (cm) & Alma (cm) & $\begin{array}{c}\text { Enrijecedor de } \\
\text { borda (cm) }\end{array}$ & Mesa (cm) & Alma (cm) \\
\hline $\mathbf{1}$ & 1,275 & 3,675 & 9 & 0,922 & 2,633 & 3,287 \\
\hline $\mathbf{2}$ & 1,1 & 3,875 & 8,75 & 0,879 & 2,777 & 3,292 \\
\hline $\mathbf{3}$ & 1,35 & 3,825 & 8,6 & 0,938 & 2,654 & 3,271 \\
\hline $\mathbf{4}$ & 1,125 & 3,9 & 8,6 & 0,884 & 2,766 & 3,273 \\
\hline
\end{tabular}




\begin{tabular}{|l|l|l|l|l|l|l|}
\hline $\mathbf{5}$ & 1,025 & 4,225 & 8,7 & 0,849 & 2,884 & 3,263 \\
\hline $\mathbf{6}$ & 0,975 & 4,125 & 8,85 & 0,831 & 2,879 & 3,275 \\
\hline
\end{tabular}

Tabela 6 - Larguras bruta e efetiva de cada elemento do perfil

\subsection{Flambagem distorcional}

Para perfis enrijecidos submetidos à compressão centrada, a verificação à instabilidade distorcional é dispensada se a relação largura do enrijecedor de borda/ largura bruta da alma $\left(\mathrm{D} / \mathrm{b}_{\mathrm{w}}\right)$ for igual ou superior aos valores indicados na Norma $A B N T$ NBR 14762:2010. A Tabela 7 mostra essa relação $\left(D / b_{w}\right)$ para as barras estudadas.

\begin{tabular}{|c|c|c|c|c|c|c|c|}
\hline Barra & $\mathbf{b}_{\mathbf{f}}(\mathbf{m m})$ & $\mathbf{b}_{\mathbf{w}}(\mathbf{m m})$ & $\mathbf{D}(\mathbf{m m})$ & $\mathbf{t}(\mathbf{m m})$ & $\mathbf{b}_{\mathbf{w}} / \mathbf{t}$ & $\mathbf{b}_{\mathbf{f}} / \mathbf{b}_{\mathbf{w}}$ & $\mathbf{D} / \mathbf{b}_{\mathbf{w}}$ \\
\hline $\mathbf{1}$ & 36,75 & 90 & 12,75 & 0,5 & 180 & 0,408 & 0,1417 \\
\hline $\mathbf{2}$ & 38,75 & 87,5 & 11 & 0,5 & 175 & 0,443 & 0,1257 \\
\hline $\mathbf{3}$ & 38,25 & 86 & 13,5 & 0,5 & 172 & 0,445 & 0,157 \\
\hline $\mathbf{4}$ & 39 & 86 & 11,25 & 0,5 & 172 & 0,453 & 0,1308 \\
\hline $\mathbf{5}$ & 42,25 & 87 & 10,25 & 0,5 & 174 & 0,486 & 0,1178 \\
\hline $\mathbf{6}$ & 41,25 & 88,5 & 9,75 & 0,5 & 177 & 0,466 & 0,1102 \\
\hline
\end{tabular}

Tabela 7- Relação $\left(b_{w} / t\right),\left(b_{f} / b_{w}\right)$ e $\left(D / b_{w}\right)$

De acordo com instrução da ABNT NBR 14762:2010, item 9.7.3, fez-se a interpolação linear dos valores mínimos da relação $D / b_{w}$ de barras com seção $U$ enrijecido e seção $Z$ para se encontrar valores intermediários. Percebeu-se que para todas as barras a relação D/bw (Tabela 7) foi superior que o valor mínimo estabelecido pela norma. Portanto, foi dispensada a verificação da instabilidade distorcional.

\subsection{Força normal de compressão resistente de cálculo}

A resistência da barra ao esforço de compressão é apresentada na Tabela 8.

\begin{tabular}{|c|c|c|c|c|c|}
\hline Barra & $\mathbf{x}$ & $\mathbf{A}_{\text {ef }}\left(\mathbf{c m}^{\mathbf{2}}\right)$ & $\mathbf{f}_{\mathbf{y}}\left(\mathbf{k N} / \mathbf{c m}^{2}\right)$ & $y$ & $\mathbf{N}_{\mathbf{c}, \mathbf{R d}} \mathbf{( k N )}$ \\
\hline $\mathbf{1}$ & 0,857 & 0.52 & 16,122 & 1,2 & 5.988 \\
\hline $\mathbf{2}$ & 0,849 & 0.53 & 16,122 & 1,2 & 6.047 \\
\hline $\mathbf{3}$ & 0,858 & 0.523 & 16,122 & 1,2 & 6.024 \\
\hline $\mathbf{4}$ & 0,857 & 0.529 & 16,122 & 1,2 & 6.085 \\
\hline $\mathbf{5}$ & 0,865 & 0.536 & 16,122 & 1,2 & 6.233 \\
\hline $\mathbf{6}$ & 0,861 & 0.535 & 16,122 & 1,2 & 6.187 \\
\hline
\end{tabular}

Tabela 8 - Resistência das barras a compressão axial 


\section{I ESTUDO EXPERIMENTAL}

Foram realizados seis ensaios de compressão centrada a fim de observar o comportamento das barras quanto a tensão suportada e deformação sofrida. Três ensaios foram em barras com os dois enrijecedores de borda apenas e os outros três procedimentos foram em barras com três enrijecedores - dois enrijecedores de borda e um enrijecedor intermediário na alma. Os ensaios experimentais foram feitos no Laboratório de Engenharia Civil da Faculdade de Engenharia Civil da Universidade do Estado do Rio de Janeiro, (LEC - FEN/UERJ).

\subsection{Procedimentos executivos}

A execução dos ensaios deu-se em uma prensa mecânica, WPM Leipzig com capacidade de carga máxima de 300 toneladas. A prensa utilizada apresenta o apoio inferior fixo enquanto o apoio superior é rotulado. Após a cruzeta se abrir à um vão superior ao do objeto a ser ensaiado, começam os ajustes.

O eixo central da barra é posicionado de forma que coincida com o centro dos apoios circulares da prensa, alinhando o centro de gravidade da chapa de topo com o centro de gravidade da seção transversal do perfil, formando um único centroide. Quando colocado na máquina, esse centroide foi alinhado com centro do prato da máquina de ensaio. Esse alinhamento permitiu que a compressão fosse centrada nas barras.

Utilizou-se duas unidades digitais do modelo TMX IP 54 cada uma em um ponto do apoio inferior para medir o deslocamento do apoio, consequente deformação da barra. A utilização de dois relógios comparadores se justifica para se ter uma redundância dos resultados alcançados.

As cargas foram aplicadas a cada $1 \mathrm{kN}$ para efetuar a leitura dos relógios comparadores e a leitura da carga foi feita através de um leitor digital ligado a prensa, pois o leitor analógico próprio do equipamento se encontrava avariado e por isso em desuso.

\subsection{Resultados experimentais}

Como são conhecidos os comprimentos e as áreas da seção, foi possível traçar o gráfico que descreve o comportamento Tensão $x$ Deformação, para as barras 1, 2, 3, 4, 5 e 6, consolidado na Figura 1. 


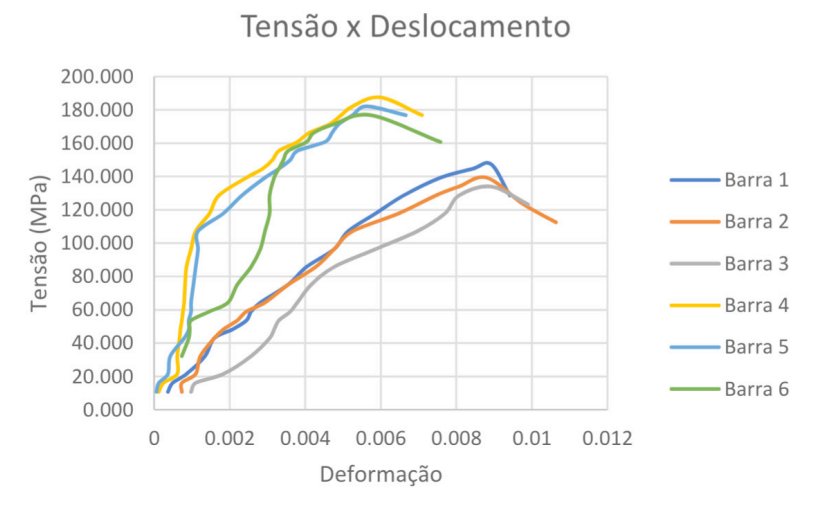

Figura 1 - Gráfico Tensão x Deformação de todas as barras ensaiadas

\section{I ANÁLISE E COMPARAÇÃO DOS RESULTADOS}

Percebe-se que a aplicação do Método das Larguras Efetivas reduziu em média 44\% a área nominal das seções transversais dos perfis para o dimensionamento das barras de aço à compressão. Isso pode ser notado através da comparação demonstrada na Tabela 9.

\begin{tabular}{|c|c|c|c|}
\hline Barra & Área Bruta $(\mathbf{A})\left(\mathbf{c m}^{2}\right)$ & Área Efetiva $\left(\mathbf{A}_{\mathrm{ef}}\right)\left(\mathbf{c m}^{2}\right)$ & Aef/A \\
\hline $\mathbf{1}$ & 0,933 & 0,52 & 0,557 \\
\hline $\mathbf{2}$ & 0,923 & 0,53 & 0,574 \\
\hline $\mathbf{3}$ & 0,935 & 0,523 & 0,559 \\
\hline $\mathbf{4}$ & 0,945 & 0,529 & 0,560 \\
\hline $\mathbf{5}$ & 0,997 & 0,536 & 0,538 \\
\hline $\mathbf{6}$ & 0,97 & 0,535 & 0,552 \\
\hline Média & 0,9505 & 0,529 & 0,557 \\
\hline
\end{tabular}

Tabela 9 - Comparação entre a área nominal e a área efetiva das seções transversais das barras estudadas

Ao analisar os gráficos de Tensão $\times$ Deformação (Figura 1) é possível encontrar a resistência ao escoamento $\left(f_{y}\right)$ das barras. Constata-se que as barras com enrijecedor intermediário (barras 4, 5 e 6) apresentaram um valor em média $30 \%$ superior aos das barras que contam apenas com os dois enrijecedores de borda.

Quando se compara a força resistente à compressão obtida teoricamente com os resultados alcançados nos ensaios de laboratório, torna-se nítido o conservadorismo do Método das Larguras Efetivas. Para as barras com enrijecedor intermediário, a resistência à compressão testada nos ensaios chega a ser $175 \%$, em média, superior ao valor 
encontrado de modo analiticamente como se pode notar na Tabela 10. Na Figura 2, registrase a diferença dos valores obtidos para cada barra ensaiada.

\begin{tabular}{|c|c|c|c|c|}
\hline Barra & $\mathbf{N}_{\mathrm{c}, \mathrm{Rd}}$ (teórico) (N) & $\mathbf{N}_{\mathrm{c}, \mathrm{Rd}}$ (experimental) (N) & $\begin{array}{c}\mathbf{N}_{\mathrm{c}, \mathrm{Rd}} \text { (experimental)/ } \mathbf{N}_{\mathrm{c}, \mathrm{Rd}} \\
\text { (teórico) }\end{array}$ & Média \\
\hline $\mathbf{1}$ & 5998 & 13750 & 2,292 & \multirow{2}{*}{$\mathbf{2 , 1 7 2}$} \\
\hline $\mathbf{2}$ & 6047 & 13000 & 2,150 & \\
\hline $\mathbf{3}$ & 6024 & 12500 & 2,075 & \multirow{2}{*}{$\mathbf{2 , 7 5 7}$} \\
\hline $\mathbf{4}$ & 6085 & 17500 & 2,876 & \\
\hline $\mathbf{5}$ & 6233 & 17000 & 2,727 & \\
\hline $\mathbf{6}$ & 6187 & 16500 & 2,667 & \\
\end{tabular}

Tabela 10 - Resistência a compressão das barras de forma teórica e de forma experimental

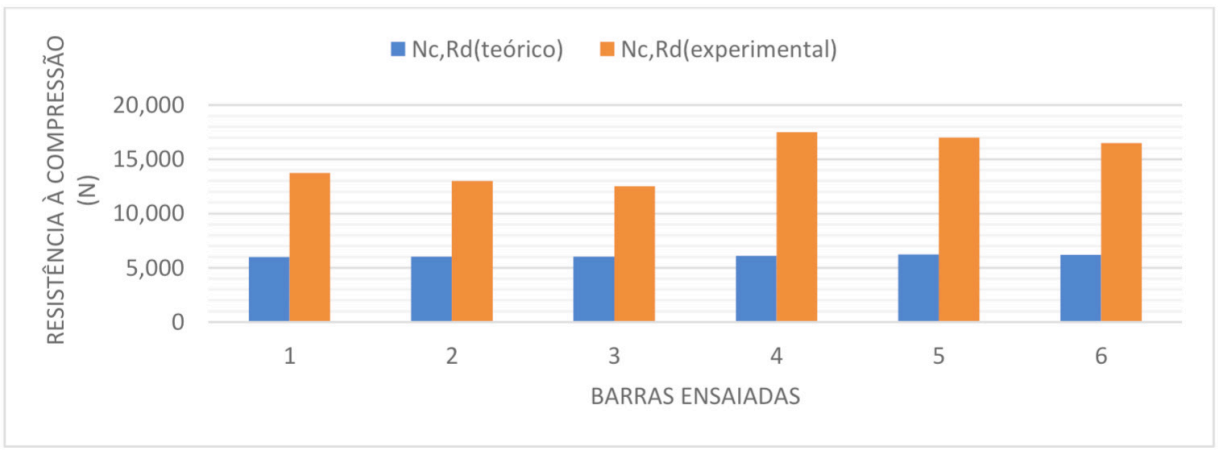

Figura 2 - Comparação entre os valores de resistência à compressão encontrados pelo modo teórico e pelo modo experimental

Os resultados registrados na Tabela 11, demonstram que o acréscimo de um enrijecedor intermediário no perfil analisado aumenta a resistência à compressão da barra. Ao avaliar as resistências obtidas por meio matemáticos, a presença do enrijecedor intermediário acrescentou $2,4 \%$ na capacidade da barra em suportar o esforço de compressão. Já os resultados experimentais demonstram que o enrijecedor intermediário aumentou a capacidade da barra em resistir à compressão em $30 \%$ relativa à resistência da barra sem o elemento. A Figura 3 mostra essa diferença dos resultados encontrados para cada modo. 


\begin{tabular}{|c|c|c|c|c|}
\hline Barra & $\mathrm{N}_{\mathrm{c}, \mathrm{Rd}}$ (teórico) (N) & Média $\mathrm{N}_{\mathrm{c}, \mathrm{Rd}}$ (teórico) $(\mathrm{N})$ & $\mathrm{N}_{\mathrm{c}, \mathrm{Rd}}($ experimental) $(\mathrm{N})$ & Média $\mathrm{N}_{\mathrm{c}, \mathrm{Rd}}$ (experimental) \\
\hline 1 & 5998 & & 13750 & \\
\hline 2 & 6047 & 6023,00 & 13000 & 13083,33 \\
\hline 3 & 6024 & & 12500 & \\
\hline 4 & 6085 & & 17500 & \\
\hline 5 & 6233 & 6168,33 & 17000 & 17000,00 \\
\hline 6 & 6187 & & 16500 & \\
\hline
\end{tabular}

Tabela 11 - Média das resistências à compressão

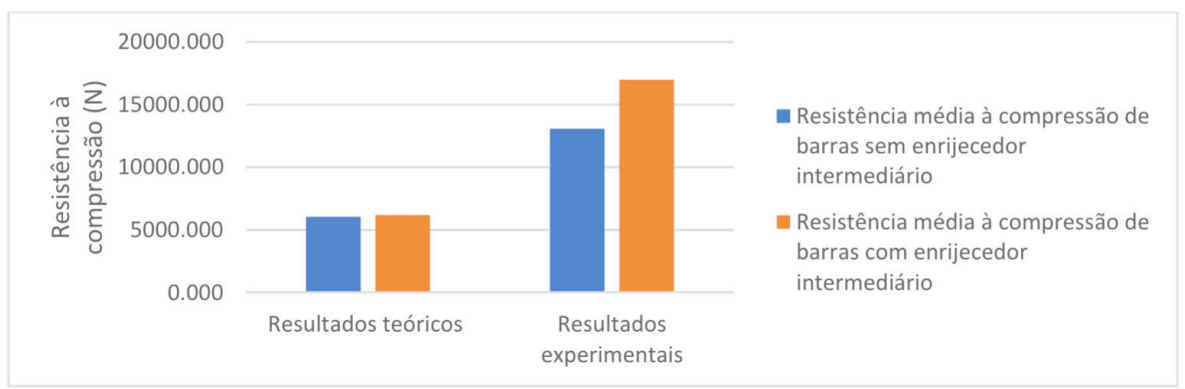

Figura 3 - Gráfico comparativo de valores obtidos para a resistência à compressão de perfis com e sem enrijecedor intermediário de forma teórica e experimental

Como houve uma diferença que chega a $175 \%$ - para barras com enrijecedor intermediário - entre os resultados obtidos teoricamente e os resultados encontrados de forma experimental, este trabalho resolveu fazer uma comparação que foge das indicações pregadas pela ABNT NBR 14762:2010. Calculou-se a resistência à compressão axial das barras levando-se em consideração toda a área transversal do perfil, ignorando, deste modo, o Método das Larguras Efetivas. Como se percebe na Tabela 12, houve um aumento de $80 \%$ em média nos resultados teóricos.

\begin{tabular}{|c|c|c|c|}
\hline Barra & $\mathbf{N}_{\mathrm{c}, \mathrm{Rd}}$ (Teórico) (Área efetiva) (N) & $\mathbf{N}_{\mathrm{c}, \mathrm{Rd}}$ (Teórico) (Área bruta) (N) & $\begin{array}{c}\mathbf{N}_{\mathrm{c}, \mathrm{Rd}} \text { (Área bruta) / } \mathbf{N}_{\mathrm{c}, \mathrm{Rd}} \text { (Área } \\
\text { efetiva) }\end{array}$ \\
\hline $\mathbf{1}$ & 5998 & 10746 & 1,79 \\
\hline $\mathbf{2}$ & 6047 & 10528 & 1,74 \\
\hline $\mathbf{3}$ & 6024 & 10776 & 1,79 \\
\hline $\mathbf{4}$ & 6085 & 10877 & 1,79 \\
\hline $\mathbf{5}$ & 6233 & 11586 & 1,86 \\
\hline $\mathbf{6}$ & 6187 & 11222 & 1,81 \\
\hline
\end{tabular}

Tabela 12 - Comparativo entre as resistências à compressão considerando a área efetiva e levando-se em consideração a área bruta da seção transversal dos perfis 
Quando se compara os resultados teóricos levando-se em consideração a área bruta da seção transversal do perfil e não mais a área efetiva (MLE) com os resultados obtidos no laboratório, nota-se que a diferença caiu de 146\% (Tabela 10) para 37\% em média como pode ser visto na Tabela 13.

\begin{tabular}{|c|c|c|c|}
\hline Barra & $\mathbf{N}_{\mathrm{c}, \mathrm{Rd}}$ (Área bruta) (N) & $\mathbf{N}_{\mathrm{c}, \mathrm{Rd}}$ (Experimental) (N) & $\begin{array}{c}\mathbf{N}_{\mathrm{c}, \mathrm{Rd}} \text { (Área bruta) } / \mathbf{N}_{\mathrm{c}, \mathrm{Rd}} \\
\text { (Experimental) }\end{array}$ \\
\hline $\mathbf{1}$ & 10746 & 13750 & 1,28 \\
\hline $\mathbf{2}$ & 10528 & 13000 & 1,23 \\
\hline $\mathbf{3}$ & 10776 & 12500 & 1,16 \\
\hline $\mathbf{4}$ & 10877 & 17500 & 1,61 \\
\hline $\mathbf{5}$ & 11586 & 17000 & 1,47 \\
\hline $\mathbf{6}$ & 11222 & 16500 & 1,47 \\
\hline
\end{tabular}

Tabela 13 - Comparação entre os resultados teóricos levando-se em conta a área bruta com os resultados experimentais para a resistência à compressão de barras

Na Figura 4, quando se expõe os três resultados (resultado teórico considerandose área efetiva (MLE), resultado teórico levando-se em conta a área bruta e resultado experimental), nota-se que a diferença entre os valores obtidos de forma teórica, independentemente de qual área da seção transversal se adotou, e os valores experimentais é maior para as barras 4, 5 e 6, aquelas que foram acrescidas de enrijecedor intermediário.

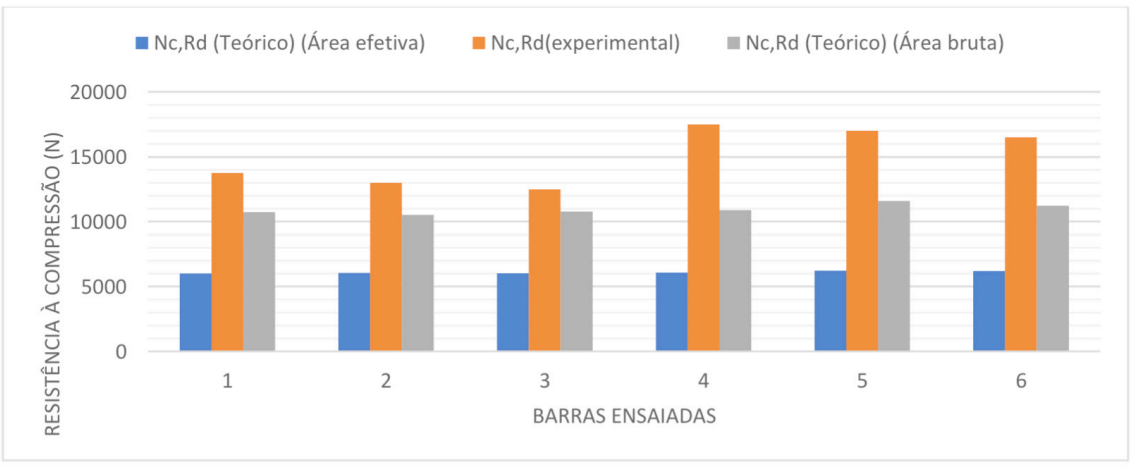

Figura 4 - Gráfico comparativo entre os resultados teóricos, levando-se em consideração área efetiva e área bruta, com os resultados experimentais 
Ao avaliar as barras após terem sido submetidas ao ensaio de compressão, notaramse deformações mais acentuadas próximas das ondulações que foram registradas no item 3.3.1 deste trabalho para as barras 1, 2, 3 e 4. Tal comportamento evidencia a interferência das imperfeições geométricas nos resultados do ensaio à compressão. Porém, a análise criteriosa desse fenômeno não se configura como objeto deste estudo.

\section{I CONCLUSÃO}

Este trabalho teve como objetivo verificar como o acréscimo de um enrijecedor intermediário altera o comportamento de uma barra quando exposta à compressão. Foram confeccionadas seis barras no total, com uma geometria inspirada em um perfil universalmente comercializado para fins de montante de drywall. Das seis barras, três foram acrescidas de um enrijecedor intermediário. Para cada uma das barras foi feito o dimensionamento da resistência à compressão pelo método mais conservador, o Método das Larguras Efetivas.

Além do estudo teórico das barras foram realizados ensaios de compressão em laboratório. Os resultados obtidos matematicamente e experimentalmente foram comparados. Foram analisados ainda os resultados obtidos nas barras com o enrijecedor intermediário e sem o elemento.

As comparações demonstraram elevado grau de segurança do Método das Larguras Efetivas, conforme descrito na ABNT NBR 14762:2010, pois a força suportada pelas barras nos ensaios experimentais foi bem superior aos valores encontrados teoricamente. Caso fosse empregado outros métodos (Método da Seção Efetiva e Método de Determinação Direta do Esforço Resistente), menos conservadores, a diferença entre resultados teóricos e experimentais seria menor. Constatou-se também, por meio dos ensaios laboratoriais, que o acréscimo de um enrijecedor intermediário aumentou a resistência à compressão centrada das barras estudadas em média em 30\%.

Quando se compara o efeito do acréscimo do enrijecedor intermediário visto somente pelo método das larguras efetivas, o ganho de resistência à compressão foi de apenas $2,4 \%$. Tal resultado comprova uma defasagem nesse método para se calcular o dimensionamento de perfis com enrijecedor intermediário.

Outra constatação é que quando se utiliza a área bruta da seção transversal do perfil para calcular teoricamente a resistência à compressão, a diferença com o resultado experimental se reduz a $37 \%$ em média. Tal análise evidencia que as barras estudadas, com índice médio de esbeltez de 55, se caracterizam como curtas e não se enquadram perfeitamente no Método das Larguras Efetivas recomendado pela ABNT NBR 14762:2010.

Apesar de não ser objeto de estudo deste trabalho, observou-se que as imperfeições geométricas ficaram mais suscetíveis às deformações ocasionadas pela compressão, conforme pode ser observado nos ensaios realizados 


\section{REFERÊNCIAS}

ASSOCIAÇÃO BRASILEIRA DE NORMAS TÉCNICAS - ABNT. NBR 14762: Dimensionamento de estruturas de aço constituídas por perfis formados a frio. Rio de Janeiro, 2010.

CHIAVERINI, Vicente. Aços e Ferros fundidos. $7^{\circ}$ Edição. Associação Brasileira de Metalurgia e Materiais - ABM, 1996.

COSTA, Alexandre Alcipreste Rodrigues. Estudo da flambagem local de perfis $U$ enrijecidos em situação de incêndio. Dissertação (Mestrado). Minas Gerais: Universidade Federal de Minas Gerais, 2012.

CTICM. CameliaX. Versão 1.0, 2013, acessado em 20/03/2019.

PFEIL, Walter. Estruturas de aço: dimensionamento prático de acordo com a NBR 8800:2008. 8.ed. Rio de Janeiro: LTC, 2009.

SILVA, Valdir Pignatta; PIERIN, Igor; SILVA, Edson Lubas. Estruturas compostas por perfis formados a frio - Dimensionamento pelo método das larguras efetivas e aplicação conforme ANBT NBR 14762:2010 e ABNT NBR 6355:2012. Rio de Janeiro: Instituto Aço Brasil/ CBCA, 2014. 


\section{PADRONIZAÇÃO DE MATERIAIS COMO MEIO DE ECONOMIA EM SUPRIMENTO DE BENS: UM ESTUDO DE CASO}

Data de aceite: 01/10/2020

Data de submissão: 03/08/2020

\section{Patrícia Aparecida Casteluber Nascimento}

Faculdade do Centro Leste - UCL Serra - ES http://lattes.cnpq.br/3132776074896021

Gabrielle Silva Ribeiro

Faculdade do Centro Leste - UCL Serra - ES http://lattes.cnpq.br/5802221265578775

Beatriz Marvila Borges

Faculdade do Centro Leste - UCL

Serra - ES

http://lattes.cnpq.br/4598111118850352

\section{Letícia dos Santos Sciortino}

Faculdade MULTIVIX

Vitória - ES

http://lattes.cnpq.br/2995674967462275

RESUMO: Este trabalho objetivou identificar e mapear as oportunidades na área de suprimento de bens, visando otimizar o processo de aquisição e reduzir o custo de estoque de materiais de uso comum de uma companhia. A metodologia empregada teve como base a padronização de atributos técnicos imprescindíveis para a caracterização do material, conjunto esse denominado PDM (Padronização de Descrições de Materiais), posteriormente é feita a análise de range de aplicação destes materiais, para assim aumentar o raio de utilização e consequentemente a substituição daqueles não padronizados. Para demonstrar o desenvolvimento da metodologia, foi realizado um estudo de caso em parafusos do tipo estojo para área naval. Os resultados apresentados demonstram uma redução na variação de especificações dos parafusos do tipo estojo disponíveis para aquisição, gerando assim uma economia significativa em custos com estoque e facilitando a compra dos materiais.

PALAVRAS-CHAVE: Gestão, padrão, materiais, estoque, parafuso estojo.

\section{STANDARDIZATION OF MATERIALS AS A MEANS OF ECONOMY IN SUPPLY CHAIN: A CASE STUDY}

ABSTRACT: This study aimed to identify and map the opportunities in the goods supply area, aiming to optimize the acquisition process and reduce the common use materials stocks cost of a company. The methodology used was based on the standardization of essential technical attributes for the material characterization this set named PDM (Standardization of Material Descriptions), afterwards is done the range analysis of these materials applications, in order to increase their use and consequently the substitution of the non-standardized materials. To demonstrate the methodology development, was realized a study case in screw of the type case for naval area. The presented results demonstrated a reduction in the number of screw of the type case available for purchase, as result a significant saving in stock costs and facilitating the acquisition of the materials.

KEYWORDS: Management, standard, materials, stock, screw, nuts. 


\section{I INTRODUÇÃO}

Estabelecer um padrão, é uma forma de garantir qualidade e, comumente, resulta, também, em redução de custos. A habilidade de realizar melhorias na base de fornecimento está entre as maiores oportunidades para aumentar a lucratividade e a competitividade das empresas (CHING, 1999). Nesse seguimento, a padronização das descrições dos materiais leva a redução da variedade de materiais utilizados em qualquer seguimento que necessita de estocagem e giro de bens. Consequentemente, gera a facilitação do controle de estoques, em diminuição do espaço físico dos armazéns e em redução dos custos de estocagem, manuseio e distribuição (área ocupada, instalações, utensílios, equipamentos, entre outros) e redução de perdas.

Basear-se em padrões técnicos (ISO, DIN, SAE, ABNT, etc) é um aspecto significativo da padronização, que permite adquirir produtos com garantia de qualidade e segurança, principalmente, quando os padrões são exigidos pela legislação. De outro modo, leva-se também a adequação do mercado fornecedor, fazendo com que os materiais sejam comercialmente viáveis e possuam a intercambialidade funcional, isto é, materiais de diferentes fabricantes podem atender a mesma função requerida pelo projeto e uso dos equipamentos (NOGUEIRA ET AL., 1984).

Considerando a importância do funcionamento adequado no transporte de fluídos em uma planta industrial, esse trabalho teve como objeto de estudo o parafuso estojo, material de extrema importância na manutenção das conexões para tubulação. Sendo assim, faz-se necessário levantar as características principais do material de estudo, realizar a padronização, para enfim obter uma redução importante em custos de suprimento e estocagem.

\section{I MATERIAL E MÉTODOS}

A área de estudo compreende uma categoria de material essencial para pleno funcionamento de plantas de tubulação que possuem ligações flangeadas: o parafuso estojo. Segundo Telles (2012), os estojos são barras cilíndricas rosqueadas com porcas e contraporcas independentes. Para cada tipo de aplicação, uma ligação flangeada é composta de dois flanges, uma junta de vedação e estojos com características compatíveis. Em geral, a quantidade de parafusos utilizados varia conforme o diâmetro nominal do flange, por exemplo: são necessários 4 jogos de estojo para uma ligação com flange de DN 1⁄2”.

Santos (2019) define o PDM como a base para identificar quais os dados técnicos para compor a descrição e consequentemente qual a ordem estará disposta na descrição, de forma a identificar, classificar e enriquecer o cadastro de materiais de uma empresa, visando a eliminação das multiplicidades dos materiais. De acordo com a montagem de descritivos técnicos para a aquisição do material em questão, as especificações e 
propriedades requeridas, existem inúmeras combinações de características técnicas para adquirir o parafuso estojo. Desta maneira, realizou-se a identificação das características mais comuns nos descritivos técnicos, para atender as diversas áreas envolvidas na utilização de tubulações industriais (GONÇALVES, 2013).

Segundo Deus (2013), "[...] a especificação (descrição) é a identificação dos aspectos mais relevantes de um produto, que ajuda a classificá-lo de acordo com algum critério de interesse circunstancial. Para que a descrição seja feita de maneira adequada, é preciso considerar alguns critérios ou regras, que ajudam a tornar o processo preciso e eficiente [...]", portanto, para elaboração das combinações, foi analisado tecnicamente e definido as seguintes características como principais: Material de fabricação do parafuso, revestimento do parafuso, especificação das porcas, revestimento da porca, tamanho (passo, série e classe), e por fim o comprimento do parafuso. Para cada especificação do flange, foi padronizado os materiais de fabricação conforme Tabela 1.

\begin{tabular}{|c|c|c|}
\hline Material do flange & Material dos parafusos & Material das porcas \\
\hline $\begin{array}{l}\text { ASTM B } 62 \\
\text { ASTM A } 536 \text { Gr 65-45-12 } \\
\text { ASTM A } 126 \text { CL B } \\
\text { ASTM A } 105 \\
\text { ASTM A } 216 \text { Gr WCB }\end{array}$ & $\begin{array}{l}\text { AL ASTM A193 gr. B7 revestido em } \\
\text { Zn-Ni ASTM B841 cl1-B/E gr 5-8 }\end{array}$ & $\begin{array}{l}\text { AC ASTM A } 194 \text { Gr } 2 \mathrm{H} \text { revestido em } \\
\text { Zn-Ni ASTM B841 cl1-B/E gr 5-8 }\end{array}$ \\
\hline $\begin{array}{l}\text { ASTM A } 350 \text { Gr LF2 CL } 1 \\
\text { ASTM A } 352 \text { Gr LCB } \\
\text { ASTM A } 350 \text { Gr LF3 CL } 1 \\
\text { ASTM A } 352 \text { Gr LC3 }\end{array}$ & $\begin{array}{l}\text { AL ASTM A320 gr L7 revestido em } \\
\text { Zn-Ni ASTM B841 cl1-B/E gr 5-8 }\end{array}$ & $\begin{array}{l}\text { AL ASTM A194 gr 7L revestido em } \\
\text { Zn-Ni ASTM B841 cl1-B/E gr 5-8 }\end{array}$ \\
\hline $\begin{array}{l}\text { ASTM A } 217 \text { Gr C5 } \\
\text { ASTM A } 182 \text { Gr F304 } \\
\text { ASTM A } 351 \text { Gr CF8 } \\
\text { ASTM A } 182 \text { Gr F316 } \\
\text { ASTM A } 351 \text { Gr CF8M } \\
\text { ASTM A } 182 \text { Gr F317 } \\
\text { ASTM A } 351 \text { Gr CG8M } \\
\text { ASTM A } 182 \text { Gr F347 } \\
\text { ASTM A } 351 \text { Gr CF8C } \\
\text { ASTM A } 182 \text { Gr F11 CL } 2\end{array}$ & $\begin{array}{l}\text { AL ASTM A193 gr B16 revestido em } \\
\text { Zn-Ni ASTM B841 cl1-B/E gr 5-8 }\end{array}$ & $\begin{array}{l}\text { AL ASTM A194 gr } 7 \text { revestido em } \\
\text { Zn-Ni ASTM B841 cl1-B/E gr 5-8 }\end{array}$ \\
\hline
\end{tabular}

Tabela 1. Padronização de material de fabricação e revestimento para estojos. 
Considerou-se inicialmente para os parafusos e porcas, os materiais de fabricação e revestimentos mais comuns no mercado fornecedor, o dimensional em um range de 3/16" à 4.1/2", e o comprimento variando entre 1.1/8" até 90.1/2", isto é, sempre avaliando a viabilidade funcional, a intercambialidade e o fornecimento comercial.

Seguindo para a padronização, definiu-se os três principais materiais de fabricação dos parafusos, e de acordo com as respectivas normas, que são eles: o estojo A193 gr B16, que é conhecido como high strength bolting, por atuar em ambientes de grandes pressões e temperaturas, em flanges que requerem torques elevados e reaperto, quando necessário, apresentando alto nível de escoamento. Já a definição pela especificação de AL ASTM A193 gr. B7 se dá devido às condições de uso, suas propriedades mecânicas e à temperatura que se atinge, esse também é muito utilizado nas grandes indústrias para alta temperatura ou pressão, além de outras aplicações severas. Por fim, e não menos importante, o $\mathrm{AL}$ ASTM A320 gr L7, que é fabricado em aço liga 4140, que garante durabilidade e fixação precisa, sendo comumente especificado para uso geral.

Outro aspecto importante para padronização é o dimensional dos parafusos e porcas, por isso foi especificado que as dimensões dos parafusos para flanges devem ser conforme as ASME B16.5 e ASME B18.2.1. As roscas devem ser conforme a ASME B1.1, sendo que para parafusos de diâmetros 1" e menores devem ser do tipo "coarse threads series" UNC-2A e para parafusos de diâmetros 1 1/8" e maiores devem ser do tipo "8 threads series" 8UN-2A. As dimensões das porcas devem ser conforme a ASME B18.2.2 e as roscas devem ser conforme a ASME B1.1, sendo que, para porcas de diâmetros 1" e menores, usar a série UNC-2B, para diâmetros de 1 1/8" e maiores, usar a série 8UN-2B.

Os comprimentos dos estojos e parafusos a partir de 3 1/2" são definidos em múltiplos de 1/2", com arredondamento para cima, tornando-se a última característica avaliada na metodologia aplicada.

Através dessas definições, foi possível realizar o saneamento das combinações possíveis, conforme exemplo da Tabela 2.

\begin{tabular}{l|c|c}
\hline Característica Técnica & Objeto não padronizado & Objeto padronizado \\
\hline Nome padronizado & Parafuso estojo & Parafuso estojo \\
\hline Porcas & $\begin{array}{c}\text { Com 2 porcas sextavadas } \\
\text { pesadas }\end{array}$ & $\begin{array}{c}\text { Com 2 porcas sextavadas } \\
\text { pesadas }\end{array}$ \\
\hline Padrão das porcas & Padrão ASME B18.2.2 & Padrão ASME B18.2.2 \\
\hline $\begin{array}{l}\text { Tratam. Alívio tensões } \\
\text { hidrog. }\end{array}$ & Conforme ASTM B849 e B850 & $\begin{array}{c}\text { Conforme ASTM B849 e } \\
\text { B850 }\end{array}$ \\
\hline Material de fabricação & AL ASTM A193 gr B7M & AL ASTM A193 gr. B7 \\
\hline Revestimento do parafuso & Zn-Ni ASTM B841 cl1-B/E gr 5-8 & $\begin{array}{c}\text { Zn-Ni ASTM B841 cl1-B/E } \\
\text { gr 5-8 }\end{array}$ \\
\hline
\end{tabular}




\begin{tabular}{l|c|c}
\hline $\begin{array}{l}\text { Tamanho, passo, série e } \\
\text { classe }\end{array}$ & Tam. 1 1/2pol - 6 UNC-2A & Tam. 11/2pol - 8 UN-2A \\
\hline $\begin{array}{l}\text { Comprimento do parafuso } \\
\text { estojo }\end{array}$ & Comprimento 10 1/4pol & Comprimento 10 1/2pol \\
\hline $\begin{array}{l}\text { Material/ } \\
\text { especificação(porcas) }\end{array}$ & AC ASTM A194 gr 2HM & AC ASTM A194 gr 2H \\
\hline \begin{tabular}{l} 
Revestimento da porca \\
\hline
\end{tabular} & Zn-Ni ASTM B841 cl1-B/E gr 5-8 & $\begin{array}{c}\text { Zn-Ni ASTM B841 cl1-B/E } \\
\text { gr 5-8 }\end{array}$ \\
\hline
\end{tabular}

Tabela 2. Exemplificação de PDM padronizado.

\section{I RESULTADOS E DISCUSSÃO}

Pelos resultados obtidos, observa-se uma redução significativa na variedade de descritivos (Tabela 3).

De acordo com o demonstrativo de redução após a padronização, foi possível obter uma diminuição de $60 \%$ da variedade fixando-se o revestimento Zn-Ni ASTM B841 cl1-B/E gr 5-8 para o parafuso e as porcas.

\begin{tabular}{l|c|c|c}
\hline \multicolumn{1}{c|}{ Características } & Sem padronização & Com padronização & Redução (\%) \\
\hline Revestimento do parafuso & 10 & 4 & $60 \%$ \\
\hline Revestimento da porca & 10 & 4 & $60 \%$ \\
\hline Material de fabricação (parafuso) & 37 & 20 & $46 \%$ \\
\hline Tamanho, passo, série e classe & 58 & 32 & $45 \%$ \\
\hline Comprimento do parafuso estojo & 137 & 91 & $34 \%$ \\
\hline Material de fabricação (porcas) & 35 & 29 & $17 \%$ \\
\hline Total de combinações viáveis & $\mathbf{4 4 1 4}$ & $\mathbf{2 5 8 3}$ & $\mathbf{4 1 \%}$ \\
\hline
\end{tabular}

Tabela 3. Demonstrativo de redução da variedade com a padronização

Observa-se neste trabalho que existe uma gama considerável de materiais de fabricação para estojos. Dos 37 tipos diferentes de materiais mais utilizados no mercado, percebe-se que, conforme Tabela 1, ao determinar três materiais de parafusos como principais, foi possível obter 20 materiais diferentes que atendem e substituem tecnicamente todas as exigências de uma instalação, para as respectivas aplicações, representando uma redução de $46 \%$.

Já para a característica do material de fabricação das porcas, não foi possível alcançar uma perda relevante da variedade, pois a especificação depende também da classificação do material do parafuso, resultando em apenas $17 \%$.

O comprimento do parafuso foi o atributo mais crítico a ser quantificado e avaliado. Entretanto, foi possível determinar os ranges conforme catálogos comerciais, alcançando um índice de 34\% de redução. 
Por fim, foi possível ajustar o tamanho (DN), apenas corrigindo o passo, série e classe conforme o diâmetro especificado. Portanto, de 58 possibilidades foi possível a utilização de somente 32 dimensões distintas.

\section{I CONCLUSÃO}

Através do objeto de estudo e a proposta de metodologia aqui apresentados, constatou-se que é possível reduzir $41 \%$ da variedade de descritivos comercialmente viáveis de parafuso estojo, fixando-se as características essenciais para definição do material.

Analisando a demanda e o ramo da companhia, além de padronizar, permitisse catalogar de forma estruturada e sistemática os materiais, garantindo assim a uniformização dos dados e a qualidade da informação, consequentemente na restrição da diversidade de especificações.

Conforme o referencial e a metodologia aplicada, conclui-se que uma empresa que pretende introduzir inovações ou melhorias na gestão de materiais, visando economia na cadeia de suprimento de bens, deve padronizar suas especificações técnicas de modo a atender às necessidades das partes interessadas, pois segundo Ching (1999), 1\% de redução do custo de suprimento, proporciona $10 \%$ de aumento do lucro.

\section{REFERÊNCIAS}

AMERICAN SOCIETY FOR TESTING AND MATERIALS. ASTM 193 - Standard specification for alloy-steel and stainless steel bolting for high temperature or high pressure service and other special purpose applications. [S.I.], p. 13. 2017.

AMERICAN SOCIETY FOR TESTING AND MATERIALS. ASTM 194 - Standard Specification for carbon steel, alloy steel, and stainless steel nuts for bolts for high pressure or high temperature service, or both. [S.I.], p. 12. 2018.

AMERICAN SOCIETY FOR TESTING AND MATERIALS. ASTM A320 - Standard specification for alloy-steel and stainless steel bolting for low-temperature service. [S.I.], p. 8. 2018.

AMERICAN SOCIETY FOR TESTING AND MATERIALS. ASTM B841 - Standard Ssecification for electrodeposited coatings of zinc nickel alloy deposits. [S.I.], p. 5. 2018.

CHING, H. Y. Gestão de estoques na cadeia de logística integrada. $1^{2}$. ed. [S.I.]: Atlas, 1999.

CHOPRA, S.; MEINDL, P. Gerenciamento na cadeia de suprimentos - Estratégia, planejamento e operação. $1^{\text {a }}$. ed. [S.I.]: Prentice Hall, 2003.

DEUS, T. T. A Importância de se estabelecer procedimentos de controle de estoque na tree computação. Fundação Pedro Leopoldo, Agosto 2013. Disponivel em: <http://www.fpl.edu.br/2018/ media/pdfs/graduacao/tcc/2013/tcc_tamar_teles_de_deus_2013.pdf>. Acesso em: 27 Março 2019.

DIAS, M. A. P. Administração de materiais - princípios, conceitos e gestão. [S.I.]: Atlas, 2009. 
GONÇALVES, P. S. Administração de materiais. [S.I.]: Elsevier, 2013.

NOGUEIRA, E. A.; GOMES, A. J. S. Classificação de materiais suprimento método \& técnica. [S.I.]: Copyright, 1984.

SANTOS, C. N. A Padronização Descritiva de Materiais (PDM) e sua Importância como Ferramenta de Maximização de Processos e Atividades Empresariais. Avm, 2012. Disponivel em: <http://www.avm. edu.br/docpdf/monografias_publicadas/K220513.pdf>. Acesso em: 16 Fevereiro 2019.

TELLES, P. C. S. Tubulações industriais - materiais, projetos, montagem. [S.I.]: LTC, 2012. 


\section{A GENERALIZED INTEGRAL TRANSFORMED TECHNIQUE: LITERATURE REVIEW AND COMPARATIVE RESULTS WITH FINITE VOLUME METHOD}

Data de aceite: 01/10/2020

\section{Hildson Rodrigues de Queiroz}

Petróleo Brasileiro S.A - PETROBRAS

UNISUAM - Engenharias

Rio de Janeiro - RJ

Flavio Maldonado Bentes

FUNDACENTRO - Fundação Jorge Duprat

Figueiredo

UNISUAM - Engenharias

Rio de Janeiro - RJ

Marcelo de Jesus Rodrigues da Nóbrega Centro Federal de Educação Tecnológica Celso

Suckow

Universidade Santa Úrsula - Coordenação das Engenharias

Rio de Janeiro - RJ

Fabiano Battemarco da Silva Martins

Universidade Santa Úrsula Unigama - Centro Universitário Gama e Souza

Rio de Janeiro - RJ

ABSTRACT: This work aims to carry out a brief review of the literature on the use of the Generalized Integral Transform Technique (GITT) in diffusion-advection problems in engineering and to analyze two works that compare the solution of a problem via GITT and the Finite Element Method (FVM). A bibliographic survey was carried out in the Google Scholar and Science Direct databases, in conference proceedings and periodicals. During the bibliographic survey phase, care was taken to research whether there was any work in the literature like the one proposed in this article, but it was not found. GITT's step by step will be presented, through the mathematical development of an engineering problem present in one of the selected articles. A brief review of the literature on the technique over the past 25 years, with a summary of 24 papers, shows the range of applications of the technique in different areas. After reviewing the literature, comparative results are presented between the solutions via GITT and FVM, two studies analyzed, showing the effectiveness of GITT and a higher rate of convergence. It is concluded that GITT has been shown to be a powerful tool in solving diffusionadvection problems, in addition to providing low computational cost, when compared to FVM.

KEYWORDS: Generalized Integral Transform Technique, Diffusion-advection, Convergence Rate, Literature Review.

\section{I INTRODUCTION}

The use of GITT in diffusion-advection problems in engineering has grown in importance over the last two decades, it is understood that there is a gap in the literature in presenting a work that, in a clear and objective way, makes a compilation of works that demonstrate the importance and effectiveness of this hybrid analytical-numerical methodology for resolving EDP. Thus, this work was organized to initially search the literature for a GITT review paper, which was not found. Then, a search was made for jobs in the engineering area that used GITT 
to solve the problem addressed. After a careful choice of works, which will be detailed in the methodology used, two works were chosen to show the development of GITT and to analyze the solutions obtained through GITT and FVM. After the Methods section, a summary of twenty-five articles is presented, whose solutions to the engineering problems addressed were implemented via GITT. To compare the techniques of GITT and FVM, in the results section, the data obtained in the two studies whose techniques were compared are presented. The main contribution of this article is to provide a summary of a collection of works, in different areas of engineering, whose solutions were implemented via GITT, demonstrating its importance in the analytical-numerical solution of applications in diffusionadvection problems. Corroborating this contribution, the results of two comparative studies between GITT and FVM are demonstrated, in which the solution via GITT is in line with the results found in the literature.

\section{I METHODS}

The main objective of this work is to provide the academic engineering community with a brief compendium on the application of GITT in the solution of diffusion-convection problems, mainly in the areas of Fluid Dynamics and Heat and Mass Transfer. As a way of showing the effectiveness of GITT, two papers are presented that compare the solutions to their problems via GITT and FVM. To fulfill the objective, a rigorous bibliographic survey on the topic was carried out, as shown below.

\subsection{Literature Review}

The bibliographical survey was carried out in the Science Direct and Google Scholar databases, in the period between 1993 and 2019. Articles that did not meet this period were excluded. The keyword used in the research was "Generalized Integral Transform Technique". In the Science Direct database, 253 results were found and in Google Scholar 220 results. The first exclusion criterion was the year of publication of the article, as already mentioned. The second criterion was the preference for works related to mechanical engineering. However, articles in the fields of environmental engineering and oil were also included. Globally, the problems addressed are related to the areas of fluid mechanics, heat transfer, dispersion of pollutants and contaminants and flow in porous media (petroleum reservoir). At the end, twenty-nine papers were selected, with nineteen articles published in journals, two master's dissertations and eight papers published in conference proceedings.

\subsection{The Generalized Integral Transformed Technique}

Generalized Integral Transform Technique (GITT) is a hybrid analytical-numerical technique for solving Partial Differential Equations (PDE) applied to convective-diffusive problems and is an extension of the classic transform, where it is used in purely diffusive problems of heat and mass, according to Cotta [9]. The technique of the classical integral 
transform, in general, transforms the PDE into an infinite system decoupled from Ordinary Differential Equations (ODE) that can be easily solved. However, when the classical approach is applied to convective-diffusive problems, the infinite system of transformed ODE is coupled, making the classical integral transform not to be used for this class of problems.

Miyagawa [18] mentions in his work that GITT differs from other numerical methods used to solve strongly non-linear and coupled problems, because there is no need to discretize the domain for meshing, which requires a lower computational cost. In the same work, the author summarized the steps for the application of GITT, as shown below.

i. Definition of the auxiliary problem, based, for example, on the diffusive terms of the original formulation.

ii. Solving the auxiliary problem and obtaining the self-functions, eigenvalues, norms, and orthogonality properties.

iii. Development of the transformed-inverse pair.

iv. Integral transformation of the partial differential problem into a system of coupled algebraic or ordinary differential equations or yet another partial differential equation.

v. Truncation of the infinite system and numerical solution of the resulting differential system to obtain the transformed potentials.

vi. Obtaining the original potential, using the inversion formula.

\subsection{Comparative Results GITT x FVM}

Next, an analysis will be made of two studies in which the central problem was solved via GITT and the Finite Volume Method (FVM). One of the works used a commercial CFD software called FLUENT, which is based on FVM. In this part of the work, the mathematical development of the models used by the authors will be presented, as well as the results obtained by the applied methodologies, verifying agreement with the model validated in the literature and comparing the convergence rates.

2.3.1 Immiscible displacement of oil by water injection in the reservoir Petroleum Engineering (Dias et al. [13])

The first work used to compare GITT with FVM (using the CFD Fluent computational package) is by Dias et al. [13], which deals with the problem of water injection in oil reservoirs (porous medium) to promote immiscible displacement of the oil, allowing the reservoir's recovery factor to increase, and maintaining its static pressure. The work uses two formulations used in reservoir engineering, the differential saturation equation, obtained through the application of Darcy's Law and the continuity equation for each phase, and the mixture theory equation applied to fluid flow in porous media. GITT is used to solve the saturation equation, while the solution of the mixing theory is reached numerically using the 
computational code Fluent, whose basis is the Finite Volume Method. Only the development of the mathematical formulation related to GITT will be presented and, however the results of the formulation via FVM (mixing theory) will be shown for comparison purposes.

The following nomenclature was used by Dias et al. [13]:

$\begin{array}{lc}\mathrm{x} & \text { Coordinates } \\ \mathrm{S}_{\mathrm{w}}, \mathrm{S}_{\mathrm{o}} & \text { Water and oil saturations } \\ \boldsymbol{v}_{s w}, \boldsymbol{v}_{s o} & \text { Water and oil superficial velocity } \\ \boldsymbol{v}_{s t} & \text { Total superficial velocity } \\ \mathrm{K} & \text { Absolute permeability } \\ \mathrm{k}_{\mathrm{w}}, \mathrm{k}_{\circ} & \text { Water and oil relative permeability } \\ \mathrm{p}_{\mathrm{w}}, \mathrm{p}_{\mathrm{o}} & \text { Water and oil mass densities } \\ \mu_{\mathrm{w}}, \mu_{\circ} & \text { Water and oil viscosities } \\ \mathrm{p}_{\mathrm{w}}, \mathrm{p}_{\mathrm{o}} & \text { Water and oil pressures } \\ \mathrm{f}_{\mathrm{w}} & \text { Fractional flow function } \\ \Phi & \text { Porosity } \\ \boldsymbol{v}_{i} & \text { Constituent velocity vector } \\ \mathrm{S}_{\mathrm{F}} & \text { Filter function } \\ \mathrm{S}_{\mathrm{H}} & \text { Filtered potential } \\ \mathrm{S}_{\mathrm{wi}} & \text { Connate water saturation } \\ \mathrm{S}_{\mathrm{wo}} & \text { Residual oil saturation } \\ \mathrm{H} & \text { Diffusion parameter } \\ \mathrm{F}(\mathrm{x}) & \text { Source term of the equation } \\ \Psi, \mathrm{h} & \text { Eigenfunctions and eigenvalues } \\ \mathrm{N} & \text { Norm } \\ \mathrm{a}, \mathrm{b} & \text { Linearization coefficients } \\ A, B, C, D & \end{array}$

\subsubsection{Problem Formulation}

\section{a) Differential Saturation Equation}

Darcy's Law for multiphase flow in the porous medium is given, for each phase and disregarding the gravitational effects, by equation 1 .

$$
\boldsymbol{v}_{S w}=-\frac{K k_{w}}{\mu_{w}} \nabla p_{w} ; \quad \boldsymbol{v}_{s o}=-\frac{K k_{o}}{\mu_{o}} \nabla p_{o}
$$

here $v_{s w}$, and $v_{\text {so }}$ are the superficial velocities for the water and oil, respectively, $\mu_{w}$ and $\mu_{o}$ are the respective viscosities. $k_{w}$ and $k_{o}$ are the relative permeabilities for flow for each of the two fluids and $\mathrm{K}$ is the absolute permeability of the medium.

Conservation of the mass for the water and oil phases in the porous medium is given by equation 2 . 


$$
\frac{\partial\left(\phi \rho_{w} S_{w}\right)}{\partial t}+\nabla \cdot\left(\rho_{w} \boldsymbol{v}_{s w}\right)=0 ; \quad \frac{\partial\left(\phi \rho_{o} S_{o}\right)}{\partial t}+\nabla \cdot\left(\rho_{o} v_{s o}\right)=0
$$

here $S_{w}$ and $S_{o}$ are the water and oil saturations, $p_{w}$ and $p_{o}$ are water and oil mass densities.

Equation 3 is the differential saturation equation.

$$
\begin{gathered}
\phi \frac{\partial S_{w}(x, t)}{\partial t}+\nabla \cdot\left(v_{s t} f_{w}\left(S_{w}\right)\right) \\
=0
\end{gathered}
$$

where $v_{\mathrm{st}}$ is the total speed, as equation 4.

$\mathrm{v}_{\mathrm{st}}=\mathrm{v}_{\mathrm{sw}}+\mathrm{v}_{\mathrm{so}}$

The one-dimensional differential saturation equation as in equation 5 is called the Buckley-Leverett equation, which is a non-linear hyperbolic transport equation. The BuckleyLeverett Equation represents a simple mathematical model for simulating fluid displacement in porous media, according to Araújo and Márquez [3].

$$
\begin{gathered}
\phi \frac{\partial S_{w}(x, t)}{\partial t}+v_{s t} \frac{d f_{w}\left(S_{w}\right)}{d S_{w}} \frac{\partial S_{w}(x, t)}{\partial x} \\
=0
\end{gathered}
$$

\section{b) Relative Permeability}

The relative permeability curve is responsible for the interaction between the water/ oil phases. Then, the following relative permeability curves were considered, as seen in equation $6 . \mathrm{S}_{\text {ro }}$ is the oil residual saturation. $\mathrm{K}_{\text {romax }}$ and $\mathrm{K}_{\mathrm{rwmax}}$ are the maximum relative permeability to oil and water, respectively.

$$
k_{w}\left(S_{w}\right)=\frac{K_{r w \max }\left(S_{w}-S_{w i}\right)^{n w}}{\left(1-S_{o r}-S_{w i}\right)}, \quad k_{o}\left(S_{w}\right)=\frac{K_{\text {romax }}\left(S_{o r}-S_{w}\right)^{n o}}{\left(1-S_{o r}-S_{w i}\right)}
$$

Another important function, as seen in equation 7, is the fractional flow, responsible for the non-linearity of the Buckley-Leverett equation.

$$
f_{w}\left(S_{w}\right)=\frac{\frac{k_{w}\left(S_{w}\right)}{\mu_{w}}}{\frac{k_{w}\left(S_{w}\right)}{\mu_{w}}+\frac{k_{o}\left(S_{w}\right)}{\mu_{o}}}
$$

The solutions were selected for linear and non-linear relative permeability curves. The linear and non-linear permeability curves are shown below.

The relative permeability curves and the fractional flow function for linear case is showed in Fig. 1. 


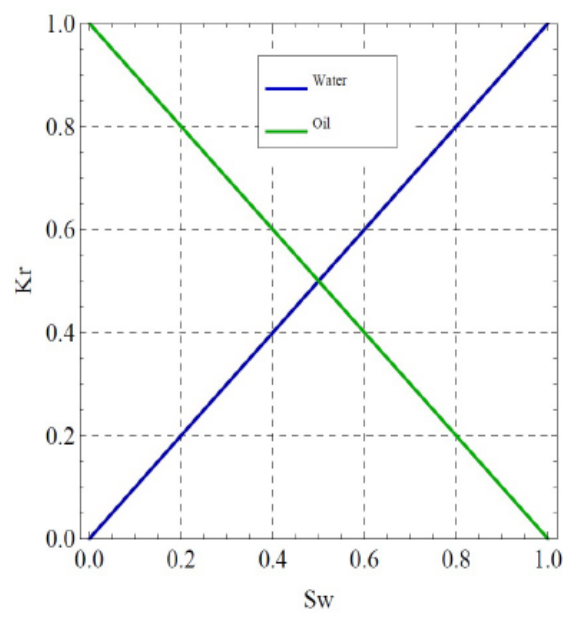

(a) Relative Permeability Curves

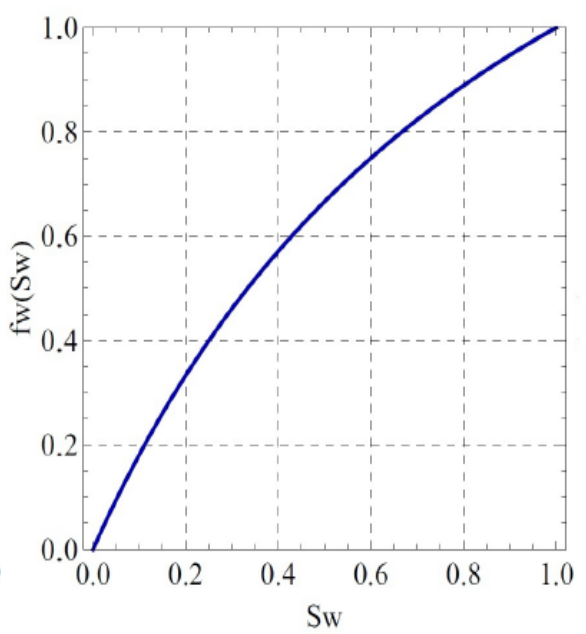

(b) Fractional Flow Function

Figure 1. Linear Permeability Curves.

The relative permeability curves and the fractional flow function for nonlinear case is showed in Fig. 2. This case of relative permeability curves is more common in reservoir simulation.

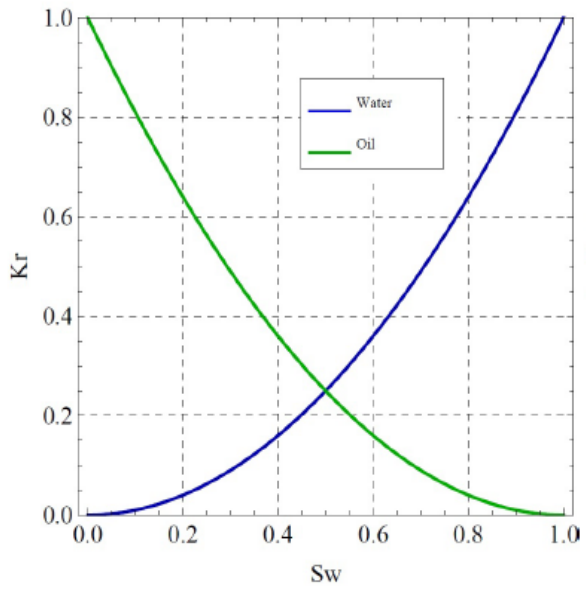

(a) Relative Permeability Curves

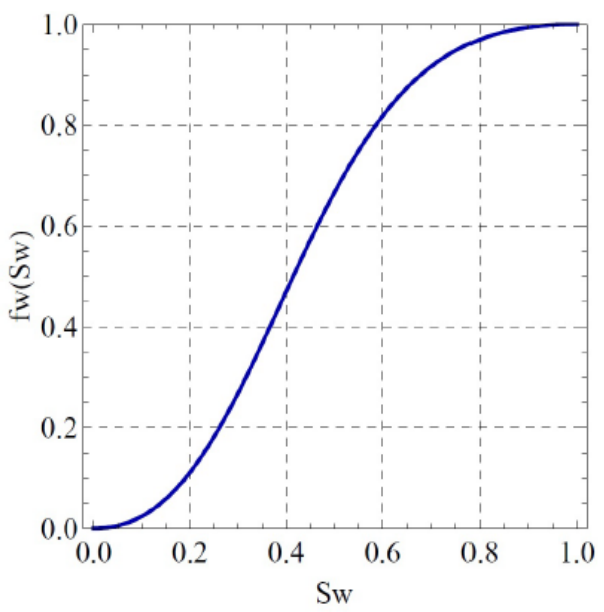

(b) Fractional Flow Function

Figure 2. Non-Linear Permeability Curves. 


\subsubsection{Integral Transform Solution}

To proceed with the integral transformation and obtain an expansion of eigenfunction, a diffusion term is introduced to the Buckley-Leverett equation, in which the diffusive parameter, $H$, will be considered as having a large value, as seen equations in 8 and 9 .

$$
\begin{aligned}
& \phi \frac{\partial S_{w}(x, t)}{\partial t}+v_{s t} \frac{d f_{w}\left(S_{w}\right)}{d S_{w}} \frac{\partial S_{w}(x, t)}{\partial x}-\frac{1}{H} \frac{\partial^{2} S_{w}(x, t)}{\partial x^{2}}=0 ; \\
& \mathrm{S}_{w}(0, \mathrm{t})=1-\mathrm{S}_{\mathrm{or}}, \mathrm{S}_{w}(1, \mathrm{t})=\mathrm{S}_{\text {wirr }}, \mathrm{S}_{w}(\mathrm{x}, 0)=\mathrm{S}_{\text {wirr }}
\end{aligned}
$$

To eliminate non-homogeneous boundary conditions, a filter function is introduced (equations 10).

$$
S_{w}(x, t)=S_{H}(x, t)+S_{F}(x) \text { wich } S_{F}(x)=\left(S_{\text {wirr }}-S_{w o}\right) x+S_{w o}
$$

Applying equation 10 to equations 8 and 9 , we obtain equation 11 .

$$
\begin{aligned}
& \frac{\partial S_{H}}{\partial t}+f_{w}^{\prime}\left(S_{w}\right)\left(\frac{\partial S_{H}}{\partial x}+\frac{\partial S_{F}}{\partial x}\right)-\frac{1}{H} \frac{\partial^{2} S_{H}}{\partial x^{2}}=\frac{1}{H} \frac{\partial^{2} S_{F}}{\partial x^{2}} ; \\
& \mathrm{S}_{w}(0, \mathrm{t})=0-\mathrm{S}_{H}(1, \mathrm{t})=\mathrm{S}_{H}(\mathrm{x}, 0)=\mathrm{S}_{\text {wirr }}-\mathrm{S}_{\mathrm{F}}(\mathrm{x})
\end{aligned}
$$

The eigenfunction expansion solution is based the following transformed-inverse pair:

$$
\begin{aligned}
& \text { Inversion } \longrightarrow \mathrm{S}_{\mathrm{H}}(\mathrm{x}, \mathrm{t})=\sum_{k=1}^{\infty} \frac{\bar{S}_{H k}(t) \Psi_{k}(x)}{N_{k}}, \\
& \text { Transform } \longrightarrow \overline{\mathrm{S}}_{\mathrm{Hk}}(\mathrm{x}, \mathrm{t})=\int_{0}^{1} S_{H}(x, t) \Psi_{k}(x) \mathrm{d} x
\end{aligned}
$$

Where $\Psi_{k}(x)$ are orthogonal solutions of a Sturm-Liouville eigenvalue problem. Dias et al. [13] chose the one-dimensional Helmholtz problem as an auxiliary problem, according to equation 15 .

$$
\Psi "(x)+\lambda^{2} \Psi(x)=0 \quad \Psi(0)=0, \quad \Psi(1)=0
$$

The norms of the eigenfunction, $\Psi_{k}(x)$, are given by:

$$
\mathrm{N}_{\mathrm{k}}=\int_{0}^{1} \Psi_{\mathrm{k}}^{2}(\mathrm{x}) \mathrm{dx}
$$

To obtain the transformed system, the transformation operator (equation 14) is applied in equation 11. After the development of the transformation, we arrive at the transformed system represented by equation 17 . 


$$
\frac{d \bar{S}_{H k}}{d t}+\frac{\lambda_{k}^{2}}{H} \bar{S}_{H k}-\bar{F}_{k}=-\int_{0}^{1} \Psi_{k} f_{w}^{\prime} \frac{\partial S_{F}}{\partial x} \mathrm{~d} x-\int_{0}^{1} \Psi_{k} f_{w}^{\prime} \frac{\partial S_{H}}{\partial x} \mathrm{~d} x
$$

To transform the 2 terms on the right side of the equation, a linear transformation of the function $\mathrm{f}_{\mathrm{w}}$ is used in the subdomain $\left(\mathrm{x}_{\mathrm{q}-1}<\mathrm{x}<\mathrm{x}_{\mathrm{q}}\right)$, so that we got equation 18 .

$$
\int_{0}^{1} f_{w}^{\prime} g\left(S_{H}, x\right) d x=\sum_{q=1}^{q_{\max }} \int_{x_{q-1}}^{x_{q}}\left[a_{q}(t) x+b_{q}(t)\right] g\left(S_{H}, x\right) \mathrm{d} x
$$

Where the coefficients of the linearization are:

$$
a_{q}(t)=\frac{f_{w_{q}}^{\prime}-f_{w_{q-1}}^{\prime}}{x_{q}-x_{q-1}}, \quad b_{q}(t)=\frac{x_{q} f_{w_{q-1}}^{\prime}-x_{q-1} f_{w_{q}}^{\prime}}{x_{q}-x_{q-1}}
$$

Applying the linearization (equation 18) in equation 17, we obtain the transformed system represented in equation 20.

$$
\begin{aligned}
& \frac{d \bar{S}_{H k}}{d t}+\frac{\lambda_{k}^{2}}{H} \bar{S}_{H k}-\bar{F}_{k} \\
& =-\sum_{q=1}^{q_{\max }}\left(f_{w_{q}}^{\prime}-f_{w_{q-1}}^{\prime}\right) A_{q k}-\sum_{q=1}^{q_{\max }}\left(x_{q} f_{w_{q-1}}^{\prime}-x_{q-1} f_{w_{q}}^{\prime}\right) B_{q k} \\
& -\sum_{q=1}^{q_{\max }} \sum_{i=1}^{\infty}\left(f_{w_{q}}^{\prime}-f_{w_{q-1}}^{\prime}\right) C_{i q k} \bar{S}_{H i} \\
& -\sum_{q=1}^{q_{\max }} \sum_{i=1}^{\infty}\left(x_{q} f_{w_{q-1}}^{\prime}-x_{q-1} f_{w_{q}}^{\prime}\right) D_{i q k} \bar{S}_{H i}
\end{aligned}
$$

Where

$$
\begin{aligned}
& f_{w_{q}}^{\prime}=f_{w_{q}}^{\prime}\left(S_{w}, x_{q}\right)=f_{w_{q}}^{\prime}\left(S_{H}+S_{F}, x_{q}\right)=f_{w_{q}}^{\prime}\left(\sum_{k=1}^{\infty} \frac{\bar{S}_{H k} \Psi_{k}}{N_{k}}+S_{F}, x_{q}\right) \\
& f_{w_{q-1}}^{\prime}=f_{w_{q-1}}^{\prime}\left(S_{w}, x_{q-1}\right)=f_{w_{q-1}}^{\prime}\left(S_{H}+S_{F}, x_{q-1}\right)=f_{w_{q-1}}^{\prime}\left(\sum_{k=1}^{\infty} \frac{\bar{S}_{H k} \Psi_{k}}{N_{k}}+S_{F}, x_{q-1}\right) \\
& A_{q k}=\frac{1}{x_{q}-x_{q-1}} \int_{x_{q-1}}^{x_{q}} x \frac{d \bar{S}_{F}}{d x} \Psi_{k} \mathrm{~d} x, \quad B_{q k}=\frac{1}{x_{q}-x_{q-1}} \int_{x_{q-1}}^{x_{q}} \frac{d \bar{S}_{F}}{d x} \Psi_{k} \mathrm{~d} x \\
& C_{i q k}=\frac{1}{N_{i}\left(x_{q}-x_{q-1}\right)} \int_{x_{q-1}}^{x_{q}} x \Psi_{k} \Psi_{i}^{\prime} \mathrm{d} x, \quad C_{i q k}=\frac{1}{N_{i}\left(x_{q}-x_{q-1}\right)} \int_{x_{q-1}}^{x_{q}} \Psi_{k} \Psi_{i}^{\prime} \mathrm{d} x
\end{aligned}
$$

The transformation of the initial condition leads to:

$$
\bar{S}_{H k}(0)=\int_{0}^{1}\left(S_{w i r r}-S_{F}\right) \Psi_{k}(x) \mathrm{d} x
$$


The solution of the transformed potentials is obtained through the solution of the infinite ODE system, equation 20. Dias et al. [13] used the Mathematica software, using the NDSolve routine, and to arrive at the solution of the original potential, the inversion equation, equation 13 , is used.

\subsubsection{Comparative results}

\section{a) Results for Linear Permeability Curve}

Figures 3 and 4 show comparisons of the results obtained by GITT, Fluent and the analytical solution.

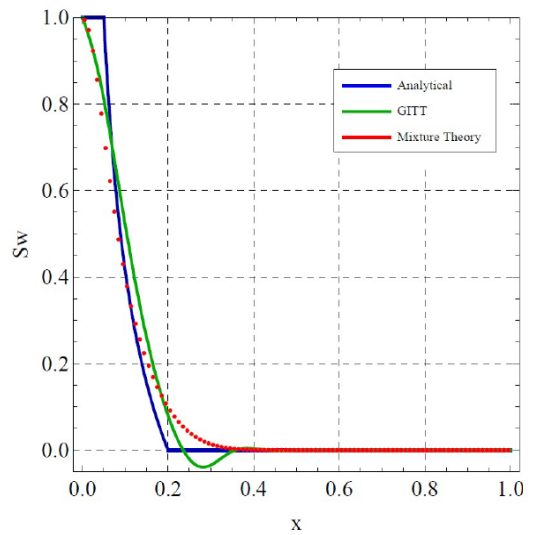

(a) Dimensionless Time $=0.1$

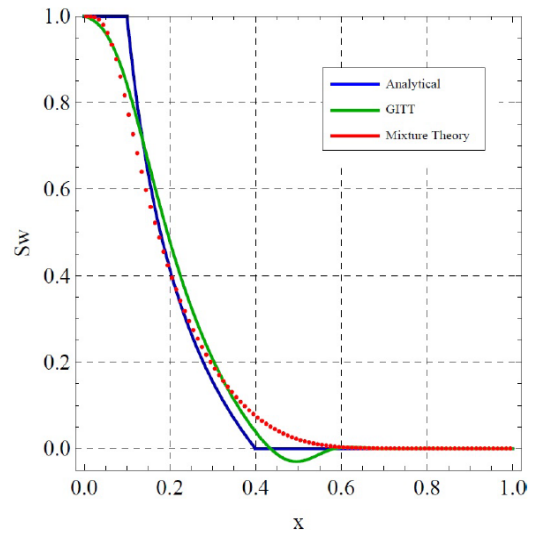

(b) Dimensionless Time $=0.2$

Figure 3. Results for the Linear Permeability Curve.

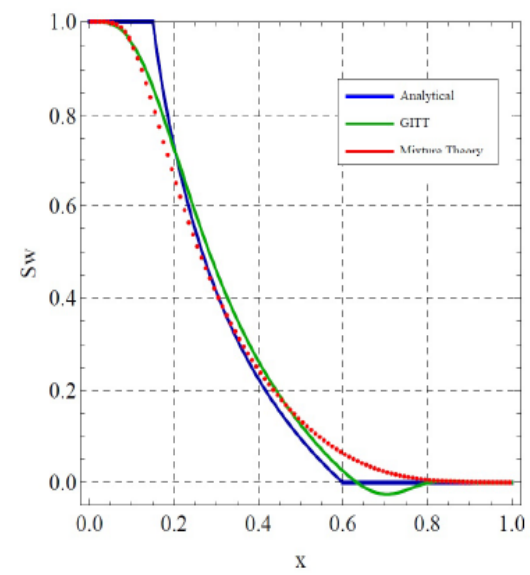

(a) Dimensionless Time $=0.3$

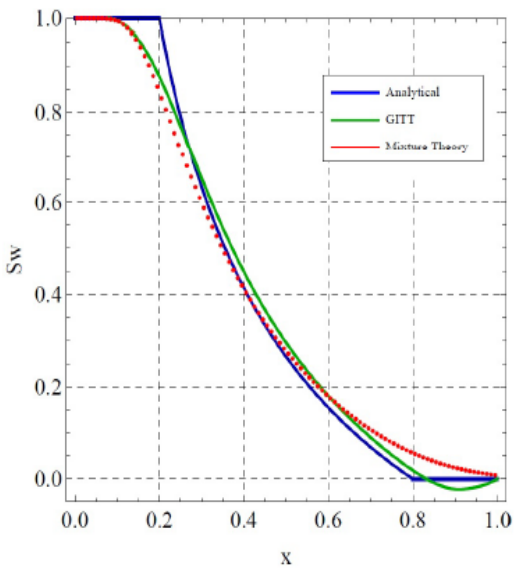

(b) Dimensionless Time $=0.4$

Figure 4. Results for the Linear Permeability Curve. 
It can be seen from the above comparative curves that the numerical solutions converge to the analytical solution, despite some small detachments at certain points and regions of the analysis.

\section{b) Results for Nonlinear Permeability Curve}

Figures 5 and 6 show comparisons of the results obtained by GITT, Fluent and the analytical solution.

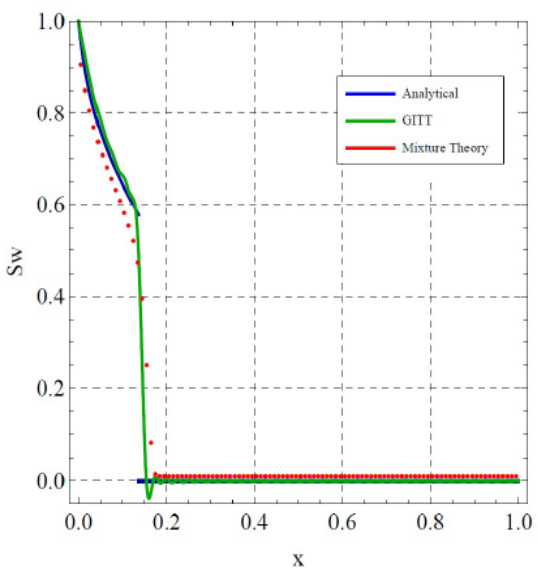

(a) Dimensionless Time $=0.1$

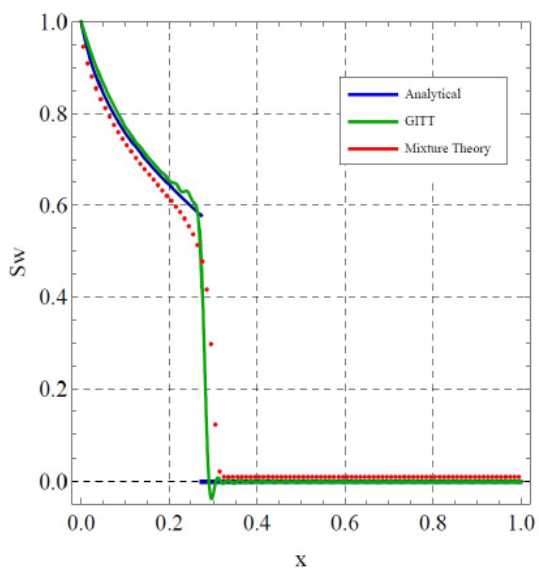

(b) Dimensionless Time $=0.2$

Figure 5. Results for the Nonlinear Permeability Curve.

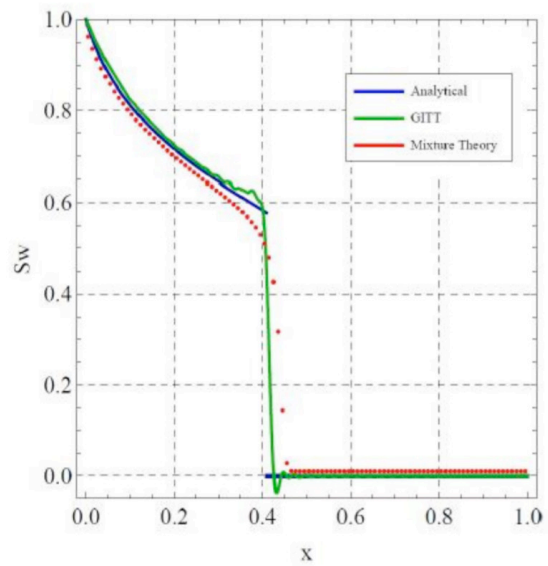

(a) Dimensionless Time $=0.3$

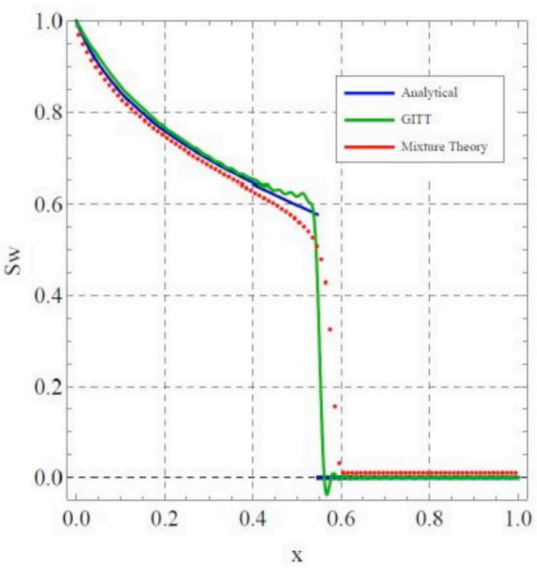

(b) Dimensionless Time $=0.4$

Figure 6. Results for the Nonlinear Permeability Curve. 
The behavior of the simulated curves is well adjusted to the analytical solution, as well as to the linear permeability curve. In the work in question, the results of GITT and the Fluent code were very well adjusted to the analytical solution, showing the good accuracy of the methodologies studied.

\subsubsection{Laminar Flow between Parallel Flat Plates in Thermal Development}

Queiroz et al. [25] compared two solution methodologies for convection-diffusion problems: The Generalized Integral Transform Technique and the Finite Volume Method. A problem was selected to illustrate the two approaches, laminar flow in thermal development between parallel plates. The present study evaluated the effect of the variation in the number of Péclet, based on the transverse length, on the convergence of the two techniques. The flow was considered hydrodynamically developed, with the Hagen-Poiseuille velocity profile, however, results for simplified slug-flow cases were also presented. The advantages and disadvantages of each method are presented, where the results indicate that, in general, the Integral Transform Technique presents a better convergence rate.

The following nomenclature was used by Queiroz et al. [25]:

$\begin{array}{lc}\mathrm{x}, \mathrm{y} & \text { Cartesian coordinates } \\ \mathrm{N} & \text { norm of eigenfunctions } \\ \mathrm{Nu}_{H} & \text { Nusselt Number } \\ \mathrm{Pe}_{H} & \text { Péclet Number } \\ \mathrm{T}_{\mathrm{s}} & \text { surface temperature } \\ \mathrm{T}_{0} & \text { entrance temperature } \\ \mathrm{T}_{\mathrm{m}} & \text { Bulk or average mixing temperature } \\ \mathrm{u} & \text { velocity component in x-direction } \\ \bar{u} & \text { average velocity in x-direction } \\ \mathrm{Y}_{\mathrm{n}} & \text { eigenfunctions } \\ \mathrm{a} & \text { thermal diffusivity } \\ \bar{\varepsilon}, \mathrm{n} & \text { dimensionless coordinates } \\ \Phi & \text { arbritary function } \\ \lambda_{\mathrm{n}} & \text { eigenvalues } \\ \Theta & \text { dimensionless temperature } \\ \bar{\Theta} & \text { transformed dimensionless temperature } \\ \bar{\varepsilon}_{\max } & \text { dimensionless channel length }\end{array}$

\subsubsection{Problem formulation}

As in the previous work, mathematical model of the studied phenomenon and the mathematical development of the GITT will also be shown. Equation 26 is the government equation with its respective boundary conditions (equation 27 ). 


$$
\begin{aligned}
& \frac{1}{2} u^{*} \frac{\partial \theta}{\partial \xi}=P e_{H}^{-2} \frac{\partial^{2} \theta}{\partial \xi^{2}}+\frac{\partial^{2} \theta}{\partial \eta^{2}}, \quad 0 \leq \xi \leq \infty \text { e } 0 \leq \eta \leq 1 \\
& \theta(\xi, 1)=0, \quad\left(\frac{\partial \theta}{\partial \eta}\right)_{\eta=0}=0, \quad \theta(0, \eta)=1, \quad\left(\frac{\partial \theta}{\partial \xi}\right)_{\xi \rightarrow \infty}=0,
\end{aligned}
$$

The dimensionless quantities are given by equations 28 :

$$
\theta=\frac{T-T_{0}}{T_{\text {in }}-T_{0}}, \quad \eta=\frac{y}{H / 2}, \quad \xi=\frac{x}{L}, \quad \mathrm{Pe}_{H}=\bar{u} \frac{H}{\alpha},
$$

The dimensionless speed profile is given by the Hagen-Poiseuille profile, as equation 21.

$$
u^{*}=\frac{u}{\bar{u}}=\frac{3}{2}\left(1-\eta^{2}\right)
$$

The Nusselt number in terms of the dimensionless variables is given by equation 30 .

$$
N u_{D_{H}}=\frac{-4(\partial \theta / \partial \eta)_{\eta=1}}{\int_{0}^{1} u^{*} \theta \mathrm{d} \eta}
$$

The solution of the problem is started by defining the transformation pair (equations 31 and 32):

$$
\begin{aligned}
& \text { Inversion } \longrightarrow \theta(\xi, \eta)=\sum_{n=1}^{\infty} \frac{\bar{\theta}_{n}(\xi) \mathrm{Y}_{n}(\eta)}{N\left(\lambda_{n}\right)}, \\
& \text { Transform } \longrightarrow \bar{\theta}_{n}(\xi)=\int_{0}^{1} \theta(\xi, \eta) \mathrm{Y}_{n}(\eta) \mathrm{d} \eta
\end{aligned}
$$

where $Y_{n}$ are orthogonal solutions to a Sturm-Liouville eigenvalue problem. For the convection-diffusion problem considered in the work of Queiroz et al. [25], the following eigenvalue problem is selected (equations 33 and 34 ):

$$
Y_{n}^{\prime \prime}(\eta)+\lambda_{n}^{2} Y_{n}(\eta)=0, \text { for } 0 \leq \eta \leq 1, Y^{\prime}(0)=0, Y(1)=0
$$

The norms of the $Y_{n}$ are given by:

$$
N\left(\lambda_{n}\right)=\int_{0}{ }^{1} Y_{n}{ }^{2}(\eta) d \eta
$$

The transformation of the given problem is accomplished by multiplying equation 26 by $Y_{n}$, integrating within $0 \leq \eta \leq 1$, and applying the inversion formula (31) to the nontransformable terms. This process yields (equations 35 and 36 ):

$$
\mathrm{Pe}_{H}^{-2} \bar{\theta}_{n}^{\prime \prime}(\xi)-\frac{1}{2} \sum_{m=1}^{\infty} A_{n, m} \bar{\theta}_{m}^{\prime}(\xi)-\lambda_{n}^{2} \bar{\theta}_{n}(\xi)=0,
$$


with the boundary conditions

$$
\bar{\theta}_{n}(0)=b_{n}=\int_{0}^{1} Y_{n}(\eta) \mathrm{d} \eta \quad \text { and } \quad \lim _{\xi \rightarrow \infty} \bar{\theta}_{n}^{\prime}(\xi)=0,
$$

where the $A_{n, m}$ coefficients are given by equation 37 :

$$
A_{n, m}=\frac{1}{N\left(\lambda_{m}\right)} \int_{0}^{1} u^{*}(\eta) Y_{n}(\eta) Y_{m}(\eta) \mathrm{d} \eta
$$

For the flow situation with Hagen-Poiseuille velocity profile, equations 35 and 36 can be written in the following matrix form (equations 38 and 39 ):

$$
\overline{\boldsymbol{\theta}}^{\prime \prime}(\xi)-\boldsymbol{B} \overline{\boldsymbol{\theta}}^{\prime}(\xi)-\boldsymbol{D} \overline{\boldsymbol{\theta}}(\xi)=\mathbf{0}, \quad \overline{\boldsymbol{\theta}}(0)=\boldsymbol{b}, \quad \overline{\boldsymbol{\theta}}^{\prime}\left(\xi_{\max }\right)=\mathbf{0}
$$

in which the coefficients of $\boldsymbol{b}$ are given by equation 38 and matrices $\boldsymbol{B}$ and $\boldsymbol{D}$ are given by equations 39 :

$$
B_{n, m}=\frac{1}{2} \mathrm{Pe}_{H}^{2} A_{n, m}, \quad D_{n, n}=\mathrm{Pe}_{H}^{2} \lambda_{n}^{2} \delta_{n, m},
$$

Where $\delta_{n, m}$ is the Kronecker delta. The system above (equation 38) can be converted to a first order initial-value problem if the boundary condition at $\delta_{\max }$ is replaced by an initial condition and a new variable is introduced (equation 40 and 41):

$$
\bar{\theta}^{\prime}(0)=p, \quad \bar{\theta}^{\prime}(\xi)=\bar{\phi}(\xi),
$$

yielding

$$
\frac{\mathrm{d}}{\mathrm{d} \xi}\left\{\frac{\bar{\phi}}{\bar{\theta}}\right\}=\left(\begin{array}{ll}
\boldsymbol{B} & \boldsymbol{D} \\
\boldsymbol{I} & \mathbf{0}
\end{array}\right)\left\{\frac{\bar{\phi}}{\bar{\theta}}\right\}
$$

Where $\boldsymbol{I}$ is the identity matrix and $\mathbf{0}$ is a zero matrix.

\subsubsection{Comparative results}

The comparative results are presented in terms of the Nusselt Number, varying the number of Péclet and the position from the channel entrance. 


\begin{tabular}{cc|cccc|cc|cccc}
\multicolumn{9}{c}{$\mathrm{Pe}_{H}=10$} & \multicolumn{9}{c}{$\mathrm{Pe}_{H}=1$} \\
\hline$n_{\max }$ & $\mathrm{WP}$ & $\xi=0.001$ & $\xi=0.01$ & $\xi=0.1$ & $\xi=1$ & $n_{\max }$ & $\mathrm{WP}$ & $\xi=0.001$ & $\xi=0.01$ & $\xi=0.1$ & $\xi=1$ \\
\hline 5 & 100 & 37.6242 & 23.5100 & 8.15700 & 7.74044 & 5 & 100 & 39.7508 & 37.5555 & 23.1993 & 8.45041 \\
10 & 200 & 69.5288 & 27.7774 & 8.14983 & 7.73986 & 10 & 100 & 78.8666 & 69.6035 & 27.9173 & 8.45012 \\
20 & 300 & 120.003 & 28.7805 & 8.14897 & 7.73982 & 20 & 100 & 155.286 & 120.397 & 29.0950 & 8.45011 \\
30 & 500 & 156.839 & 28.8167 & 8.14889 & 7.73982 & 30 & 100 & 229.341 & 157.494 & 29.1452 & 8.45010 \\
40 & 600 & 183.733 & 28.8168 & 8.14887 & 7.73982 & 40 & 100 & 301.107 & 184.589 & 29.1472 & 8.45010 \\
50 & 700 & 203.372 & 28.8164 & 8.14886 & - & 50 & 100 & 370.653 & 204.379 & 29.1472 & 8.45010 \\
60 & 800 & 217.714 & 28.8162 & 8.14886 & - & 60 & 100 & 438.048 & 218.833 & 29.1472 & 8.45010 \\
70 & 1000 & 228.188 & 28.8161 & - & - & 70 & 100 & 503.358 & 229.390 & 29.1472 & 8.45010 \\
80 & 1100 & 235.837 & 28.8160 & - & - & 80 & 200 & 566.649 & 237.101 & 29.1472 & 8.45010 \\
90 & 1300 & 241.424 & 28.8160 & - & - & 90 & 200 & 627.982 & 242.733 & 29.1472 & 8.45010 \\
100 & 1400 & 245.504 & 28.8160 & - & - & 100 & 200 & 687.418 & 246.847 & 29.1472 & 8.45010 \\
110 & 1500 & 248.483 & - & - & - & 110 & 200 & 745.016 & 249.851 & 29.1472 & 8.45010 \\
120 & 1700 & 250.660 & - & - & - & 120 & 200 & 800.833 & 252.046 & - & - \\
130 & 1800 & 252.249 & - & - & - & 130 & 200 & 854.923 & 253.649 & - & - \\
140 & 1900 & 253.410 & - & - & - & 140 & 200 & 907.341 & 254.820 & - & - \\
150 & 2100 & 254.258 & - & - & - & 150 & 300 & 958.137 & 255.675 & - & - \\
160 & 2200 & 254.877 & - & - & - & 200 & 300 & 1189.50 & 257.510 & - & - \\
170 & 2300 & 255.329 & - & - & - & 250 & 400 & 1387.24 & 257.891 & - & - \\
180 & 2500 & 255.659 & - & - & - & 300 & 500 & 1556.23 & 257.970 & - & -
\end{tabular}

Table 1. Nusselt numbers for Hagen-Poiseuille (GITT).

\begin{tabular}{|c|c|c|c|c|c|c|c|c|c|c|c|}
\hline \multicolumn{6}{|c|}{$\mathrm{Pe}_{H}=10$} & \multicolumn{6}{|c|}{$\mathrm{Pe}_{H}=1$} \\
\hline$I$ & $J$ & $\xi=0.001$ & $\xi=0.01$ & $\xi=0.1$ & $\xi=1$ & $I$ & $J$ & $\xi=0.001$ & $\xi=0.01$ & $\xi=0.1$ & $\xi=1$ \\
\hline 12 & 12 & 142.762 & 107.173 & -20.8444 & 7.73673 & 12 & 12 & 144.438 & 123.545 & 30.9689 & 8.45042 \\
\hline 12 & 25 & 297.397 & 219.275 & -57.1762 & 7.75869 & 12 & 25 & 298.694 & 233.484 & 4.57372 & 8.43917 \\
\hline 12 & 50 & 594.589 & 434.854 & -126.822 & 7.76699 & 12 & 50 & 594.554 & 439.571 & -48.4931 & 8.43693 \\
\hline 12 & 100 & 1188.88 & 866.008 & -266.010 & 7.77077 & 12 & 100 & 1186.24 & 852.247 & -151.747 & 8.43643 \\
\hline 12 & 200 & 2377.44 & 1728.32 & -544.336 & 7.77431 & 12 & 200 & 2369.72 & 1679.08 & -355.683 & 8.43637 \\
\hline 12 & 400 & 4754.48 & 3452.93 & -1100.96 & 7.77433 & 12 & 400 & 4736.78 & 3333.82 & -762.009 & 8.43634 \\
\hline 25 & 12 & 138.154 & 70.5440 & 8.25530 & 7.77968 & 25 & 12 & 144.190 & 122.079 & 38.4667 & 8.46242 \\
\hline 25 & 25 & 286.594 & 133.459 & 8.25791 & 7.79041 & 25 & 25 & 295.355 & 208.840 & 32.7172 & 8.45054 \\
\hline 25 & 50 & 571.951 & 255.049 & 8.25796 & 7.79382 & 25 & 50 & 580.491 & 333.474 & 29.8808 & 8.44809 \\
\hline 25 & 100 & 1142.62 & 498.577 & 8.25787 & 7.79521 & 25 & 100 & 8.14 & 563.546 & 29.2981 & 8.44750 \\
\hline 25 & 200 & 2283.95 & 985.823 & 8.25783 & 7.79638 & 25 & 200 & 3.56 & 1025.35 & 29.1925 & 8.44737 \\
\hline 25 & 400 & 4566.56 & 1960.41 & 8.25782 & 7.79640 & 25 & 400 & 4555.12 & 1954.67 & 29.1697 & 8.44734 \\
\hline 50 & 12 & 131.320 & 33.5192 & 8.16864 & 7.77186 & 50 & 12 & 287 & 123.483 & 38.7984 & 8.46474 \\
\hline 50 & 25 & & 32.1 & & 7.77924 & 50 & 25 & & & & 8.45274 \\
\hline 50 & 50 & & 30.9 & 8.17 & 7.78115 & 50 & 50 & & & & 8.45025 \\
\hline 50 & 100 & 99 & 30.2 & 8.17 & 7.78 & 50 & 100 & & & 280 & 8.44964 \\
\hline 50 & 200 & & 29.8 & 3 & 7.78 & 50 & 200 & & & & 8.44949 \\
\hline 50 & 400 & 3.78 & 29.6 & 8.17 & 7.78 & 50 & 400 & & & & 8.44946 \\
\hline 100 & 12 & 124.318 & 26.3 & & 7.75112 & 100 & 12 & & 53 & 017 & 8.46529 \\
\hline 100 & 25 & & -7.2 & & 7.7 & 100 & 25 & & & 56 & 8.45326 \\
\hline 100 & 50 & 94 & -74.3 & 1 & 7.7. & 100 & 50 & & & 871 & 8.45076 \\
\hline 100 & 100 & & -205 & & 7.7 & 100 & 100 & & & & 8.45015 \\
\hline 100 & 200 & 32 & -465 & & 7.7 & 100 & 200 & & 27 & & 8.44999 \\
\hline 100 & 400 & & -984 & 8.15 & 7.75973 & 100 & 400 & & -479.736 & & 8.44996 \\
\hline 200 & 12 & 121.577 & & & 7.73862 & 200 & 12 & & 125.246 & 261 & 8.46542 \\
\hline 200 & 25 & & 30 & & 7.7 & 200 & 25 & & & & 8.45338 \\
\hline 200 & 50 & & & & 7.74 & 200 & 50 & & & & 8.45088 \\
\hline 200 & 100 & & 26 & & 7.74 & 200 & 100 & & & & 8.45027 \\
\hline 200 & 200 & & 7 & & & 200 & 200 & & & & 012 \\
\hline 200 & 400 & & 36 & & 7.7 & 200 & 400 & 41 & 972 & & 8.45008 \\
\hline 400 & 12 & 538 & 37. & 8.14 & 7.7 & 400 & 12 & & & 321 & 8.46545 \\
\hline 400 & 25 & & & & & 40 & 25 & & & & 8.45341 \\
\hline 400 & 50 & & & & & 400 & 50 & & & & 8.45091 \\
\hline 400 & 100 & & & & 7.7 & 400 & 100 & & & & 8.45030 \\
\hline 400 & 20 & & & & & 400 & 200 & & & & \\
\hline 400 & 400 & & 28.7 & & 7.7 & 400 & 400 & 70 & 82 & 32 & 8.45011 \\
\hline 800 & 12 & 123.951 & 37.9 & 8. & 7.73 & 800 & 12 & & 61 & 36 & 8.46546 \\
\hline 800 & 25 & & & & & 80 & 25 & & & & \\
\hline 800 & 50 & & & & 7.73 & 80 & 50 & & & & 92 \\
\hline 800 & 100 & 242.552 & 28.9124 & 8. & 7.74 & 800 & 100 & 8.09 & 632 & 504 & 8.45030 \\
\hline 800 & 200 & & & & & 80 & 200 & & & & 8.45015 \\
\hline 800 & 400 & & & & & 800 & 400 & & & & 8.45011 \\
\hline 1600 & 12 & & 37.9 & & 7.73 & 1600 & 12 & & 66 & & 8.46546 \\
\hline 1600 & 25 & & 31.9 & & 7.73 & 160 & 25 & & & & 8.45342 \\
\hline 1600 & 50 & & & & & 160 & 50 & & & & 8.45092 \\
\hline 1600 & 100 & 338.681 & 28.9122 & 8.1 & 7.73987 & 1600 & 100 & 1062.65 & 351 & 1504 & 8.45031 \\
\hline 1600 & 200 & 298.107 & 28.8392 & 8.148 & 7.73995 & 160 & 200 & 1842.04 & 305.906 & 29.1716 & 8.45015 \\
\hline 1600 & 400 & 261.858 & 28.8221 & 8.14888 & 7.73996 & 1600 & 400 & 2790.44 & 266.832 & 29.1532 & 8.45012 \\
\hline
\end{tabular}

Tabela 2. Nusselt numbers for Hagen-Poiseuille flow (FVM). 
Evaluating tables 1 and 2 above, it appears that for higher values of the number of Péclet and positions further away from the entrance of the channel, the convergence rates are better, providing lower computational cost. Regarding the results achieved by the two methods, a higher rate of convergence for the GITT methodology is shown. In the case of FVM, due to the high number of equations to obtain the same precision, it was necessary to perform discretization in the axial direction.

\section{I LITERATURE REVIEW}

Almeida and Cotta [1] used GITT to analytically solve a convection-diffusion problem present in petroleum engineering: the injection of tracers in injection wells, assuming the unit mobility rate hypothesis. In this application of GITT in oil reservoir problems, the plotter's twodimensional equation is solved for a fully developed five spot well distribution pattern, that is, infinite square cells composed of an oil producing well at each vertex and an injector well in the center of the square. The following classic hypotheses were assumed: homogeneous, horizontal, and isotropic reservoir, monophasic, incompressible, and steady flow, and ideal tracer (without adsorption, chemical reaction, or radioactive decay). Comparisons were made with alternative analytical solutions and numerical solutions obtained by the finite difference method, where reference results were established.

Cheroto, Dos Santos and Kakaç [7] presented a theoretical study of the transient laminar forced convection for a flow between parallel plates in thermal development. The flow is subjected to periodic variation of the inlet temperature and GITT is used to provide a hybrid solution (analytical-numerical) and the periodic analysis is performed using two similar coupled problems. The problem is analyzed by solving the thermal boundary layer equations for forced laminar convection using a complementary formulation that consists of dividing the problem into two parts, one real and the other imaginary. In the end, the results obtained were compared with others already existing in the literature to provide validation.

Barbuto and Cotta [4] applied GITT to elliptical problems in irregular domains, obtaining an analytical-numerical solution. The authors initially used a general formulation, which includes pipelines with irregular geometry as a special case, where recent developments in computational implementation are highlighted, including automatic global error control. Basically, the original partial differential equation is transformed into an infinite system coupled with ordinary 2 nd order differential equations for the transformed potentials, in the non-eliminated direction, through the integral transformation process. For the solution of the transformed system commercial packages are used that offer a robust error control. An adaptive procedure is implemented, which automatically controls the order of the truncated system until the required accuracy is achieved. To complement the study and show the application of the methods, three configurations of ducts were analyzed, namely, triangular isosceles, circular, and elliptical. Numerical results were obtained for the field of longitudinal 
speed and friction factor, but due to the lack of reference results in the literature, it was not possible to validate them.

Almeida and Cotta [2] investigated the solution of diffusion-convection problems within a domain without borders using the Generalized Integral Transform Technique (GITT). GITT was tested in a borderless domain using two schemes: simple domain truncation procedure and a coordinate transformation method. A classic one-dimensional problem based on the Burgers Equation was used, where, despite its simplicity, it is provided with important characteristics that allow an efficient exploratory analysis, in addition to having several practical applications.

Chongxuan et al. [8] applied GITT to solve the advection-dispersion equation $(A D E)$ in heterogeneous porous medium coupled with linear and non-linear adsorption and decomposition. When both are linear, analytical solutions are obtained using the GITT for one-dimensional ADE's with temporal and spatial variations in flow, dispersion coefficient, initial conditions (spatial variation) and boundary conditions (temporal variation). When adsorption or decomposition is non-linear, the solution via GITT is an analytical-numerical hybrid. In both linear and both nonlinear cases, the transform-inverse pair for the problems addressed in this work is relatively simple. The authors present some illustrative examples with linear sorption and decomposition to demonstrate the problem approach via GITT and check the accuracy of the analytical solutions found.

Guerrero, Quaresma and Cotta [15] used GITT to find a hybrid analytical-numerical solution of the two-dimensional and steady-state Navier-Stokes equations, defined within domains arbitrarily, for an internal, laminar, and incompressible flow. The mathematical formalism is illustrated in a classic laminar flow test case in a gradual expansion duct. Numerical results with automatic global error control are obtained for Reynolds number values suggested in the literature. These results are compared with reference solutions published in the literature for the same problem. The authors conclude the work by stating that the solution's convergence via GITT proved to be excellent and completely in agreement with the reference results. They also concluded that automatic error control and computational cost reduction are hallmarks of GITT for this class of problems.

Sphaier and Cotta [27] used GITT to obtain solutions of Sturm-Liouville eigenvalue problems, described by multidimensional partial differential models within irregularly shaped domains. Through integral transformations, the successive elimination of independent variables generates a problem of associated algebraic eigenvalue, solved by algorithms from scientific computational libraries. A diffusion problem with an exact known solution is presented, to validate the methodology used. The approach used proved to be extremely efficient and computationally robust. The work also shows that the approach used is also applicable to non-linear formulations, providing an adequate base of self-functions.

Tunc and Bayazitoglu [29] investigated the heat transfer in rectangular microchannels. The Integral Transform Technique is applied twice, once for the speed field and 
once for the temperature field. The flow is assumed to be thermally and hydrodynamically developed with heat flow applied to all walls of the channel. The momentum equation was solved to obtain the velocity profile, and then to be replaced in the energy equation, obtaining the temperature profile. Values of the Nusselt number were calculated for various values of the aspect ratio. The results show a behavior like the studies with circular microtubes present in the literature.

Sphaier and Cotta [28] used the integral transformation to obtain an exact solution to linear diffusion problems within irregular domains. The authors used an approximate contour representation strategy for cases in which the boundary limits are points in space, as well as they can be used as an alternative to reduce computational effort for cases in which the contour has a functional representation of shape. closed and accurate. The strategy considered in this work, according to the authors, has not yet been used in previous works with the same type of approach, where it provides a significant increase in the flexibility and applicability of the proposed method. The analysis was carried out using mixed symbolicnumerical computation using the Mathematica software, where a computational code was developed that includes analytical derivations, numerical evaluations, and graphs. A test case, with an exact known solution, of heat conduction in a portion of a cylindrical region is used to verify and validate the solution methodology and computational implementation.

Neto, Quaresma and Cotta [22] studied a three-dimensional transient Darcy model of natural convection in cavities filled with porous medium, using a potential vorticity vector formulation and the generalized integral transform technique. A general formulation and solution methodology for vertical cavities are developed. Results are presented for cubic cavities, evaluating the effects of the Rayleigh number, observing the transient evolution of the heat transfer process. The behavior of the convergence of the solution for the expansion of the proposed self-functions is investigated and comparisons are made with solutions in permanent regime present in the literature.

Silva, Quaresma and Dos Santos [26] used GITT to analyze the entrance region of the two-dimensional laminar flow in parallel plate ducts. A formulation in terms of the original potentials was adopted. Expansions for the velocity field have been proposed so that the continuity equation is satisfied. After applying the integral transformation process, a coupled system of ordinary differential equations is generated, whose formulation is like the formulation by the current function. The results for the speed field and for the product of the friction factor by the Reynolds number ( $f(R e)$ are analyzed and compared with the results in the literature.

Diniz et al. [14] investigated the transient temperature distribution in a uniform flow (slug-flow) in thermal development, with conduction-radiation coupling, between two parallel flat plates. The temperature distribution was obtained through the application of GITT, while the radiative contribution is determined analytically by the Galerkin Method. The results are analyzed in terms of stability, convergence, and computational cost, considering 
the contributions of parameters such as optical medium thickness and conduction-radiation coupling factor.

Nascimento, Macedo and Quaresma [20] applied GITT to obtain the solution of the momentum equations for a laminar flow of a non-Newtonian power-law fluid under hydrodynamic development in circular ducts. A formulation of primitive variables is adopted to avoid the singularity of the auxiliary eigenvalue problem in terms of Bessel functions in the center line of the duct when GITT is applied. Results were presented for the speed field and for the friction factor, evaluated for different power-law indices, and presented graphically as functions of the dimensionless coordinates. The results obtained were compared with results found in the literature to validate the numerical codes developed and demonstrated extreme agreement.

Barros and Cotta [5] considered a mathematical model of flow in a permanent threedimensional regime to predict the behavior of contaminants dissolved in rivers and channels subjected to turbulent flow conditions. The proposed model considers variable speed fields and non-uniform turbulent diffusivities within channels of rectangular cross section. The authors used GITT to obtain a hybrid analytical-numerical solution for the fields studied. The solution's convergence behavior was investigated and the criteria for reordering the terms of the infinite series were discussed, with the objective of reducing the computational effort associated with the expansion of multiple self-functions. The authors present a test case illustrating the proposed methodology.

Lima et al. [17] obtained a hybrid solution using GITT for an MHD flow, between parallel plates, which consists of an electronically conducting Newtonian fluid and subjected to a perpendicular and uniform magnetic field, taking into account the heat transfer during the fluid movement. A simple mathematical formulation was adopted, considering the flow in a transient regime sustained only by the pressure gradient, as well as the flow in a permanent regime with constant pressure gradient and upper plate movement, with suction and injection perpendicular to the porous plates. Results for the temperature and speed fields are obtained according to the following governing parameters: pressure gradient, suction speed, upper plate speed and Hatmann numbers. A convergence analysis was carried out showing the consistency of the results and later they were compared with those already existing in the literature, showing an excellent agreement.

Naveira, Lachi and Cotta [21] used GITT to obtain a hybrid solution of a transient laminar forced convection problem on flat plates, subjected to temporal variations in the applied heat flow. From the Blasius velocity distribution and making a coordinate transformation, which takes into account only the thermally affected region along the main flow direction, the transient temperature distribution is expanded in self-functions obtained from the diffusion operator in the direction transversal to the flow. The coupled system of partial differential equations, resulting from the transformed potentials, is solved numerically in terms of the dimensionless time and longitudinal coordinate variables, using 
the Mathematica software. Numerical solutions for the wall temperature and heat transfer coefficient were obtained, generating the temporal behavior and longitudinal distribution of these parameters for the applied heat flow functions. The GITT approach proved to be robust and accurate, in addition to being quite flexible to allow the use of different combinations of boundary conditions and different geometric configurations of external flows governed by the formulation of the boundary layer.

Chalub et al. [6] performed a comparison between the solution of a convectiondiffusion problem via GITT and via the Finite Volume Method (FVM). The proposed problem was that of a laminar flow between thermally developed parallel flat plates. Both methods were focused on transforming a partial differential formulation into an ordinary differential formulation. In the case of GITT, this operation was carried out through an integral transformation and for the FVM the discretization of the independent variable transversal to the flow was made. The resulting systems of ordinary differential equations are solved analytically, and the comparison of results is presented, indicating the advantages and disadvantages of each method. The temperature fields and Nusselt numbers obtained by both methodologies are analyzed, compared, and validated using results that already exist in the literature.

Monteiro et al. [19] investigated the problem of the propagation of a thermal wave inside a finite bar using the generalized integral transform technique. The use of GITT in the analysis of the hyperbolic heat conduction equation generates a coupled system of ordinary differential equations of the 2 nd order that varies over time. The ODE system is solved numerically by the GEAR method for consistent initial value problems. The numerical results are presented for local and average temperature fields for different Biot numbers and dimensionless thermal relaxation times, allowing a critical evolution of technical performance. A comparison was made with existing results in the literature for special cases and obtained through the application of the Laplace Transform and the Finite Volume Method.

Presgrave, Guedes and Neto [23] used the Integral Transform Technique as a support tool for studying a medical procedure called Endometrial Ablation. This procedure consists of removing the endometrium by inserting a latex balloon filled with a fluid solution at high temperature into the uterine cavity. To assess the efficiency of the procedure, accurate predictions of the temperature field are necessary. The thermal problem in question is discussed in this work, where Penne's bioheat transfer equation is adopted to obtain the temperature distribution in the uterus wall. The solution to the equation is obtained by applying the integral transformation. Special attention is given to situations in which the temperature of the fluid solution present inside the flask is not constant, which may impair the effectiveness of the procedure. In analyzing the results, the authors concluded that the temperature distribution in the wall of the uterus is greatly affected by the rate of fluid temperature decay inside the balloon. 
Guerrero et al. [16] present an exact solution of the linear advection-diffusion transport equation with constant coefficients, in the permanent and transient regimes. Through a mathematical substitution, the original equation is transformed into a pure diffusion equation. The transformed diffusive problem is solved analytically through the classical integral transform, resulting in an explicit formal solution. The authors compare the convergence of the transformed diffusive problem, solved by the classical integral transformation, with the advective-diffusive transport problem, solved directly by GITT. After analyzing the results, the authors concluded that the solution of the transformed diffusive problem converged more quickly than the hybrid analytical-numerical solution obtained by the direct use of GITT in the original advective-diffusive transport problem.

Cotta et al [10] summarize the theory and describe the algorithm related to the construction of a mixed, symbolic-numerical, open computational code called UNIT (Unified Integral Transforms), which provides a development platform to obtain solutions of partial differential equations (EDP) linear and non-linear, via integral transforms. UNIT was developed on the Mathematica symbolic computing system, version 7.0, in conjunction with GITT's numerical-analytical methodology. The objective of the work was to illustrate a robust simulation with precision control in transient, non-linear, and multidimensional convectiondiffusion problems. Test cases were selected based on non-linear multidimensional formulations of Burgers' equations, providing reference results for specific numerical values of government parameters.

Cotta et al. [11] used GITT to generate a hybrid analytical-numerical solution of the bioheat transfer model in heterogeneous media, which is reduced to an exact solution obtained by applying the classical integral transform in a linear model with constant coefficients. Pennes's equation is used to describe the process of heat transfer within living tissues. Several models are present in the literature with analytical solutions that represent the temperature distribution throughout the tissue structure, however these solutions have hypotheses, such as: constant thermophysical properties and linear blood perfusion rates. The present work performs a more complex analysis, since it formulates the environment as heterogeneous, allows a spatial variation of the parameters along the thickness of the tissues and takes into account the variation of the blood perfusion rate with the temperature. The numerical results for a set of government parameters are obtained using the UNIT source code (Unified Integral Transform). In addition, an analysis of the convergence of the expansion of the proposed self-functions and the evaluation of the importance of the spatial variation of the government parameters for the prediction of the thermal response in living tissues due to external stimulus were performed. The results obtained show that the proposed approach provides an excellent estimate of temperature distributions in bioheat transfer problems, in addition to being robust and capable of generating accurate results for abrupt variations in thermophysical properties. The nonlinear behavior of the perfusion rates was modeled and computed via the integral transform. 
Da Silva and Sphaier [12] applied GITT to solve a one-dimensional problem of diffusion in a domain with irregular geometry. In general, irregular geometries are treated either by transforming coordinates or by using simpler eigenvalue problems defined in the irregular geometry itself. However, both approaches are limited, as they cannot deal with an arbitrary general domain. The authors used a new approach for treating irregular domains, which is the surrounding domain technique. This methodology provides satisfactory results to calculate eigenvalues of a Sturm-Liouville 1D problem, using an auxiliary problem defined within a surrounding domain. This work extends this technique, solving a 1D diffusion problem using expansions of the self-function in terms of a defined eigenvalue problem within a domain that involves the original domain. As a proposal for validating the methodology, results of a test case with an exact known solution were generated and compared with reference values present in the literature.

Queiroz [24] applied the generalized integral transform technique to analyze different strategies for solution of flows in thermal development, but hydrodynamically developed, and to determine which solution is more efficient for each configuration. The author used the classic boundary conditions of forced internal convection, namely: constant flow on the wall and constant temperature on the surface. Different Péclet numbers were analyzed, from high Péclet (without axial diffusion) to single Péclet (advection rate with the same order of magnitude as diffusion in the same direction). Three different eigenvalue problems were analyzed, generating three possibilities of integral transformation of the problem: the simple Helmholtz problem for the transversal direction, a variation of this, which takes the speed profile into account, and a eigenvalue problem in the flow direction. In addition to these different strategies for integral transformation, different strategies for the solution of the transformed system were analyzed, from totally numerical solutions to analytical solutions. The comparison between the different solution strategies was performed by analyzing the convergence rate of the Nusselt number. The computational time spent by different solution strategies of the transformed system was also analyzed, as well as the rate of convergence for the temperature in different positions. The computational solutions and implementations were validated by comparing the value calculated for the Nusselt number away from the channel entrance with the known value in the literature for the flow developed. Every implementation of the problem was carried out in the Mathematica program through mixed symbolic-numerical computation.

\section{I CONCLUSIONS}

This work aimed to perform a literature review on the Generalized Integral Transform Technique and analyze the comparison of GITT with the Finite Volume Method, through the results of two articles that used both methodologies to obtain the solution of the problem in question. and compare your results. The first conclusion that can be drawn is about the 
diversity of diffusion-advection problems in which GITT is used as a solution tool. These diverse problems are in areas such as: heat transfer, flow of fluids in ducts and channels, flow in porous media, pollutant dispersions, biomedical engineering, petroleum engineering, among others. GITT basically transforms a system of partial differential equations into an infinite system of ordinary differential equations transformed by eliminating spatial dependencies. This infinite transformed ODE system is solved with a lower computational cost when compared to the purely numerical solution of the original EDP system, where these can be solved in a simpler way, with the advantage of producing a more accurate and more economical solution besides allowing control over the relative error of the results. The conclusion mentioned above was verified, mainly in Queiroz et al. [25], where the convergence rates in the solution of the problem via GITT were higher than the solution via FVM, showing the accuracy of the technique.

\section{REFERENCES}

1. Almeida, A. R.; Cotta, R. M. Integral transform methodology for convection-diffusion problems in petroleum reservoir engineering. International Journal of Heat and Mass Transfer, v. 38, p. 3359-3367, 1995.

2. Almeida, A. R.; Cotta, R. M. On the integral transform solution of convection-diffusion problems within unbounded domain. Journal of The Franklin Institute, v. 336, p. 821-832, 1999.

3. Araújo, J. C.; Mb, R. G. Problema de Buckley e Leverett: aproximação de funções para a estimativa da saturação de choque. Revista Eletrônica Paulista de Matemática, Bauru, v. 16, p. 163180, 2019. Available in: http://www.fc.unesp.br/\#!/departamentos/matematica/revista-cqd/

4. Barbuto, F. A. A., Cotta, R. M. Integral transformation of elliptic problems within irregular domain. Applied Mathematical Modelling, v. 7, n. 8, p.778-793, 1997.

5. Barros, F. P. J.; Cotta, R. M. Integral transforms for three-dimensional steady turbulent dispersion in rivers and channels. Applied Mathematical Modelling, v. 31, p. 2719-2732, 2007.

6. Chalub, D. J. N. M. et al., 2008. Comparisons between GITT and FVM solutions for thermally developing flow in parallel-plates channels. In: BRAZILIAN CONGRESS OF THERMAL SCIENCES, 12th., Rio de Janeiro-RJ, Brasil.

7. Cheroto, S.; dos Santos, C. A. C.; Kakaç, S. Hybrid-analytical investigation of unsteady forced convection in parallel-plates channels for thermally developing flow. Heat and Mass Transfer, v. 32, p. 317-324, 1997.

8. Chongxuan, L. et al., Use of the generalized integral transform method for solving equations of solute transport in porous media. Advances in Water Resources, v. 23, n. 5, p. 483492, 2000.

9. Cotta, R. M. Integral transforms in computational heat and fluid flow. New Jersey: CRC, 1993. 
10. Cotta, R. M. et al., Unified integral transform approach in the hybrid solution of multidimensional nonlinear convection-diffusion problems. In: INTERNATIONAL HEAT TRANSFER CONFERENCE, 14th., Ohio, USA 2010a.

11. Cotta, R. M. et al., Hybrid integral transforms analysis of the bioheat equation. International Journal of Thermal Sciences, v. 49, p. 1510-1516, $2010 \mathrm{~b}$.

12. Da silva, L. M.; Sphaier, L. A., 2010. Integral transform solution of one-dimensional diffusion problems using an enclosing domain approach. In: National Congress of Mechanical Engineering, Campina Grande-PB, Brasil.

13. Dias, R. A. C. et al., 2012. Analysis of oil displacement throughwater in porous Media using integral transforms and CFD package. In: BRAZILIAN CONGRESS OF THERMAL SCIENCES, 14th., Rio de Janeiro-RJ, Brasil.

14. Diniz, L. S. et al., 2005. Theorical analysis of the channel flow with radiation in participating media through the use of the generalized integral transform technique. In: INTERNATIONAL CONGRESS OF MECHANICAL ENGINEERING, 18th., Paraíba-PB, Brasil.

15. Guerrero, J. S. P., Quaresma, J. N. N.; Cotta, R. M. Simulation of laminar flow inside ducts of irregular geometry using integral transforms. Computational Mechanics, v. 25, p. 413-420, 2000.

16. Guerrero, J. S. P. et al., Analytical solution of the advection-diffusion transport equation using a change-of-variable and integral transform technique. International Journal of Heat and Mass Transfer, v. 52, p. 3297-3304, 2009.

17. Lima, J. A. et al. Integral transform analysis of MHD flow and heat transfer in parallel plates channels. International Communications in a Heat and Mass Transfer, v. 34, p. 420-431, 2007.

18. Miyagawa, H. K., 2014, A Técnica da Transformada Integral Generalizada no Escoamento em Dutos Bidimensionais de Geometria Irregular na Forma Senoidal. $87 \mathrm{f}$. Dissertação (Mestrado) - Programa de Pós-Graduação em Engenharia Química - Universidade Federal do Pará, Belém, PA.

19. Monteiro, E. R. et al. Integral transform solution for hyperbolic heat conduction in a finite slab. International Communications in a Heat and Mass Transfer, v. 36, p. 297-303, 2009.

20. Nascimento, S. C. C.; Macedo, E. N.; Quaresma, J. N. N. Generalized integral transform solution for hydrodynamically developing non-newtonian flows in circular tubes. Journal of the Brazilian Society of Mechanical Sciences and Engineering, v. 28, p. 125-130, 2006.

21. Naveira, C. P.; Lachi, M.; Cotta, R. M. Integral transform solution of transient forced convection in external flow. International Communications in Heat and Mass Transfer, v. 34, p. 703712, 2007.

22. Neto, H. L., Quaresma, J. N. N., Cotta, R. M. Natural convection in threedimensional porous cavities: integral transform method. International Journal of Heat and Mass Transfer, v. 45, p. 3013-3032, 2002. 
23. Presgrave, A. V., Guedes, R. O., Neto, F. S. Integral transform solution to the endometrial ablation problem. Journal of the Brazilian Society of Mechanical Sciences and Engineering, v. 31, n. 2, p. 117-124, 2009.

24. Queiroz, H. R., 2010, Análise de estratégias de solução por transformada integral para escoamentos em desenvolvimento térmico. 126 f. Dissertação (Mestrado) - Programa de PósGraduação em Engenharia Mecânica) - Universidade Federal Fluminense, Niterói, RJ.

25. Queiroz, H. R.; Nogueira, D.; Sphaier, L. A., 2009. Effect of péclet number on the convergence of integral-transform and finite-volumes solutions in thermally developing flow. In: INTERNATIONAL CONGRESS OF MECHANICAL ENGINEERING, Gramado, 20th., Gramado-RS, Brasil.

26. Silva, R. L., Quaresma, J. N. N., dos Santos, C. A. C., 2004. Integral transform analysis of flow development in parallel-plates ducts. In: BRAZILIAN CONGRESS OF THERMAL SCIENCES AND ENGINEERING, 10th., Paraíba-PB, Brasil.

27. Sphaier, L. A., Cotta, R. M. Integral transform analysis of multidimensional eigenvalue problems within irregular domains. Numerical Heat Transfer, v. 38, p. 157-175, 2000.

28. Sphaier, L. A., Cotta, R. Analytical and hybrid solutions of diffusion problems within arbitrarily shaped regions via integral transform. Computational Mechanics, v. 29, p. 265-276, 2002.

29. Tunc, G., Bayazitoglu, Y. Heat transfer in rectangular microchannels. International Journal of Heat and Mass Transfer, v. 45, p. 765-773, 2002. 


\section{UTILIZAÇÃO DE WC NA MOAGEM DE ALTA ENERGIA DE CAVACOS DE AÇO ALTO CROMO}

Data de aceite: 01/10/2020

Data de submissão: 06/07/2020

Roberta Alves Gomes Matos Universidade Federal de Itajubá - UNIFEI Itajubá - MG http://lattes.cnpq.br/5343820532259748

Bruna Horta Bastos Kuffner Universidade Federal de Itajubá - UNIFEI Itajubá - MG http://lattes.cnpq.br/1598312330444780

Gilbert Silva Universidade Federal de Itajubá - UNIFEI Itajubá - MG http://lattes.cnpq.br/1912171391296662

RESUMO: Os carbetos são comumente utilizados na moagem de alta energia com o objetivo de reduzir o tamanho das partículas num menor tempo de moagem. Neste trabalho estudou-se a viabilidade da utilização de carbeto de tungstênio (WC) na moagem de alta energia dos cavacos de uma liga da série $X 22$. Os tempos de moagem utilizados foram 10, 20, 30, 40 e 50 horas. Nas primeiras horas de moagem, o metal se deforma adquirindo formato de placas. À medida que a moagem prossegue, ocorre a soldagem a frio das partículas, aumentando o diâmetro médio. Ao final da moagem, tem-se uma variabilidade no tamanho das partículas de 11 a 44 microns.

PALAVRAS-CHAVE: Aço da Série X22, Moagem de Alta Energia, Carbeto de Tungstênio.
USE OF WC IN THE HIGH ENERGY BALL MILLING OF HIGH CHROMIUM STEEL SCRAPS

ABSTRACT: Carbides are commonly used in high energy ball milling in order to reduce the particle size in a shorter milling time. In this work, it was studied the feasibility of the use of tungsten carbide (WC) in the high energy ball milling of scraps of an X22 series alloy. The milling times used were 10, 20, 30, 40 and 50 hours. In the first hours of milling, the metal deforms to a plate shape. As the milling proceeds, the particles are cold welded, increasing their average diameter. At the end of the milling, there is a variability in particle size from 11 to 44 microns.

KEYWORDS: X22 Series Steel, High Energy Ball Milling, Tungsten Carbide.

\section{I INTRODUÇÃO}

A moagem mecânica é uma técnica simples de ajuste das propriedades do pó: a moagem de alta energia resulta na diminuição do tamanho das partículas e na deformação severa da estrutura do cristal. Diminuir o tamanho das partículas aumenta a concentração de átomos e íons localizados na superfície das partículas (TALIMIAN, et al, 2019).

A moagem de alta energia (MAE) é uma técnica de processamento do pó envolvendo processos repetidos de soldagem, fratura, e resoldagem de partículas de pó em um moinho de bolas de alta energia (SURYANARAYANA, 2001). O elevado tempo de moagem dos 
pós resulta na formação de soluções sólidas supersaturadas, compostos intermetálicos ou compostos como carbetos, boretos, nitretos e silicatos. O tipo de produto formado durante a moagem depende da composição dos pós e das condições de moagem (TRAPP EKIEBACK, 2013). É uma técnica promissora, pois oferece a oportunidade não só para o refinamento microestrutural mas também para a obtenção de materiais de alta homogeneidade estrutural (WEN-BIN, et al, 2011).

Para Benjamin e Volin 1974, o processo de moagem de alta energia pode ser dividido em cinco fases: o período inicial; o período de predominância de soldagem; o período de formação de partículas equiaxiais; o início de soldagem com orientação aleatória; e processamento de estado estacionário.

Com o objetivo de diminuir o tamanho de partículas aumentando a eficiência de moagem, são adicionados carbetos a moagem de alta energia. O WC encontra potenciais aplicações, devido às suas propriedades específicas, tais como alto ponto de fusão (2275 $\left.{ }^{\circ} \mathrm{C}\right)$, densidade $\left(19,25 \mathrm{~g} / \mathrm{cm}^{3}\right)$, dureza superior, baixo coeficiente de atrito, alta resistência à oxidação e boa condutividade elétrica (GERMAN, 2005; SHANMUGAM, et al, 2005). É usado principalmente para ferramentas de corte e peças resistentes ao desgaste (JIN, et al, 2007).

\section{I MATERIAIS E MÉTODOS}

O processo de moagem de alta energia dos cavacos do aço X22CrMoV 12-1 foi realizado utilizando 30 gramas de cavaco de metal e adição de $3 \%$ em massa de WC manufaturado industrialmente e com tamanho médio de partículas 2-4 $\mu \mathrm{m}$ e realizado em moinho planetário de alta energia da marca Noah-Nuoya, modelo NQM 0,25 L. A velocidade de moagem foi $350 \mathrm{rpm}$, e a razão massa/esfera 1:10. A moagem foi realizada no tempo de 10,40 e 50 horas.

A medição do tamanho médio das partículas foi realizada pelo equipamento Microtrac, S3500 e as imagens dos pós foram obtidas por microscópio eletrônico de varredura (Carl Zeiss ${ }^{\circledR}$ EVO MA 15).

\section{3। RESULTADOS E DISCUSSÃO}

A Figura 1 corresponde as partículas de X22 após 10 horas de moagem. Observase que as partículas adquiriram morfologia de placas, o que também foi observado na pesquisa de Raimundo et al (2020). O diâmetro médio das partículas neste tempo ficou em torno de 53 microns, como pode ser visto na Figura 6. 


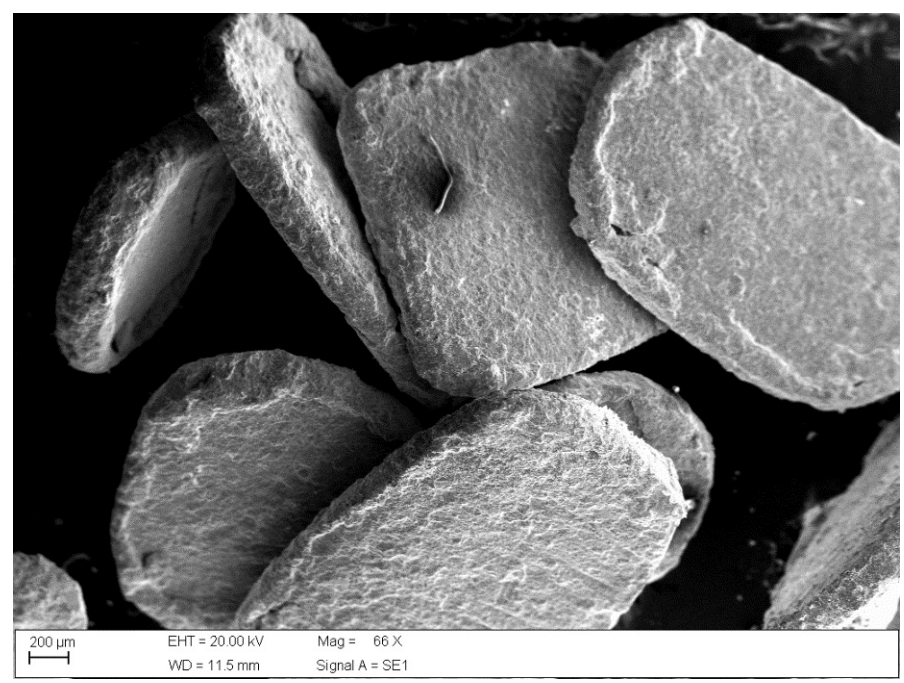

Fig. 1. Micrografia do aço X22 com adição de WC após 10 horas de moagem de alta energia

As Figuras 2 e 3 representam as partículas após 20 e 30 horas de moagem, respectivamente. De acordo com as imagens e a Figura 6, observa-se aglomerados de partículas. Este fato ocorre devido a intensidade das forças eletrostáticas e Van Der Waals (CHRISTIAN, et al, 2008; DAUTHAL e MUKHOPADHYAY, 2012) e levam a uma aglomeração mais forte. Em ambas situações ocorre aparecimento de partículas com diâmetro médio de 10 microns, porém com baixa fração em volume (aproximadamente 5\% ao todo).

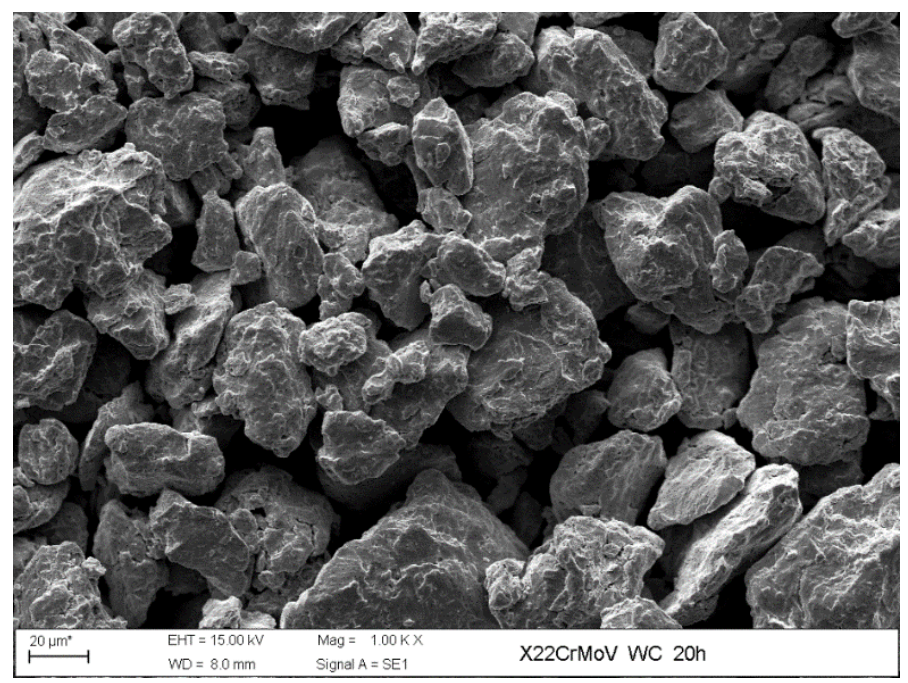

Fig. 2. Micrografia do aço X22 com adição de WC após 20 horas de moagem de alta energia 


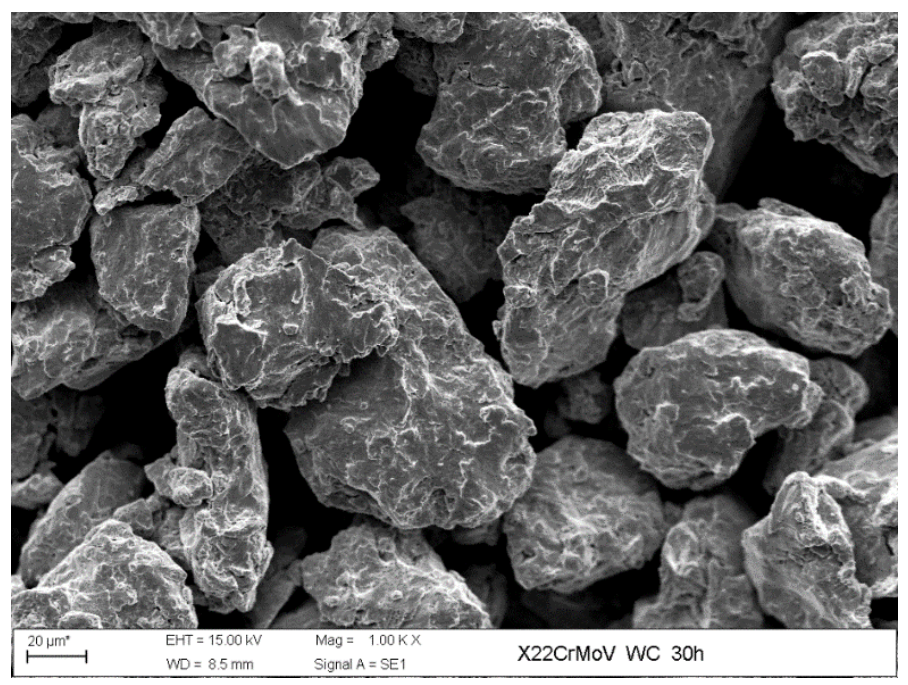

Fig. 3. Micrografia do aço X22 com adição de WC após 30 horas de moagem de alta energia

A Figura 4 mostra as partículas após 40 horas de moagem com diâmetro médio de aproximadamente 44 microns. A morfologia das partículas é irregular. A redução relativa ao tamanho encontrado após 10 horas de moagem foi de aproximadamente $18 \%$. Para Rajaonarivony et al (2019), o fenômeno da aglomeração pode limitar a redução de tamanho e até criar partículas maiores através de um efeito de agrupamento.

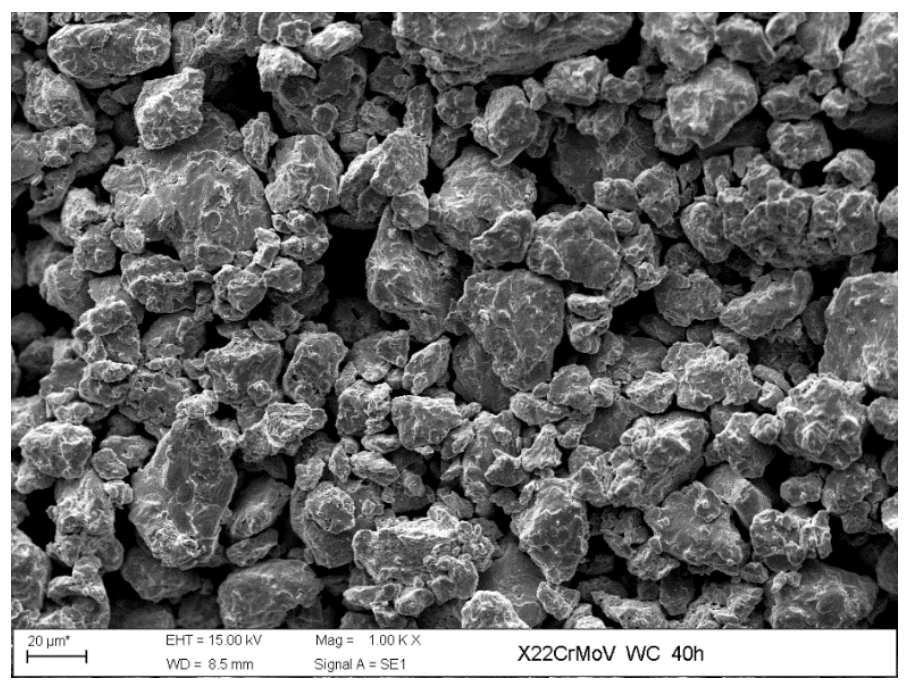

Fig. 4. Micrografia do aço X22 com adição de WC após 40 horas de moagem de alta energia 
Após 50 horas de moagem as partículas permanecem com morfologia irregular, sendo que uma fração volumétrica de $87 \%$ possui diâmetro médio de partículas em torno de aproximadamente 44 microns (Figura 6).

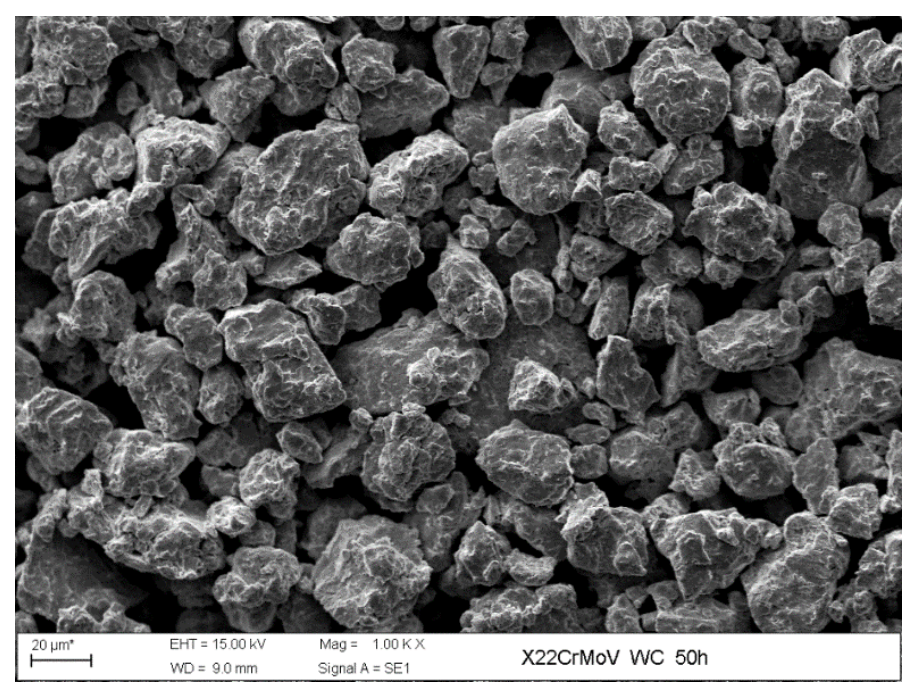

Fig. 5. Micrografia do aço X22 com adição de WC após 50 horas de moagem de alta energia

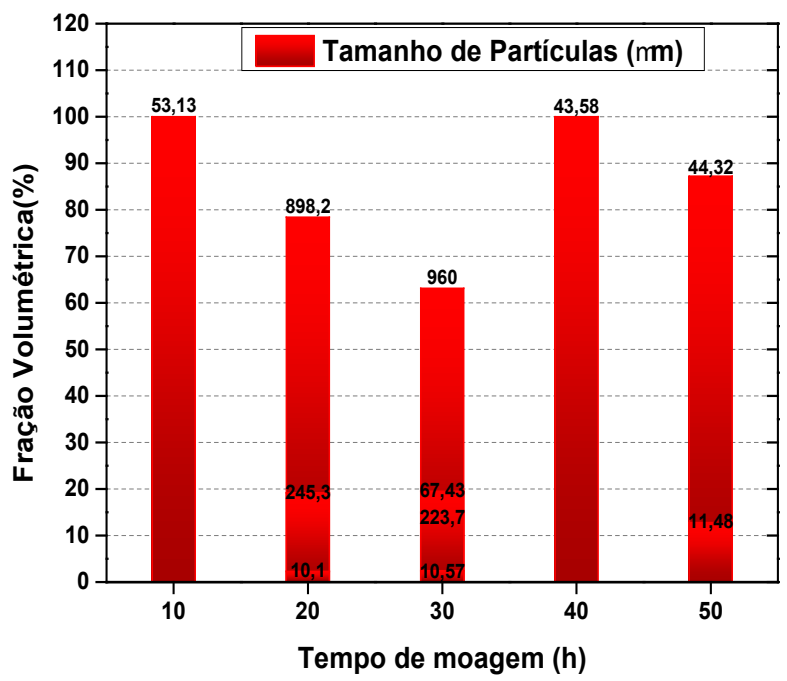

Fig. 6. Fração volumétrica versus tempo de moagem aço da série X22 


\section{I CONCLUSÕES}

A moagem utilizando WC como objetivo de alcançar um menor tamanho de partículas em menor tempo, não mostrou-se viável. O fenômeno da aglomeração após as primeiras horas limitou a redução no tamanho criando partículas maiores, inviabilizando assim o processo, visto que a redução final ficou em torno de $16 \%$ do tamanho inicial, considerando a maior fração em volume.

\section{AGRADECIMENTOS}

Os autores agradecem a CAPES pelo aporte financeiro, e UNIFEI pelo suporte técnico.

\section{REFERÊNCIAS}

BENJAMIN, J.S; Fundamentals of mechanical alloying; Aluminum Company of America, Alcoa Laboratories, Alcoa Center, PA, USA; Materials Science Forum Vols. 88-90 (1992), p. 5.

CHRISTIAN, P.; VON DER KAMMER, F.; BAALOUSHA, M.; HOFMANN, T. Nanoparticles: Structure, properties, preparation and behaviour in environmental media. Ecotoxicology 2008, 17, 326-343.

DAUTHAL, P.; MUKHOPADHYAY, M. In-vitro free radical scavenging activity of biosynthesized gold and silver nanoparticles using Prunus armeniaca (apricot) fruit extract. J. Nanopart Res. 2012, 15, 1366.

GERMAN, R. M.; A - Z OF POWDER METARLLURGY. 1. ed. Metal Powders Technology: Elsevier Science, 2005.

JIN G.; XU B.S.; WANG H.D.; LI Q. F., WEI S.C.; Characterization of WC/Co coatings on metal substrates. Mater Lett 2007; 61:2454-6.

RAIMUNDO, R. A.; COSTA, F. A.; MORALES, M. A.; SILVA, A. G. P.; GOMES,U. U.; Effect of the high energy milling on the microstructure of $\mathrm{Cu}-20 \% \mathrm{WC}$ composite powders prepared with recycled WC; International Journal of Refractory Metals and Hard Materials; Volume 90, August 2020, 105223;

SHANMUGAM S, JACOB DS, GEDANKEN A. Solid state synthesis of tungsten carbide nanorods and nanoplatelets by a single-step pyrolysis. J Phys Chem B 2005; 109: 19056-9.

SURYANARAYANA, C.; Mechanical alloying and milling, Department of Metallurgical and Materials Engineering, Colorado School of Mines, Golden, CO 80401-1887, USA, Progress in Materials Science 46 (2001) 1-184;

TALIMIAN, A.; POUCHLY, V.; MAGHRABY, H.; MACA, K.; GALUSEK, D.; Impact of high energy ball milling on densification behaviour of magnesium aluminate spinel evaluated by master sintering curve and constant rate of heating approach, Ceramics International, Volume 45, Issue 17, Part B, 1 December 2019, Pages 23467-23474; 
TRAPP, J.; KIEBACK, B.; Solid-state reactions during high-energy milling of mixed powders,

Fraunhofer Institute for Manufacturing and Advanced Materials, Department of Powder Metallurgy and Composite Materials, D-01277Dresden, Germany. ActaMaterialia 61 (2013) 310-320.

WEN-BIN, F.; XUE-WEN, L.; HONG-FEI, S.; YONG-FENG, D.; Characterization of Ti-50\%AI composite powder synthesized by high energy ball milling, School of Materials Science and Engineering, Harbin Institute of Technology, Harbin 150001, China. Trans. Nonferrous Met. Soc. China 21(2011) s-333-s337.

RAJAONARIVONY, K. et al.; Fine Comminution of Pine Bark: How Does Mechanical Loading Influence Particles Properties and Milling Efficiency; Bioengineering 2019, 6, 102; doi:10.3390/ bioengineering6040102. 


\section{SOBRE OS ORGANIZADORES}

HENRIQUE AJUZ HOLZMANN - Professor da Universidade Tecnológica Federal do Paraná (UTFPR). Graduação em Tecnologia em Fabricação Mecânica e Engenharia Mecânica pela Universidade Tecnológica Federal do Paraná. Mestre em Engenharia de Produção pela Universidade Tecnológica Federal do Paraná Doutorando em Engenharia e Ciência do Materiais pela Universidade Estadual de Ponta Grossa. Trabalha com os temas: Revestimentos resistentes a corrosão, Soldagem e Caracterização de revestimentos soldados.

JOÃO DALLAMUTA - Professor da Universidade Tecnológica Federal do Paraná (UTFPR). Graduação em Engenharia de Telecomunicações pela UFPR. MBA em Gestão pela FAE Business School, Mestre em engenharia elétrica pela UEL. Doutorando em Engenharia Espacial pelo INPE. Trabalha com os temas: Gestão da Inovação, Inteligência de Mercado e Planejamento de Missões Espaciais. 


\section{ÍNDICE REMISSIVO}

\section{A}

Aerelasticidade 31

Atuador Eletromagnético 21, 22, 26

Automação Industrial 42, 45

B

Barras Comprimidas 56

C

Circuitos Shunt Multimodais 31

Controle Ativo de Vibrações 12, 15, 19, 21

Controle Passivo de Vibrações 31, 32

E

Enrijecedor Intermediário 56, 58, 59, 63, 64, 65, 66, 67, 68

ERA/OKID 12, 13, 15, 20

Estoque 70,75

Evolução Diferencial (ED) 1, 2, 3, 5, 8, 9, 10, 11, 30, 41, 55, 69, 75, 106

G

Gestão 70, 75, 108

I

Inteligência Artificial 1,2

L

LQR (Regulador Linear Quadrático) 12, 13, 15, 21, 28, 29, 30

M

Materiais $13,31,32,42,43,46,47,69,70,71,72,73,74,75,76,102,108$

Material Compósito 12, 13, 16, 19, 35

Mecatrônica 42, 54

Microcontroladores 42, 44, 55

$\mathbf{P}$

Padrão 24, 25, 26, 27, 70, 71, 73

Parafuso Estojo 70, 71, 72, 73, 74, 75

Perfis Formados a Frio 56, 57, 58, 69 
$\mathbf{R}$

Rede Neural Artificial (RNA) 1

Resistência à Compressão 56, 57, 58, 64, 65, 66, 67, 68

S

Sistema Dinâmico 1, 21

V

Viga Flexível 21, 22 


\section{ATIVIDADES CIENTÍFICAS E TECNOLÓGICAS NO CAMPO DA ENGENHARIA MECÂNICA}

www.atenaeditora.com.br

我 contato@atenaeditora.com.br $\ltimes$

@atenaeditora 우

www.facebook.com/atenaeditora.com.br ff 


\section{ATIVIDADES CIENTÍFICAS E TECNOLÓGICAS NO CAMPO DA ENGENHARIA MECÂNICA}

www.atenaeditora.com.br

我 contato@atenaeditora.com.br $\bowtie$

@atenaeditora 우

www.facebook.com/atenaeditora.com.br ff 